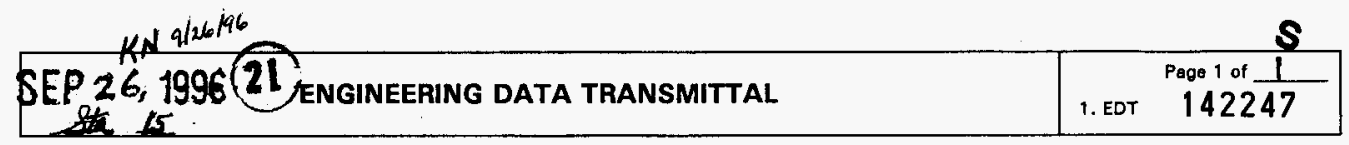

\begin{tabular}{|c|c|c|}
\hline $\begin{array}{l}\text { 2. To: (Receiving Organization) } \\
\text { Conaequenco Analysis }(8 M 400)\end{array}$ & $\begin{array}{l}\text { 3. From: (Originating Organization) } \\
\text { Consequence Analysis (8M400) }\end{array}$ & $\begin{array}{l}\text { 4. Related EDT Mo.: } \\
\text { NA }\end{array}$ \\
\hline $\begin{array}{l}\text { 5. Proj./Prog./Dept./Div.: } \\
\text { 8M400 }\end{array}$ & $\begin{array}{l}\text { 6. Cog. Engr.: } \\
\text { T. B. Powers }\end{array}$ & $\begin{array}{l}\text { 7. Purchase order Mo.: } \\
\text { NA }\end{array}$ \\
\hline \multirow{2}{*}{\multicolumn{2}{|c|}{$\begin{array}{l}\text { 8. Originator Remarks: } \\
\text { Calculation notes are used to document the originator's } \\
\text { analysis but are not to be used as the final or sole } \\
\text { document to authorize activities or justify facility } \\
\text { modifications. }\end{array}$}} & $\begin{array}{l}\text { 9. Equip./Component No.: } \\
\text { NA }\end{array}$ \\
\hline & & $\begin{array}{l}\text { 10. System/B ldg./Faci L i ty: } \\
\text { Singlo-Shell Tank: } \\
\text { Doublo-Shell Tanks }\end{array}$ \\
\hline \multirow{3}{*}{\multicolumn{2}{|c|}{ 11. Receiver Remarks: }} & $\begin{array}{l}\text { 12. Major Assm. Dwg. Mo.: } \\
\text { NA }\end{array}$ \\
\hline & & $\begin{array}{l}\text { 13. Permit/Permit Application Mo.: } \\
\text { NA }\end{array}$ \\
\hline & & $\begin{array}{l}\text { 14. Required Response Date: } \\
\text { NA }\end{array}$ \\
\hline
\end{tabular}

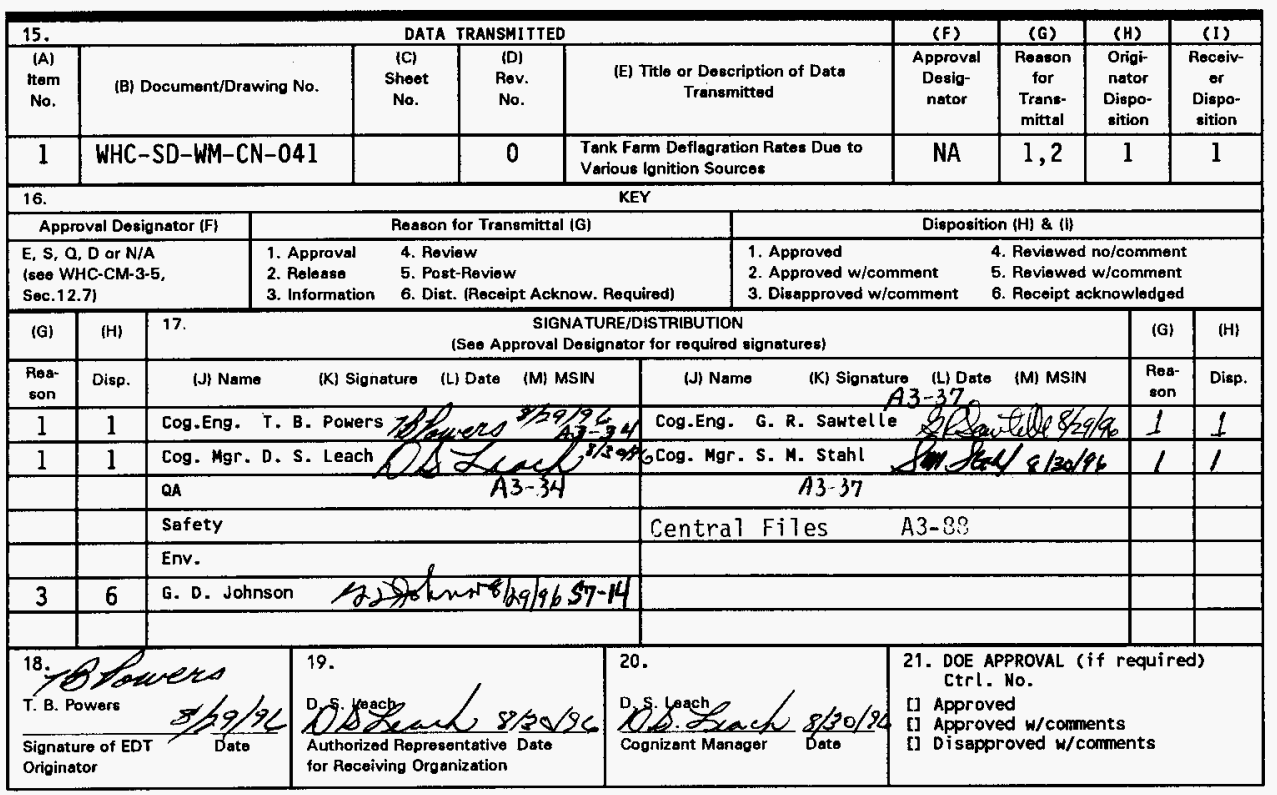




\section{Tank Farm Deflagration Rates Due to Various Ignition Sources}

T. B. Powers G. R. Sawtelle

Westinghouse Hanford Company, Richland, WA 99352

U.S. Department of Energy Contract DE-AC06-87RL10930

EDT/ECN: 142247

Org Code: 8M400

UC:

B\&R Code: EW3120072 Total Pages: 118

Key Words: deflagration, GRE, ignition

Abstract: This supporting document evaluates potential ignition sources, documents calculated deflagration rates in flammable gas tanks from these ignition sources, and assesses the efficacy of controls to mitigate or prevent ignition.

TRADEMARK DISCLAIMER. Reference herein to any specific comercial product, process, or service by trade name, trademark, manufacturer, or otherwise, does not necessarily constitute or imply its endorsement, recommendation, or favoring by the United states Government or any agency thereof or its contractors or subcontractors.

Printed in the United States of America. To obtain copies of this document, contact: HHC/BCS Document Control Services, P.O. Box 1970, Mailstop H6-08, Richland WA 99352, Phone (509) 372-2420; Fax (509) 376-4989.
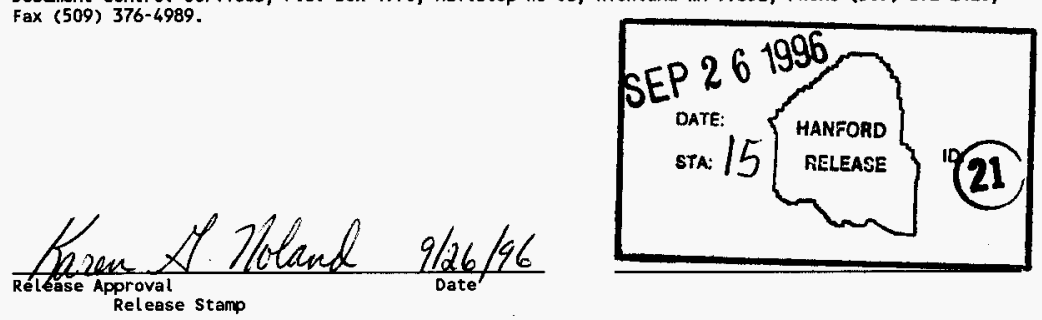
WHC-SD-WM-CN-041, REN.O

\section{TANK FARM DEFLAGRATION RATES DUE TO VARIOUS IGNITION SOURCES}

Tom B. Powers

George R. Sawte1le

August 29, 1996 
WHC-SO-WM-CN-041, REV. O

CONTENTS

1.0 PURPOSE .......................... 4 of 117

$2.0 \mathrm{SCOPE} \ldots \ldots . \ldots . \ldots . . . \ldots 4$ of 117

3.0 METHODOLOGY . . . . . . . . . . . . . 5 of 117

3.1 PROBABILISTIC CALCULATIONS ................ 5 of 117

3.2 IGNITION SOURCES THAT CAN EXIST UNDETECTED PRIOR TO A GRE 9 of 117

3.2.1 Method For Calculating GRE Rates ........ 9 of 117

3.2.2 Method For Calculating Ignition Source Probabilities ............ 9 of 117

3.3 IGNITION SOURCE THAT COMES INTO EXISTENCE AFTER A GRE: 10 of 117 3.3.1 Method For Calculating Ignition Source Rates . . 10 of 117

3.3.2 Method For Calculating Proportion of Time Headspace Is in Hazardous Condition ...... 10 of 117

4.0 ASSUMPTIONS . . . . . . . . . . . . . . . . . 11 of 117

4.1 ASSUMPTIONS FOR DEFLAGRATION RATE CALCULATIONS, WITHOUT AND WITH CONTROLS . ............. 11 of 117

4.2 ASSUMPTIONS FOR GRE RATE DETERMINATIONS ...... 19 of 117

5.0 INPUT DATA _............ 20 of 117

5.1 DATA FOR DEFLAGRATION RATE CALCULATIONS, WITHOUT AND WITH CONTROLS . . . . . . . 20 of 117

5.2 DATA FOR GRE RATES AND PROPORTION OF TIME DETERMINATIONS 21 of 117

6.0 CALCULATIONS . . . . . . . . . . . . . . . . 22 of 117

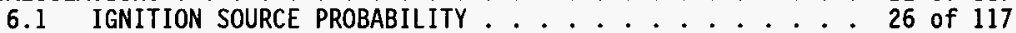

6.2 VARIOUS INSTRUMENTATION AND EQUIPMENT . . . . . . 26 of 117

6.3 TANK HIGH LEVEL DETECTOR ............. 27 of 117

6.4 VIDEO CAMERA AND LIGHTS .............. 29 of 117

6.5 PUMP PIT LEAK DETECTOR . . . . . . . . . . 30 of 117

6.6 PRIMARY TANK ACTIVE VENTILATION SYSTEM . . . . . 32 of 117

6.7 FIBERGLASS LOWS AND PLASTIC RISER SLEEVES . . . . . 35 of 117

6.8 TRANSFER PUMP ........................ 36 of 117

6.9 VEHICLE FUEL FIRE . . . . . . . . . . . . 37 of 117

6.10 HOT DRILLING CHIPS ............ . . 39 of 117

6.11 WELDING OR TORCH BURNING SLAG OR HOT METAL . . . . 40 of 117

6.12 GRINDING .................... 42 of 117

6.13 ELECTRICAL EQUIPMENT USED OUTSIDE A TANK ..... 43 of 117

6.14 GREENHOUSE FIRE ASSOCIATED WITH A PIT OR RISER . . 44 of 117

6.15 BRUSH FIRE .................. 46 of 117

6.16 ADJACENT TANK FIRE . . . . . . . . . . . 47 of 117

6.17 LIGHTNING STRIKE . . . . . . . . . . . . . . . 48 of 117

6.18 SEISMIC EVENT ............... . . 49 of 117

6.19 STILL CAMERA AND LIGHTS . . . . . . . . . . . 49 of 117

6.20 REMOVING RISER COVER THAT DOES NOT HAVE SAMPLE PORT . . 50 of 117

6.21 REMOVING RISER COVER THAT HAS A SAMPLE PORT . . . . . 52 of 117

6.22 AIR LANCING ........................ 53 of 117

6.23 HYDRAULIC JETTING . . . . . . . . . . . . . . . . . 54 of 117

6.24 AIR LIFT CIRCULATOR . . . . . . . . . . . . 56 of 117

6.25 WASTE OR WATER ADDITION . . . . . . . 57 of 117 
WHC-SD-WM-CN-041, REV,O

6.26 INSTALLATION OF VARIOUS EQUIPMENT INTO WASTE . . . . 58 of 117 6.27 ROTARY MODE CORE DRILL OVERHEATING .......... 59 of 117 6.28 ROTARY MODE CORE SAMPLING TRUCK VENTILATION SYSTEM • . 60 of 117

6.29 SALT WELL PUMPING SYSTEM .............. 60 of 117

7.0 RESULTS ......................................... 60 of 117

8.0 CONCLUSIONS . . . . . . . . . . . . . . . . . . 64 of 117

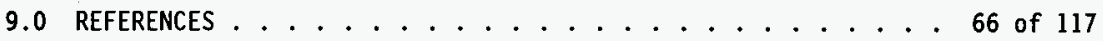

APPENDIX A ................................ 69 of 117

\section{LIST OF TABLES}

Table 1. Numbers of Operations Used in Calculations . . . . . . 19 of 117

Table 2. Frequency of Hazardous Gas Release Events . . . . . . . . 21 of 117

Table 3. Ignition Sources for SSTs and DSTs . . . . . . . . 23 of 117

Table 4. Deflagration Rate (Def. Rate) for Normal Storage

Conditions............................. 61 of 117

Table 5. Deflagration Rate (Def. Rate) for Intrusive Operations: 63 of 117 
WHC-SD-WM-CN-041, REN,O

TANK FARM DEFLAGRATION RATES

DUE TO VARIOUS IGNITION SOURCES

\subsection{PURPOSE}

The purpose of this supporting document is to evaluate potential ignition sources, to document calculated deflagration rates in flammable gas tanks from these ignition sources, and to assess the efficacy of controls to mitigate or prevent ignition.

\subsection{SCOPE}

The scope of the evaluations in this document include the calculation of known and identified potential ignition sources for flammable gas and to a limited extent for organic waste as well. The conditions considered included normal storage, routine surveillance, maintenance and instrument repair, installation of equipment, natural phenomena (1ightning and seismic activities), and waste sampling for characterization. The flammable gas deflagration calculations are focused on the potential for large gas release events (GREs) such that if ignited could result in a pressure exceeding the tank dome design pressure.

This evaluation was scoped as a limited effort study to categorize various ignition sources and evaluate the efficacy of controls. A more exhaustive study with an expanded level of effort was considered unwarranted because of the lack of an empirical data base related to general equipment and spark source likelihood. Many of the ignition likelihood values are based on engineering judgement. Hence the results are considered to be of primary value in defining the relative risk of a given initiator and the efficacy of controls.

This study included most but not all possible ignition sources or tank operations contributions. Some potential ignition sources were identified late in the analysis effort and were not quantified. The potential ignition sources analyzed are listed in Table 3 . Mixer pump operation, rotary mode core sampling, and salt well pumping are addressed in detail in other reports.

The following potential ignition sources were identified but not quantified in these deflagration calculations:

- heated vapor probe for vapor sampling

o auger sampling

- grab sampling

- propane heater used to heat greenhouses

o core drill spark

o sludge weight spark

o nonconductive material use

- beta Continuous Air Monitors (CAMs) in exhaust stack 
WHC-SD-WM-CN-041, REV, $O$

$\begin{array}{ll}0 & \text { use of aluminum in waste } \\ 0 & \text { thermite flashes } \\ 0 & \text { organic nitrate reactions } \\ 0 & \text { mechanical sparks from actuation of salt well pump foot valve }\end{array}$

The methodology for calculating GRE rates and ignition source

probabilities are discussed in Section 3.0. The major assumptions related to the calculations of the deflagration rates both with and without controls are listed in Section 4.0. The input data (equipment failure rates, GRE rates, proportion of time the dome space is hazardous) are defined in Section 5.0. The deflagration rate calculations are presented in Section 6.0 . The results and conclusions are summarized and presented in Section 7.0 and 8.0, respectively.

\subsection{METHODOLOGY}

The methodology used to calculate the deflagration rates consists of three basic methods. First, if the calculation of the deflagration rate is dominated by an ignition source that can exist undetected prior to a gas release event (GRE) then one method is used. Second, if the calculation of the deflagration rate is dominated by an ignition source that comes into existence after a GRE then a second method is used. Third, if there is a common cause between the occurrence of a GRE and the existence of an ignition source, then a common cause method is used. SCENARIOS.

FOR THIS REPORT DEFLAGRATION RATES ARE CALCULATED ONLY FOR DOME DAMAGE

\subsection{PROBABILISTIC CALCULATIONS}

The following discussion provides a basis for understanding probabilistic calculations. Almost all of the following discussion in Section 3.1 is quoted (except italics) from an American National Standard published by The Institute of Electrical and Electronics Engineers, Inc. [IEEE] (IEEE 352-1975).

Quantitative analysis uses what is known or assumed about the failure characteristics of individual component parts to predict the failure probability of the system. A mathematical model for system success is used as a function of some or all of the following: failure rates, repair rates, test intervals, mission time, system logic, and surveillance test schedule. In practice the validity of quantitative results may be limited by the quality and quantity of data; however, useful comparative results and sensitivity analyses do not depend on the availability of extensive data. 
Mission Definition. A detailed description of what the system must do for success for the time interval or task of interest, and for the environmental conditions under which the system must perform is called the mission definition. There may be more than one function of interest, and each must have its own particular mission definition.

Two ways in general use to express mission success, reliability, and, availability, are discussed in the following sections.

Reliability. Reliability is the characteristic of an item expressed by the probability that it will perform a required mission under stated conditions for a stated mission time. In the simplest case, repair is not allowed during the stated period of time. If redundant channels comprise a system, one or more channels may fail and may be repaired, provided there is no discontinuity of function. The exact ground rules for treating repair must be clearly delineated.

In all cases, the exact period of time of interest must be stated. A statement of numerical reliability without an accompanying statement of time is meaningless. Two examples of valid reliability missions are as follows:

(1) A pressure switch monitoring reactor pressure is inaccessible for maintenance during reactor operation. An assessment of the numerical reliability of the switch to survive one fuel cycle (a stated time) is a meaningful measure of integrity.

(2) A safeguard system is initiated and must continue to operate without failure for 100 hours.

The reliability of any component for a mission time $t$ may be calculated exactly by the expression:

$$
R(t)=\exp \left[-\int t_{t_{1}}^{t_{2}} h(t) d t\right]
$$

where

$$
\begin{aligned}
R(t) & =\text { reliability (probability of success) } \\
h(t) & =\text { hazard rate (instantaneous failure rate) } \\
t & =\text { stated time duration of the mission which begins at time } t_{1} \\
& \text { and ends at } t_{2}
\end{aligned}
$$

Equation 1 is perfectly general and does not require any approximations for its use. Since the hazard rate $h(t)$ is time variant, the reliability can be calculated through times of break-in as well as wear-out.

Generally, data are not available to give a good description of the hazard rate throughout a component's whole iifetime. Also, it has been demonstrated that on many components, there is a 


$$
\text { WHC-SD-WM-CN-041, REN.O }
$$

period of middle life wherein the hazard rate is relatively constant. Under these conditions Equation 1 reduces to

$$
R(t)=\exp [-\lambda t]
$$

where $\lambda$ is the constant component failure rate which is characteristic of the exponential distribution. Equation 2 is the form generally used in most reliability calculations. The exponential form can be expressed as a series form:

$$
\exp [-\lambda t]=1-\lambda t+(\lambda t)^{2} / 2 !-(\lambda t)^{3} / 3 !+\ldots
$$

For small values of the product $\lambda t$,

$$
R(t)=1-\lambda t
$$

(Equation 3)

Where $\lambda t$ is equal to 0.1 , the error when using Equation 3 is approximately 5 percent. For the range of values of $\lambda$ t normally encountered (less than 0.1 ), the error is trivial.

The unreliability $R(t)$ is the complement of the reliability, $[R(t)=1-R(t)]$, and, for small values of $\lambda t$,

$$
\bar{R}(t)=\lambda t
$$

(Equation 4)

Availability. Availability may be considered as the fraction of the time the system is operational. If a record is maintained on an operating system, the availability may be computed from the following formula:

$$
\text { Availability }=\frac{\text { Up Time }}{\text { Up Time + Down Time }}
$$

(Equation 5)

Availability allows for failure, that is, complete loss of function, and subsequent repair. Unlike reliability, availability is not expressed as a function of time, since the long-term availability is time invariant.

For a system that is being designed, the availability may be predicted by calculating the expected down time in any period of interest, usually the interval between tests. Some of the failures that occur in systems annunciate themselves, and the repair process may start immediately. Other failures are not self-annunciating and can be discovered only by periodic testing. Thus, the down time in Equation 5 is a function of the test interval as well as the actual repair time.

Power $\mathrm{plant}$ protection systems are standby systems awaiting a command that may come at any random instant in time. Thus, availability is a good measure of the integrity of such systems.

$$
\begin{gathered}
\text { Availability }=\frac{\begin{array}{c}
\text { Average time in the "good" } \\
\text { state per test interval }
\end{array}}{\text { Average time per test interval }} \\
7 \text { of } 117
\end{gathered} \text { (Equation 6) }
$$


WHC-SD-WM-CN-041, REL, O

For a single component, the availability may be calculated from:

$$
\text { Availability }=\frac{\theta-(\lambda \theta)(\theta / 2)}{\theta}
$$

where $\theta$ is the average time per test interval, $\lambda \theta$ is the probability that the single component fails sometime in interval $\theta$ (Equation 4$)$, and $(\theta / 2)$ is the expected (average) time that the component was in a failed state.

Equation 7 reduces to

$$
\text { Availability }=1-\frac{\lambda \theta}{2}
$$

for a single component.

Equation 8 for availability is valid if the following criteria are satisfied:

(1) The system consists of a single component with failure rate $\lambda$

(2) The product $\lambda \theta$ is small compared to unity

(3) The system is known to be good at the beginning of each test interval

(4) Every test interval lasts for a time $\theta$

(5) When a failure occurs, it is not detected until a test is conducted at the end of the time interval $\theta$

(6) When a failure is detected at the end of a test interval, it is repaired instantaneously, or the process to be protected is placed in a state not requiring the protection (for example, plant shut down)

Alternatively, the availability can be viewed as the "average" reliability during a given test interval, expressed as

$$
\text { Availability }=1 / \theta \int_{0}^{\theta} R(t) d t
$$

where $R(t)$ is an expression for either the reliability of a system, or a single component. In the special case of a single component with a constant failure rate $\lambda$ and the product $\lambda \theta$ small compared to unity, Equation 9 yields Equation 8.

For a system consisting of multiple components, the procedure is the same as that above except that the average time in the "good" state per test interval must be calculated by using mathematical modeling techniques and using Equation 9.

Availability is frequently defined as the probability that the system will be operational at a randomiy selected future instant in time. This definition follows directly from Equation 5 , and is a useful definition regardless of whether the availability of a system is being measured or predicted. 
WHC-SD-WM-CN-041, REV, O

The unavailability is the complement of the availability, [Unavailability = 1-availability].

\subsection{IGNITION SOURCES THAT CAN EXIST UNDETECTED PRIOR TO A GRE}

For ignition sources that can exist undetected prior to a GRE, the deflagration rate is a GRE rate combined with a probability that the ignition source exists during the period of time between failure detection [Deflagration rate $=$ GRE rate * probability of ignition from ignition source].

\subsubsection{Method For Calculating GRE Rates}

The method for calculating GRE rates is based on gas retention rates and volumes of flammable gases that if burned result in hazardous consequences. The rate of gas retention can be used to calculate how often "large" gas releases might occur by noting that the gas has to exist in the waste before it can be released from the waste. The retention rate of gas is estimated from level rise (noting that certain assumptions were made about the pressure at which the gas is held in the waste). The volumes of flammable gases that if burned can result in dome damage have been calculated.

Calculations of GRE rates is constructed as a combination of two gas release rates. The first is an "intrinsic" release rate and the second is a rate of seismic induced gas release. The seismic induced releases are hypothetical. For double shell tanks, the intrinsic releases modeled are the observed rollovers. For single shell tanks, the intrinsic releases are hypothesized releases that have not been observed yet.

The method of determining GRE rates that are used in this report is documented in Pacific Northwest National Laboratory (PNNL) letter report TWSFG96.24 that is reproduced in Appendix A of this report. THE CALCULATIONS IN THIS REPORT ONLY USE GRE RATES RELATED TO DOME DAMAGE.

\subsubsection{Method For Calculating Ignition Source Probabilities}

The method for calculating ignition source probabilities assumes that the ignition sources are first identified. Identifying ignition sources of concern to the tank farms involved reviewing previous work related to possible ignition sources (Scaief 1991, Scaief 1996). Draft documents related to flammable gases, organic liquids, organic solids, and tank farm fire hazard analysis were also reviewed to compile a list of ignition sources of concern to tank farms.

The method for calculating the probability of ignition for each identified ignition source involves understanding how each piece of equipment could fail and produce an ignition possibility, or what phenomena could occur that would result in the production of an ignition possibility. Once the equipment failures or phenomena are postulated that could produce an ignition possibility, probabilities are calculated that represent these failures or phenomena. The assumptions involved in the calculations are documented. Examples of how the calculations are actually made are included. 
WHC-SD-WM-CN-041, REV.O

If the product of the average rate that a potential ignition source can be capable of producing an ignition source $(\lambda)$ and the dominant time of concern $(t)$ is small $(<0.1)$, the probability of ignition is approximated by $\lambda t$ as discussed in Section 3.1. Thus if the calculations discussed in Section 6.0 are within this limitation, the probability of ignition is expressed as At.

Where applicable, three types of calculations are performed relative to each potential ignition source. First, a calculation is performed or number assumed that represents the unmitigated possibility of an ignition source. This means equipment is off-the shelf or of a standard design with no particular consideration for ignition source reduction, and there are no controls on limiting the number of activities or no methods that would limit the possibility of ignition sources. Second, a calculation is performed or a number assumed that represents the mitigated possibility of an ignition source. This means equipment is designed to industrial standards for flammable gas (hydrogen) environments according to National Fire Protection Association (NFPA) requirements for Class 1, Division 1 or 2, group locations. Also controls are in place to limit number of activities and implement other methods (in addition to industry standards for flammable gas environments) to reduce ignition sources. Third, if applicable, controls are designed with human factors considerations to maximize compliance.

\subsection{IGNITION SOURCE THAT COMES INTO EXISTENCE AFTER A GRE}

For ignition sources that come into existence after a GRE, the deflagration rate is an ignition source existence rate per year combined with the proportion of time that the tank headspace is in the hazardous condition [Deflagration rate $=$ ignition rate * probability that headspace is hazardous].

\subsubsection{Method For Calculating Ignition Source Rates}

The method for calculating ignition source rates has the same basis as that described in section 3.2.2 for calculating the ignition source probabilities. The ignition sources that come into existence after a GRE must be identified, the mechanisms of failure causing an ignitor to exist must be understood, and the average rate that a potential ignition source can be capable of producing an ignition source $(\lambda)$ is represented on a per year basis. The same three types of calculations (unmitigated, mitigated, and mitigated with human factors considerations) are made as appropriate as discussed in section 3.2.2.

\subsubsection{Method For Calculating Proportion of Time Headspace Is in Hazardous Condition}

The method for calculating the proportion of time the tank headspace is in a hazardous condition is based on gas retention rates and volumes of flammable gases that if burned result in hazardous consequences, similar to section 3.2.1. The proportion of time varies as a function of the volume of an individual release. Thus the proportion of time the tank headspace is in a hazardous condition is represented by the formula 


$$
\begin{aligned}
& \text { WHC-SD-WM-CN-041, REN,O } \\
& \text { POT }=\left(f_{\mathrm{sm}} * \tau_{\mathrm{sm}}\right)+\left(\mathrm{f}_{\mathrm{int}} * \tau_{\text {int }}\right)
\end{aligned}
$$

where

$$
\begin{aligned}
& \text { POT }= \text { Proportion of time } \\
& f_{\text {sm }}=\text { frequency of gas release related to a seismic event } \\
& \tau_{s m}=\text { duration for which the tank headspace contains a hazardous amount } \\
& \text { of flammable gas related to a seismic event } \\
& f_{\text {int }}=\text { frequency of gas release related to an intrinsic release } \\
& \tau_{\text {int }}=\text { duration for which the tank headspace contains a hazardous amount } \\
& \text { of flammable gas related to an intrinsic release }
\end{aligned}
$$

The method of calculating proportion of time the tank headspace is in a hazardous condition as used in this report is documented in Pacific Northwest National Laboratory (PNNL) letter report TWSFG96.24 that is reproduced in Appendix $A$ of this report. THE CALCULATIONS IN THIS REPORT ONLY USE PROPORTION OF TIME RELATED TO DOME DAMAGE.

\subsection{ASSUMPTIONS}

\subsection{ASSUMPTIONS FOR DEFLAGRATION RATE CALCULATIONS, HITHOUT AND WITH CONTROLS}

The following assumptions are used in the various calculations of the deflagration rate calculations. Note that many of the assumptions may constitute an implied control required to achieve the reduced deflagration rate.

- All calculated deflagration rates are on a "per tank" basis unless otherwise noted [general assumption]

- A probability of 1E-5 per year represents each potential instrumentation spark source that was ranked as "low", "very low", or "none" as an ignition source by Chuck Scaief in his report, WHC-SD-WM-ES-362, REV 1 (Scaief 1996) [general assumption, Section 6.1]

High level detector [Section 6.3]

$0 \quad$ An average of 2 transfers per week for tanks on the approved transfer list

- Al1 tanks (to be transferred into) on the tank farms approved transfer list are double shell tanks (DSTs)

0 Any of the 19 non watch list DSTs could be on the transfer list

- One mistransfer per 100 transfers

o One out of ten mistransfers will cause a tank level to rise to the tank high level limit 


$$
\text { WHC-SD-WM-CN-041, REV. } O
$$

- The probability that the humidity in a tank is $100 \%$ given a gas release event is $1 \mathrm{E}-2$

- The probability of a spark from the high level detector is lE-1 given there is $100 \%$ humidity in the tank vapor space

- A GRE of concern will occur every mistransfer

o The probability of increased moisture from a GRE causing a high level detector to spark is assumed to be $1 \mathrm{E}-2$

Video [Section 6.4]

- A11 video systems have no purge systems for the unmitigated case

0 The mitigated probability of ignition for a video system is $1 E-5$ because of purge systems and explosion proof lights

\section{Pump pit leak detector [Section 6.5]}

- Two days per year there is either sufficient rainfall or snow melt to leak into unsealed pump pits and cause a spark when conductive liquid connects the two probes of the pit leak detector

- All pump pits allow in-leakage of liquids from above the pit

- The average transfer of waste occurs for 8 hours

- The probability that the humidity in a pump pit is $100 \%$ given a gas release event is $1 \mathrm{E}-3$ and the probability of a spark from the pump pit leak detector is $1 E-1$

- The probability of propagation of deflagration from the pump pit to the tank has a probability of 0.1

- The leak detectors will be re-designed to the equivalent probability of $1 \mathrm{E}-5$ for the mitigated case

- A GRE of concern will occur every transfer

Primary tank ventilation system [Section 6.6]

- A control is in place to preclude startup when flammable concentrations may be present

- For a ventilation fan, the ignition source is due to the fan blades contacting the fan housing due to an imbalanced system that does not cause the fan to shutdown catastrophically

- Fan imbalance failure rate is $3 E-5 / h o u r$, the failure rate for a ventilator fan failure to run

- The time between failure detection of a fan imbalance is 1 week, the time the fan blades could continue striking the fan housing before it was shutdown for correction 


$$
\text { WHC-SD-WM-CN-041, REV.O }
$$

- A failed temperature sensor that could result in sparks would be detected in 24 hours

- The ventilation system heater elements have the same probability as the fan to produce an ignition

- The probability of propagation of deflagration from the active ventilation system to the tank has a probability of 0.01 because of the velocity of the exhaust stream

0 Deflagration rate does not include ignition sources outside of the ventilation duct

\section{Fiberqlass Liquid Observation Wells (LOWs) and Plastic Riser Sleeves}

[Section 6.7]

- Because electrostatic charges are associated with fiberglass Liquid Observation Wells (LOWs) and plastic riser sleeves, the bounding probability of ignition in the unmitigated case is 1.0

0 The mitigated probability of ignition is $1 \mathrm{E}-2$ related to bonding and grounding

- If human reliability related to bonding and grounding is brought to its best by superior procedures and independent verification the mitigated probability of ignition with high human reliability is $1 E-4$

- Fiberglass LOWs and plastic riser sleeves that are actively being used are of the most concern related to electrostatic sparks

\section{Iransfer pump [Section 6.8]}

- A transfer pump motor fails in such a way as to produce a spark at the rate of $3 E-5 /$ hour

- 5 transfers per year for any given DST

- The average transfer of waste occurs for 8 hours

- The probability of propagation of deflagration from the pump pit to the tank has a probability of 0.1

- The operator will fail to shut off power to the transfer pump in the unmitigated case with a probability of 1.0

- The operator may fail to shut off power to the transfer pump in the mitigated case with a probability of $1 E-2$

- The operator may fail to shut off power to the transfer pump [human error with verification] given greater than 25 percent of lower flammability limit (LFL) with probability $1 \mathrm{E}-3$ 
WHC-SD-WM-CN-041, REV.O

Vehicle fuel fire [Section 6.9]

- A frequency of 1 vehicle accident fue 1 tank rupture per year in a tank farm

$0 \quad$ Making sure fuel tanks are mechanically protected (bumpers, frame, etc.) reduces the fuel tank ruptures by a factor of 10

Drilling [Section 6.10]

- The probability of any given drilling activity being performed on a riser or near enough to a riser that hot drilling chips could enter the riser if open is $1 \mathrm{E}-1$

- If drilling were near enough to a riser so that hot drilling chips could enter the riser if open, the probability that the riser is open is $5 E-1$

- The probability that hot drilling chip controls fail is 0.01

- Human reliability related to preventing hot drilling chips from entering a tank is brought to its best by superior procedures and independent verification thus the mitigated probability of ignition with high human reliability is $1 E-3$

Welding [Section 6.11]

- The probability of any given welding or torch activity being performed on a riser or near enough to a riser that burning slag/hot metal could enter the riser if open is estimated to be less than drilling and thus $5 \mathrm{E}-2$

- If welding or torch activities were near enough to a riser so that burning slag/hot metal could enter the riser if open, the probability that the riser is open is $5 \mathrm{E}-1$

o The probability that welding or torch cutting controls fail is 0.01

- Human reliability related to preventing burning slag or hot metal from entering a tank is brought to its best by superior procedures and independent verification thus the mitigated probability of ignition with high human reliability is $1 E-3$

\section{Grinding [Section 6.12]}

o The probability of any given grinding activity being performed on a riser or near enough to a riser that grinding sparks could enter the riser if open is $5 \mathrm{E}-2$

- If grinding were near enough to a riser so that grinding sparks could enter the riser if open, the probability that the riser is open is $5 \mathrm{E}-1$

0 The probability that grinding controls fail is 0.01 


$$
\text { WHC-SD-WM-CN-041, REV, D }
$$

- Human reliability related to preventing grinding sparks from entering a tank is brought to its best by superior procedures and independent verification thus the mitigated probability of ignition with high human reliability is $1 \mathrm{E}-3$

\section{Electrical equipment used outside the tank [Section 6.13]}

- Electrical equipment will be used outside of any given tank once every week during a year

- The probability of propagation of deflagration from outside the tank to the tank has a probability of 0.1

- The probability of ignition related to electrical equipment used outside of a tank is 1.0

0 The probability of ignition is $1 \mathrm{E}-2$ if the control was to not use electrical equipment near a tank but human error resulted in a failure to follow the control

$0 \quad$ The probability of ignition is $1 \mathrm{E}-3$ considering human error with independent verification

\section{Greenhouse fire [Section 6.14]}

- 3 greenhouses will be used over a pit or riser for any given tank during a year

- The probability of propagation of deflagration from outside the tank to the tank has a probability of 0.1

- The probability of ignition related to electrical equipment used in a greenhouse is 1.0

0 The probability of ignition is $1 \mathrm{E}-2$ if the control was to not use electrical equipment in a greenhouse without sniffing for flammable gas but human error resulted in a failure to follow the control

- The probability of ignition is 1E-3 considering human error with independent verification

\section{Brush fire [Section 6.15]}

o The probability that burning material would enter the tank when present in the tank farm is $1 E-1$

- In a controlled situation, brush is cleared from the inside of a tank farm

- For a controlled situation related to brush fires, the probability of fire getting inside the tank farm is $1 E-1$

o In a controlled situation, the underside of vehicles entering a tank farm are checked for collected brush 
- In a controlled situation, a probability of fire getting inside the tank farm is $1 E-2$ (human error of failure to check for brush under vehicles)

Adjacent tank fire [Section 6.16]

o Probability of propagation of a tank fire from one tank to another through connecting piping of 0.1

\section{Lightning [Section 6.17]}

$0 \quad$ Lightning protection system was installed that could prevent nine out of ten lightning strikes on the tank of concern

- One out of a hundred lightning strikes on a SST tank farm results in a gas release at the same time

- Since DST wastes are more fluid, one out of ten lightning strikes on a DST tank farm results in a gas release at the same time

\section{Seismic [Section 6.18]}

- A $0.2 \mathrm{~g}$ earthquake will cause an ignition source within the tank dome space with a probability of 1.0 due to metal striking metal or electrical faults producing continual sparks

- For common cause cases, the rate of seismic events of $0.2 \mathrm{~g}$ is the deflagration rate for both unmitigated and mitigated cases

\section{Still camera [Section 6.19]}

- The unmitigated probability of ignition for a still camera and lights is 1.0 because these cameras and lights were not designed to operate in a flammable gas environment, and they produce an electrical flash as part of operation

- The mitigated probability of ignition for a still camera and lights is $1 \mathrm{E}-5$ because the camera and lights will be designed to industrial standards for flammable gas environments

Removal of riser cover without sample port [Section 6.20]

0 The unmitigated probability of ignition from electrostatic sparks is 1.0 because there would be no provisions for bonding and grounding in an unmitigated situation and electrostatic sparks would be expected as part of operation

- The mitigated probability of ignition is $1 \mathrm{E}-2$ because of human error in failing to apply the bonding and grounding provisions when a procedure says to use them

- Human reliability related to bonding and grounding is brought to its best by superior procedures and independent verification thus the mitigated probability of ignition with high human reliability is $1 \mathrm{E}-4$ 
WHC-SD-WM-CN-041, REV. O

\section{Removal of riser cover with sample port [Section 6.21]}

- The unmitigated probability of ignition from electrostatic sparks is 1.0 because there would be no provisions for bonding and grounding in an unmitigated situation and electrostatic sparks would be expected as part of operation

- The mitigated probability of ignition is the combined human error of 1E-4 because of human error in sampling for flammable gas through the riser sample port prior to riser cover removal and human error in failing to applying the bonding and grounding provisions when a procedure says to use them. These two human errors are assumed independent because different personnel perform the two different operations of sampling and bonding/grounding.

o Human reliability related to bonding and grounding is brought to its best by superior procedures and independent verification thus the mitigated probability of ignition with high human reliability for the combined human error is $1 \mathrm{E}-5$

\section{Air lancing [Section 6.22]}

- Unmitigated operation of the air lances means no grounding of the air lances

- Probability of human error to attach bonding properly is $1 \mathrm{E}-2$

- Human reliability related to bonding and grounding is brought to its best by superior procedures and independent verification thus the mitigated probability of ignition with high human reliability is $1 E-4$

- Air lancing will cause a GRE once per every hundred air lance activities independent of whether performed in a SST or a DST

$0 \quad 8$ hours per air lance activity

Hydraulic jetting [Section 6.23]

$0 \quad$ Unmitigated operation of hydraulic jetting means no grounding of the hydraulic jetting conduits

- Probability of human error to attach bonding properly is $1 \mathrm{E}-2$

- Human reliability related to bonding and grounding is brought to its best by superior procedures and independent verification thus the mitigated probability of ignition with high human reliability is $1 E-4$

o Hydrautic jetting will cause a GRE once per every hundred hydraulic jetting activities independent of whether performed in a SST or a DST

$0 \quad 8$ hours per hydrautic jetting activity 


\section{WHC-SD-WM-CN-041, REV, O}

\section{Air lift circulators [Section 6.24]}

- Unmitigated operation of the air 1 ift circulators means no grounding of the air lift circulators

- Probability of human error to attach bonding properly is $1 E-2$

- Human reliability related to bonding and grounding is brought to its best by superior procedures and independent verification thus the mitigated probability of ignition with high human reliability is $1 \mathrm{E}-4$

- Air lift circulator installation and operation will cause a GRE once per every hundred air $1 \mathrm{ift}$ circulator activities independent of whether performed in a SST or a DST

$0 \quad 8$ hours per air lift circulator activity

\section{Addition of waste or water [Section 6.25]}

- Unmitigated operations of adding waste liquids to tanks means no grounding is possible related to the addition of wastes

- The mitigated probability of producing an ignition source for waste flow is 1.0 because there is no known way to ground waste flow into tank. For water flow into a tank there may be possibilities to ground the water piping unless it is totally buried (human failure to bond $1 E-2$ )

- Human reliability related to bonding and grounding (if it is possible) is brought to its best by superior procedures and independent verification thus the mitigated probability of ignition with high human reliability is $1 E-4$

o Waste or water addition will cause a GRE once per every hundred waste or water addition activities independent of whether performed in a SST or a DST

$0 \quad 8$ hours per waste or water addition activity

\section{Installation of various equipment in the waste [Section 6.26]}

- The unmitigated probability of installation of equipment into waste in a tank producing an ignition source is 1.0

0 The mitigated probability of producing an ignition source is 0.01 because of human error to bond/ground or successfully install without producing mechanical sparks

- Human reliability related to bonding and grounding is brought to its best by superior procedures and independent verification or extreme care is taken during installation thus the mitigated probability of ignition with high human reliability is $1 \mathrm{E}-3$ 
- Installation of equipment into the waste will cause a GRE once every hundred installations independent of whether performed in a SST or a DST

- 8 hours per installation activity

The number of operations assumed and used in the following calculations are 1 isted in Table 1. The numbers of operations for a mitigated or unmitigated case is number of operations that are assumed and used in the calculations for the unmitigated and mitigated cases as described in the last paragraph of Section 3.2.2.

Table 1. Numbers of Operations Used in Calculations

\begin{tabular}{|c|c|c|c|}
\hline & \multicolumn{2}{|c|}{$\begin{array}{l}\text { Number of Operations per Tank } \\
\text { per Year (except as noted) }\end{array}$} & \multirow{2}{*}{$\begin{array}{l}\text { Section of } \\
\text { Report Where } \\
\text { Mumber of } \\
\text { Operations are } \\
\text { Used in a } \\
\text { Calculation }\end{array}$} \\
\hline & $\begin{array}{l}\text { Unmitigoted } \\
\text { Case }\end{array}$ & Mitigated Case & \\
\hline Vehicle fuel fire & $\begin{array}{c}\text { SST - } \\
1000 / \text { tank } \\
\text { farm-year } \\
\text { DST - 500/tank } \\
\text { farm-year }\end{array}$ & $\begin{array}{l}\text { SST - } 100 / \text { tank } \\
\text { farm-year } \\
\text { DST - } 50 / \text { tank } \\
\text { farm-year }\end{array}$ & 6.9 \\
\hline Hot drilling chips & 100 & 3 & 6.10 \\
\hline Welding or torch burning slag or hot metal & 300 & 3 & 6.11 \\
\hline Grinding causes sparks & 200 & 3 & 6.12 \\
\hline Brush fire & $\begin{array}{l}\text { SST }=1000 \\
\text { DST }=500\end{array}$ & $\begin{array}{l}\text { SST }=100 \\
\text { DST }-50\end{array}$ & 6.15 \\
\hline still camera and lights & 10 & 1 & 6.19 \\
\hline $\begin{array}{l}\text { Removing riser cover that does not have gas } \\
\text { sample port }\end{array}$ & 100 & 3 & 6.20 \\
\hline Renoving riser cover that has gas sample port & 100 & 3 & 6.21 \\
\hline Air lance operation & 30 & 3 & 6.22 \\
\hline Hydraulic jetting operation & 30 & 3 & 6.23 \\
\hline Air lift circulator operation & 30 & 3 & 6.24 \\
\hline Waste or water addition & 30 & 3 & 6.25 \\
\hline $\begin{array}{l}\text { Installation of a Mult ifunction Instrunent } \\
\text { Tree (MIT), Liquid Observation Well (LOW), } \\
\text { Thermocouple (TC) Tree, miscellaneous waste } \\
\text { temperature sensor, air lance, hydraul ic jet, } \\
\text { etc. Also push mode sampling. }\end{array}$ & 50 & 10 & 6.26 \\
\hline
\end{tabular}

\subsection{ASSUNPTIONS FOR GRE RATE DETERMINATIONS}

The major assumption used in the calculation of the GRE rates is the number of episodic releases that produce a volume of flammable gases which if burned would cause dome damage. This assumption implies that the volume of flammable gases released remains in a flammable concentration only a short 
time before being mixed with the dome atmosphere and falling below the flammability limit. It should be noted that the number of GREs per year is not a rate of releases that has ever been observed in the tank farms for the respective type of tanks.

\subsection{INPUT DATA}

\subsection{DATA FOR DEFLAGRATION RATE CALCULATIONS, WITHOUT AND WITH CONTROLS}

The following data were used in the deflagration rate calculations related to probability calculations.

- A gasket leak occurs at the conservative rate of $3 \mathrm{E}-5 /$ hour (Eide 1990, page 13) [Section 6.5]

- $\quad 1040$ single shell tank (SST) farm entries per year and 520 DST farm entries per year (Lindberg 1995, page 2 of attachment) [Section $6.9 \& 6.15$ ]

- Probability of riser breaking due to the vehicle collision [5E-1] (Lindberg 1995, page 3 of attachment) [Section 6.9]

0 Probability that the fue] is ignited by the collision or by heat from the engine [1E-2] (Lindberg 1995, page 3 of attachment) [Section 6.9]

- Probability that the burning fuel will enter the waste tank riser [1E-1] (Lindberg 1995, page 3 of attachment) [Section 6.9]

0 Range fires of about 5,000 acres once every 5 years (Hanford Fire Department) [Section 6.15]

$0 \quad$ The Hanford Site is roughly 560 square miles in area [Section 6.15]

o One off-normal condition has been reported at Hanford that occurred in 1992 in which a truck at 241-TX tank farm picked up tumbleweeds on its carriage and then the tumbleweeds ignited (WHC-TANKFARM-1992-01) [Section 6.15]

- A lightning strike frequency of 0.06 strikes per square kilometer per year is based on a lightning ground strike plot including the Hanford Site for a five year period from January 1, 1991 to January 1, 1996 and documented by Global Atmospherics, Inc (Zach 1996). [Section 6.17]

0 The rates of a $0.2 \mathrm{~g}$ earthquake at Hanford is $9 \mathrm{E}-4 /$ year (WHC 1996) [Section 6.18] 
WHC-SD-WM-CN-041, REV,O

\subsection{DATA FOR GRE RATES AND PROPORTION OF TIME DETERMINATIONS}

Most of the following discussion comes from a PNNL letter report TWSFG96.24 that is reproduced in Appendix A of this report. A subset of the Hanford tanks were selected as "representative" double and single shell tanks in order to gather data to calculate numbers of GREs per year. The double shell tanks examined are AN-105, SY-101 and SY-103. These tanks are currently on the flammable gas watch 1 ist; see Hanlon report (Hanlon 1996, Appendix A) for a description of the flammable gas watch 1 ist. The single shell tanks examined are S-102, S-103 and S-106. Tank S-102 is also on the flammable gas watch list, while the other two tanks are not. All three of these tanks are of significant concern because they exhibit a long term rising waste level, which might indicate increasing amounts of gas trapped in the tank waste. Due to the limited scope of this effort, these tanks were chosen to represent the types (SSTs and DSTs) and range of conditions in the 177 large, underground nuclear waste storage tanks because of available data from these tanks and the various different conditions found in these tanks.

The information in Table 2 comes from the PNNL letter report that is reproduced in Appendix $A$ of this report and shows the calculations for the number of GREs per year and the proportion of time for each of the six tanks mentioned in the previous paragraph.

Table 2. Frequency of Hazardous Gas Release Events

\begin{tabular}{|l||c|c|c|c|c|c|}
\hline Tank & AN-105 & S-102 & S-103 & S-106 & SY-101 & SY-103 \\
\hline $\begin{array}{l}\text { Proportion of Time for } \\
\text { Potential Dome Failure }\end{array}$ & $1 E-4$ & $1 E-4$ & $6 E-6$ & $9 E-5$ & $4 E-3$ & 0.0 \\
\hline $\begin{array}{l}\text { Rates of GREs at Dome } \\
\text { Failure (per year) }\end{array}$ & $4 E-3$ & $8 E-3$ & $7 E-4$ & $2 E-2$ & $2 E-1$ & 0.0 \\
\hline
\end{tabular}

The calculations use numbers of GREs per year or the proportion of time that represent flammable conditions that can result in dome damage.

Tank AN-105 was used to represent DSTs and S-102 was used to represent SSTs. Thus the following data were used in the determinations of deflagration rates.

- The number of GREs per year is $8 E-3 /$ year for an SST and $4 E-3 /$ year for a DST.

0 The proportion of time used is $1 E-4$ for an SST and 1E-4 for a DST. 


\section{WHC-SD-WM-CN-041, REN.O}

\subsection{CALCULATIONS}

Table 3 lists the ignition sources for which probability of ignition calculations were performed. There are some abbreviations that are used in the following text related to the summarized deflagration rates and defined as:

$$
\begin{array}{ll}
\text { unmit. } & =\text { unmitigated } \\
\text { mit. \& rel. } & =\text { mitigated and reliable human action } \\
\text { N/A } & =\text { Not Applicable. }
\end{array}
$$

The definitions of the above abbreviations were originally defined in the last paragraph of Section 3.2.2. 
WHC-SD-WM-CN-041, REV, O

Table 3. Ignition Sources for SSTs and DSTS

\begin{tabular}{|c|c|c|c|c|c|c|c|}
\hline \multirow{2}{*}{$\begin{array}{l}\text { Potential Ignition Source } \\
\text { E - Electrical spark } \\
\text { M - Mechanical spark } \\
\text { ES - Electrostatic sperk } \\
T \text { - Thermal ignition }\end{array}$} & \multirow{2}{*}{$\begin{array}{l}\text { Equipment } \\
\text { found in } \\
\text { at least } \\
\text { one SST or } \\
\text { act ivity } \\
\text { considered }\end{array}$} & \multirow{2}{*}{$\begin{array}{l}\text { Equipment } \\
\text { found in } \\
\text { at least } \\
\text { one DST or } \\
\text { activity } \\
\text { considered }\end{array}$} & \multicolumn{3}{|c|}{$\begin{array}{l}\text { Spark location possible in the } \\
\text { following locations }\end{array}$} & \multirow{2}{*}{$\begin{array}{l}\text { Possibly } \\
\text { causing } \\
\text { gas } \\
\text { release }\end{array}$} & \multirow{2}{*}{$\begin{array}{l}\text { Possibly } \\
\text { causing } \\
\text { both gas } \\
\text { release } \\
\& \\
\text { ignition }\end{array}$} \\
\hline & & & $\begin{array}{l}\text { Under } \\
\text { waste } \\
\text { surface }\end{array}$ & $\begin{array}{l}\text { In tank } \\
\text { vapor } \\
\text { space }\end{array}$ & $\begin{array}{l}\text { Outside tank } \\
\text { with possibility } \\
\text { to propagate } \\
\text { back into tank }\end{array}$ & & \\
\hline \multicolumn{8}{|l|}{ Normal ly Instal led Instrumentation \& Equipment: } \\
\hline Thermocouple Style A (E) & $x$ & $x$ & $x$ & $x$ & & & \\
\hline Thermocouple Style B (E) & $x$ & $x$ & $x$ & $x$ & & & \\
\hline Thermocouple Type $K$ (E) & $x$ & & $x$ & $x$ & & & \\
\hline Resistance Temperature Detector (E) & $x$ & & & $x$ & & & \\
\hline Multifunction Instrument Tree (MIT) (E) & & $x$ & $x$ & $\mathrm{x}$ & & & \\
\hline Miscellaneous waste temperature sensor (E) & $x$ & $x$ & $x$ & $x$ & & & \\
\hline ENRAF level gauge (M) & $x$ & $x$ & & $\mathrm{x}$ & & & \\
\hline FIC reel type conductivity gauge $(E, M)$ & $x$ & $x$ & & $x$ & & & \\
\hline Manual tape with portable conductivity meter (E, M) & $x$ & $x$ & & $x$ & & & \\
\hline Standard hydrogen monitoring system (E) & $x$ & $x$ & & $x$ & $x$ & & \\
\hline Differential pressure transmitter (E) & & $x$ & & & $x$ & & \\
\hline Mixer punp (within waste) $(E, M)$ & & $x$ & $x$ & $\mathbf{x}$ & $x$ & $x$ & $x$ \\
\hline Tank high level sensing probe - conductivity (E) & & $x$ & & $\mathbf{x}$ & & & \\
\hline Video canera and lights (E, M) & & $x$ & & $x$ & & & \\
\hline Pump pit leak detector - conductivity (E) & $x$ & $x$ & & & $x$ & & \\
\hline Primary tank active ventilation system (E, M, ES, T) & $\mathbf{x}$ & $x$ & & & $x$ & & \\
\hline Fiberglass LOWs and plastic riser sleeves (ES) & $x$ & $x$ & $x$ & $x$ & & & \\
\hline
\end{tabular}


WHC-SD-WM-CN-041, REN. O

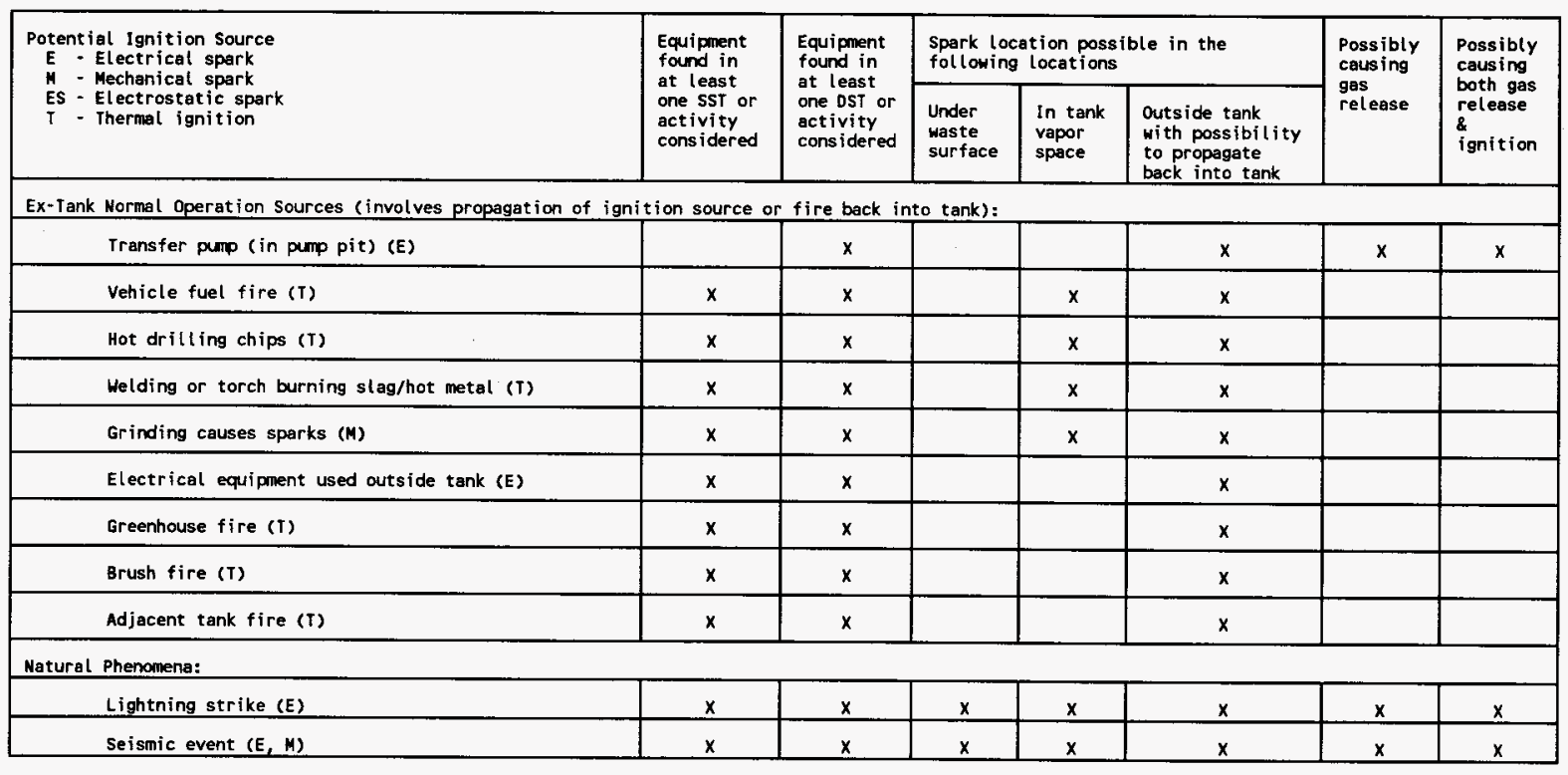


WHC-SD-WM-CN-041, REN, O

\begin{tabular}{|c|c|c|c|c|c|c|c|}
\hline \multirow{2}{*}{$\begin{array}{l}\text { Potential Ignition Source } \\
\text { E - Electrical spark } \\
\text { M - Mechanical spark } \\
\text { ES - Electrostatic spark } \\
\text { T - Thermal ignition }\end{array}$} & \multirow{2}{*}{$\begin{array}{l}\text { Equipment } \\
\text { found in } \\
\text { at least } \\
\text { one SST or } \\
\text { activity } \\
\text { considered }\end{array}$} & \multirow{2}{*}{$\begin{array}{l}\text { Equipment } \\
\text { found in } \\
\text { at least } \\
\text { one DST or } \\
\text { activity } \\
\text { considered }\end{array}$} & \multicolumn{3}{|c|}{$\begin{array}{l}\text { Spark location possible in the } \\
\text { following locations }\end{array}$} & \multirow{2}{*}{$\begin{array}{l}\text { Possibly } \\
\text { causing } \\
\text { gas } \\
\text { release }\end{array}$} & \multirow{2}{*}{$\begin{array}{l}\text { Possibly } \\
\text { causing } \\
\text { both gas } \\
\text { release } \\
\& \\
\text { ignition }\end{array}$} \\
\hline & & & $\begin{array}{l}\text { Under } \\
\text { waste } \\
\text { surface }\end{array}$ & $\begin{array}{l}\text { In tank } \\
\text { vapor } \\
\text { space }\end{array}$ & $\begin{array}{l}\text { Outside tank } \\
\text { with possibility } \\
\text { to propagate } \\
\text { back into tank }\end{array}$ & & \\
\hline \multicolumn{8}{|l|}{ Vapor Intrusive Operations Sources: } \\
\hline Still camera and lights (E, M) & $x$ & $x$ & & $x$ & & & \\
\hline Removing riser cover (ES) & $x$ & $x$ & & $x$ & & & \\
\hline \multicolumn{8}{|l|}{ Waste Intrusive Operations Sources: } \\
\hline Air lancing (ES, M) & $x$ & $x$ & $x$ & $x$ & & $x$ & $x$ \\
\hline Hydraulic jetting (ES, M) & $x$ & $x$ & $x$ & $x$ & & $x$ & $\mathbf{x}$ \\
\hline Air lift circulator (ES, M) & & $x$ & $x$ & $x$ & & $x$ & $x$ \\
\hline Waste or water addition (ES) & & $x$ & & $x$ & & $x$ & $x$ \\
\hline $\begin{array}{l}\text { Installation of a MIT, LOW, TC Tree, miscellaneous } \\
\text { Waste temperature sensor, air lance, hydraulic jet, } \\
\text { etc. Also push mode sampling(ES, M) }\end{array}$ & $\mathbf{x}$ & $x$ & $x$ & $x$ & $x$ & $x$ & $x$ \\
\hline
\end{tabular}


WHC-SD-WM-CN-041, REN. O

\subsection{IGNITION SOURCE PROBABILITY}

Since this task was designed to be of limited scope and effort, a probability of $1 \mathrm{E}-5$ was assigned to each potential instrumentation spark source discussed in the following subsections that was ranked as "low", "very low", or "none" as an ignition source by Chuck Scaief in his report, WHC-SD-WM-ES-362, REV O (Scaief 1996). This probability of $1 E-5$ is assumed to be on a per year basis so the constant component failure rate is 1E-5/year or $1 E-9 / \mathrm{hr}[(1 \mathrm{E}-5 /$ year $/(8760$ hours $/$ year $)=1.1 \mathrm{E}-9 / \mathrm{hr}]$. This constant component failure rate is the rate that the instrumentation could fail in a way to produce a spark.

\subsection{VARIOUS INSTRUMENTATION AND EQUIPNENT}

Summary of Deflagration Rates for Various Instrumentation and Equipment

\begin{tabular}{|c|l|}
\hline Deflagration Cases & Deflagration Rates (per year) \\
\hline SST unmitigated rate & $1 \mathrm{E}-9 / \mathrm{SST}$-year for each instrument \\
\hline SST mitigated rate & same as unmit. \\
\hline SST mit. \& rel. rate & not applicable (N/A) \\
\hline DST unmitigated rate & $1 \mathrm{E}-9 /$ DST-year for each instrument \\
\hline DST mitigated rate & same as unmit. \\
\hline DST mit. \& rel. rate & N/A \\
\hline
\end{tabular}

The following pieces of instrumentation and equipment are each assumed to have a bounding constant component failure rate of ignition of $1 E-5 /$ year as discussed above in Section 6.1:

o Thermocouple Style A

o Thermocouple Style B

$0 \quad$ Thermocouple Type $K$

o Resistance Temperature Detector (RTD)

$0 \quad$ Multifunction Instrument Tree (MIT)

- Miscellaneous waste temperature sensor

- ENRAF level gauge

o FIC level instrument using a reel type conductivity gauge

o Manual tape with portable conductivity meter

- Standard hydrogen monitoring system (SHMS)

o Differential pressure transmitter

These pieces of instrumentation and equipment are assumed to fail and produce an ignition source after a GRE occurs and the proportion of time method is used to calculate the deflagration rate. 
WHC-SD-WM-CN-041, REV, O

The SST unmitigated deflagration rate for each of the above pieces of instrumentation and equipment is 1E-9/SST-year (1E-5 ignitions/SST-year * 1E-4 [proportion of time above LFL, which is above concentration for Dome failure for SSTs] = 1E-9/SST-year). The SST mitigated deflagration rate is the same as the unmitigated deflagration rate because there are no additional controls proposed on these pieces of instrumentation and equipment.

The DST unmitigated deflagration rate for each of the above pieces of instrumentation and equipment is 1E-9/DST-year (1E-5 ignitions/DST-year * 1E-4 [proportion of time above LFL and concentration for Dome failure] = $1 \mathrm{E}-9 / \mathrm{DST}$-year). The DST mitigated deflagration rate is the same as the unmitigated deflagration rate because there are no additional controls proposed on these pieces of instrumentation and equipment.

The mixer pump that is installed in Tank 241-SY-101 is not addressed in the discussion above because a very detailed safety assessment has been performed related to the mixer pump (LANL 1995). This safety assessment has much more detail than could be covered in this limited scope analysis.

\subsection{TANK HIGH LEVEL DETECTOR}

\begin{tabular}{|c|l|}
\hline \multicolumn{2}{|c|}{ Summary of Deflagration Rates for Tank High Level Detector } \\
\hline Deflagration Cases & Deflagration Rates (per year) \\
\hline DST unmitigated rate & $6 \mathrm{E}-3 / \mathrm{DST}$-year \\
\hline DST mitigated rate & $\begin{array}{l}6 \mathrm{E}-5 / \mathrm{DST} \text {-year (operator } \\
\text { action to remove power or new } \\
\text { design) }\end{array}$ \\
\hline DST mit. \& rel. rate & 0/DST-year (remove detector) \\
\hline
\end{tabular}

There are two mechanisms by which a tank high level detector can produce a spark. Either the waste level rises to the level of the detector and activates the detector causing a spark (Scaief 1996, page 5 \& Scaief 1991, section 5.2.5) or there is enough moisture in the air to activate the detector causing a spark.

If the mechanism of the waste level rising to the level of the detector is considered, the most likely cause of an undetected rise is a mistransfer. Discussions with East Tank Farm Engineering personnel indicated an estimate of an average of 2 transfers per week for tanks on the approved transfer 1 ist. This 1 ist contains mostly DSTs and usually averages about 10 tanks. It is assumed that all ten of these tanks are DSTs for this calculation. Therefore about 100 transfers per year $(2 \star 52=104)$ are made. Assuming any of the 19 non watch list DSTs could be on the transfer list, means any non watch list DST could be the starting point of a transfer about 5 times per year (104 transfers/year $\div 19$ non watch 1 ist DSTs $=5.47$ transfers $/$ non watch 1 ist DST-year). Assume a probability of mistransfer of 1 per 100 transfers. Also consider 5 transfers into a non watch list DST per year. Tank high level detectors are essentially conductivity probes that spark when conductive 
WHC-SD-WM-CN-041, REN. O

liquid connects the two probes. This will happen when tank level gets too high. It is assumed that one out of ten mistransfers will cause a tank level to rise to the tank high level limit. Therefore the probability of a tank high level detector producing an ignition source during a year's mission is 5E-3 (5 transfers * 1 mistransfer 100 transfers * probability of $1 \mathrm{E}-1$ of high level detector activation given mistransfer $=5 \mathrm{E}-3$ ). It is recognized that transferring waste into a tank may also be the cause of a gas release. The common cause effect of a mistransfer causing a GRE and an ignition source is discussed below related to the rate of deflagration.

If the mechanism of enough moisture in the air to activate the detector is considered, the probability of humidity being high enough and the probability of a spark given the humidity is high enough must be known or calculated. Based on a phone conversation with Chuck Scaief on 3/19/96, even if a tank is at $100 \%$ humidity doesn't guarantee a spark. Assuming the probability that the humidity in a tank is $100 \%$ given a gas release event is $1 \mathrm{E}-2$ and the probability of a spark from the high level detector is $1 \mathrm{E}-1$, the probability of a spark due to moisture following a gas release event is $1 \mathrm{E}-3$ $(1 E-2 * 1 E-1=1 E-3)$. The common cause effect of a mistransfer causing a GRE and an ignition source is discussed below related to the rate of deflagration.

When calculating the rate of deflagration related to the tank high level detector, three possible scenarios exist. First, a mistransfer can cause a GRE and raise the level of waste such that the high level detector sparks. Second, a mistransfer can cause a GRE that increases the moisture in the tank headspace such that the high level detector might spark. Third, a random GRE could cause an increase of the moisture in the tank headspace such that the high level detector might spark.

For the first scenario, a mistransfer causing a GRE and an ignition source, the rate of GREs due to mistransfers is calculated to be 5E-2 per DST-year (5 transfers/DST-year * 1 mistransfer/100 transfers * 1 GRE/l mistransfer). It is assumed that a GRE of concern will occur every mistransfer. Thus the rate of deflagration, assuming that one out of ten mistransfers will cause a tank level to rise to the tank high level limit and cause the high level detector to activate, is 5E-3/DST-year (5E-2 GREs/DST-year *0.1 = 5E-3 deflagrations/DST-year).

For the second scenario, the rate of GRES/DST-year is the same as for first scenario (5E-2 GREs/DST-year). The probability of increased moisture from a GRE causing a high level detector to spark is assumed to be $1 E-2$. The probability of a spark from the high level detector is assumed to be $1 E-1$. Thus the rate of deflagration is $5 E-5 / D S T-y e a r$ (5E-2 GREs/DST-year *0.01*0.1 = 5E-5 deflagrations/DST-year).

For the third scenario, the rate of GRES/DST-year is independent of mistransfers but the GRE causes increased moisture in the tank headspace so it is $4 \mathrm{E}-3$ GREs/DST-year. Assuming the probability that the humidity in a tank is $100 \%$ given a gas release event is $1 \mathrm{E}-2$ and the probability of a spark from the high level detector is $1 \mathrm{E}-1$, then the rate of deflagration is 4E-6/DST-year (4E-3 GREs/DST-year * $1 \mathrm{E}-2$ * $1 \mathrm{E}-1=4 \mathrm{E}-6$ deflagrations/DST-year).

The DST unmitigated rate of deflagration for the tank high level detector is rounded up to 6E-3/DST-year (5E-3/DST-year + 5E-5/DST-year + 


$$
\text { WHC-SD-WM-CN-04I, REV,O }
$$

4E-6/DST-year $=5 \cdot 1 \mathrm{E}-3 / \mathrm{DST}-$ year). The DST mitigated rate of deflagration is rounded up to $6 \mathrm{E}-5 /$ DST-year $(5.1 \mathrm{E}-3 /$ DST-year * $1 \mathrm{E}-2$ [human error] $=$ $5.1 E-5 / D S T-y e a r)$ because human error would enter in the equation related to applying the control to shut off power to all high level detectors in tanks containing flammable gas. An intrinsically safe design could further reduce the rate.

\subsection{VIDEO CAMERA AND LIGHTS}

Summary of Deflagration Rates for Video Cameras and Lights

\begin{tabular}{|c|l|}
\hline Deflagration Cases & Deflagration Rates (per year) \\
\hline DST unmitigated rate & 4E-3/DST-year (AN-107) \\
\hline DST mitigated rate & 4E-8/DST-year (new cameras) \\
\hline DST mit. \& re1. rate & N/A \\
\hline
\end{tabular}

Since the camera in AN-107 has no purge system (Scaief 1996, page 6), all video systems will be conservatively assumed to have no purge systems for the unmitigated case. The lights for AN-107 system are not explosion proof rated lights. The pan/tilt dc motors which have brushes are considered incendive devices. It is assumed that cameras are used continuously since many of the cameras are used for time lapse recording. Therefore the video camera systems when energized are assigned an unmitigated probability of ignition of 1.0 . The mitigated probability of ignition is assumed to be $1 E-5$ because of purge systems and explosion proof lights on the new camera design.

The DST unmitigated rate of deflagration for the video camera and lights is 4E-3/DST-year (4E-3 GREs/DST-year * $1.0=4 \mathrm{E}-3 / \mathrm{DST}$-year). The DST mitigated rate of deflagration is $4 \mathrm{E}-8 / \mathrm{DST}$-year (4E-3 GRES/DST-year * $1 \mathrm{E}-5=$ 4E-8/DST-year). 
WHC-SD-WM-CN-041, REV, O

\subsection{PUMP PIT LEAK DETECTOR}

Summary of Deflagration Rates for Pump Pit Leak Detector

\begin{tabular}{|c|l|}
\hline Deflagration Cases & Deflagration Rates (per year) \\
\hline SST unmitigated rate & $2 \mathrm{E}-7 /$ SST-year \\
\hline SST mitigated rate & $\begin{array}{l}9 \mathrm{E}-12 \text { /SST-year (replace with } \\
\text { wel1 designed instrument) }\end{array}$ \\
\hline SST mit. \& rel. rate & N/A \\
\hline DST unmitigated rate & $3 \mathrm{E}-4 / \mathrm{DST}$-year \\
\hline DST mitigated rate & $\begin{array}{l}6 \mathrm{E}-9 / \mathrm{DST} \text {-year (rep lace with } \\
\text { wel1 designed instrument) }\end{array}$ \\
\hline DST mit. \& re 1. rate & N/A \\
\hline
\end{tabular}

Note: These rates are for normal storage conditions.

The pump pit leak detector is essentially the same type of circuit as the tank high level detector (Scaief 1996, page 7). There are three proposed scenarios by which the pump pit leak detector could be activated.

Rainfall/snow melt could activate the detector or a leak from a transfer pump could activate the detector or moisture in the pit atmosphere might activate the detector.

The common cause effect of a transfer causing a GRE and an ignition source is discussed below related to the rate of deflagration. It is also recognized that ignition sources in the pump pit require flammable gases in the pump pit to result in ignition plus a high enough concentration of flammable gases is required for propagation of the ignited flammable gases back into the tank vapor space. It is assumed that the probability of propagation of deflagration from the pump pit to the tank has a probability of 0.1 .

When calculating the rate of deflagration related to the pump pit leak detector, four possible scenarios exist. Only one of these scenarios does not involve a common cause consideration. First the non common cause scenario is rainfall/snow melt could activate the detector at the same time as a random GRE. The other three scenarios consider common causes. Second, a transfer can cause a GRE and a leak in the pump pit could activate pump pit leak detector. Third, a transfer can cause a GRE and increase moisture in the pump pit thus possibly activating the leak detector. Fourth, a random GRE can increase moisture in the pump pit thus possibly activating the leak detector. Only the first and fourth scenarios can occur in SSTs because transfers are not made into SSTs. Al1 four scenarios can occur in a DST.

For the first scenario, a deflagration rate calculation involves multiplying the probability per year of rainwater/snow melt (5.5E-3/year) times the proportion of time the tank headspace would be hazardous times the probability of propagation into tank (0.1). First 
assume two days per year there is either sufficient rainfall or snow melt to leak into unsealed pump pits and cause a spark when conductive liquid connects the two probes of the pit leak detector. Conservatively assume that all pump pits leak. Thus the fraction of a year that any pump pit leak detector would produce an ignition source is (2 days/365 days $=5.5 \mathrm{E}-3$ per year). Thus the deflagration rate for SSTs for this scenario is rounded up to $6 \mathrm{E}-8 / \mathrm{SST}$-year $(5.5 \mathrm{E}-3$ ignitions/SST-year * 1E-4 [proportion of time above LFL, which is above concentration for Dome failure for SSTs] $* 0.1$ [propagation] $=5.5 \mathrm{E}-8 / \mathrm{SST}-\mathrm{year}$ ). The deflagration rate for DSTs for this scenario is rounded up to $6 \mathrm{E}-7 / \mathrm{DST}$-year (5.5E-3 ignitions/DST-year * 1E-4 [proportion of time above LFL and above concentration for Dome failure for DSTs] * 0.1 [propagation] $=5.5 \mathrm{E}-7 / \mathrm{SST}$-year) .

For the second scenario, the deflagration rate calculation involves multiplying the number of transfers per year (5 transfer/year) times an assumed 1 GRE/transfer times the probability of a leak per transfer ( $3 \mathrm{E}-5 /$ hour * 8 hours/transfer) times the probability of propagation into tank $(0.1)$. If the average transfer occurs for 8 hours and a transfer leak were to occur in the transfer pump pit from a gasket leak at the conservative rate of $3 E-5 /$ hour (Eide 1990 , page 13 ), then the probability of a leak in the pump pit during a transfer is $(3 E-5 /$ hour * 8 hours/transfer). Thus the deflagration rate for this scenario is rounded up to $2 E-4 /$ non-watch 1 ist DST-year (5 transfers/non-watch 1 ist DST-year * 1 GRE/transfer * [3E-5/hour * 8 hours/transfer] * 0.1 [propagation] $=1.2 \mathrm{E}-4 /$ non-watch 1ist DST-year) .

For the third scenario, the deflagration rate calculation involves multiplying the number of transfers per year (5 transfer/year) times the probability of GRE per transfer (assume that a GRE of concern will occur every transfer) times the probability of increased moisture from a GRE causing a pump pit leak detector to spark (1E-4, assuming the probability that the humidity in a pump pit is $100 \%$ given a gas release event is $1 \mathrm{E}-3$ and the probability of a spark from the pump pit leak detector is $1 E-1)$ times the probability of propagation into tank $(0.1)$. Thus the deflagration rate for this scenario is $5 \mathrm{E}-5 /$ non-watch 1 ist DST-year (5 transfers/non-watch 1ist DST-year * 1 GRE/transfer * [1E-4, probability of increased moisture from a GRE causing a pump pit leak detector to spark] * 0.1 [propagation] $=5 E-5 /$ non-watch 1ist DST-year).

For the fourth scenario, the deflagration rate calculation involves multiplying the number of GREs/tank-year (random GREs) times the probability of increased moisture from a GRE causing a pump pit leak detector to spark (1E-4 see discussion above) times the probability of propagation into tank $(0.1)$. Thus the deflagration rate for this scenario is 8E-8/SST-year (8E-3 GREs/SST-year * [1E-4, probability of increased moisture from a GRE causing a pump pit leak detector to spark] * 0.1 [propagation] $=8 \mathrm{E}-8 / \mathrm{SST}$-year). Thus the deflagration rate for this scenario is 4E-8/DST-year (4E-3 GREs/DST-year * [1E-4, probability of increased moisture from a GRE causing a pump pit leak detector to spark] * 0.1 [propagation] $=4 \mathrm{E}-8 /$ DST-year) .

The SST unmitigated rate of deflagration related to the pump pit leak detector producing a spark is rounded up to $2 \mathrm{E}-7 / \mathrm{SST}$-year (6E-8/SST-year + $8 \mathrm{E}-8 / \mathrm{SST}-$ year $=1.4 \mathrm{E}-7 / \mathrm{SST}-$ year $)$. For the controlled situation the pump pit 
WHC-SD-WM-CN-041, REN.O

leak detectors are re-designed to represent a well designed instrument with probability of ignition of $1 E-5$ per year. The SST mitigated rate of deflagration is rounded up to $9 \mathrm{E}-12 / \mathrm{SST}$-year $((6 \mathrm{E}-8 / \mathrm{SST}$-year * 1E-5) + \{8E-3 GRES/SST-year * 1E-3 [probability that the humidity in a pump pit is $100 \%$ given a gas release event] * $1 \mathrm{E}-5 * 0.1$ [propagation] $=$ 8.6E-12/SST-year).

The DST unmitigated rate of deflagration related to the pump pit leak detector producing a spark is rounded up to $3 \mathrm{E}-4$ /DST-year (6E-7/DST-year + $2 \mathrm{E}-4 /$ non-watch 1 ist DST-year $+5 \mathrm{E}-5 /$ non-watch 1 ist DST-year $+4 \mathrm{E}-8 / \mathrm{DST}-$ year $=$ 2.5E-4/DST-year). For the controlled situation the pump pit leak detectors are re-designed to represent a well designed instrument with probability of ignition of $1 \mathrm{E}-5$ per year. The DST mitigated rate of deflagration is rounded up to 6E-9/DST-year ( $\{(\{6 \mathrm{E}-7 / \mathrm{DST}$-year $+2 \mathrm{E}-4 / \mathrm{DST}-$ year $\}$ * $1 \mathrm{E}-5)+$ ( $\{$ (5 transfers/non-watch 1 ist DST-year * 1 GRE/transfer $)+4 E-3$ GREs/DST-year $\}$ * IE-3 [probability that the humidity in a pump pit is $100 \%$ given a gas release event] * $1 \mathrm{E}-5)\} * 0.1$ [propagation] $=5.2 \mathrm{E}-9 / \mathrm{DST}$-year) .

\subsection{PRIMARY TANK ACTIVE VENTILATION SYSTEM}

Summary of Deflagration Rates for Primary Ventilation System

\begin{tabular}{|c|l|}
\hline Deflagration Cases & Deflagration Rates (per year) \\
\hline SST unmitigated rate & $6 \mathrm{E}-7 /$ SST-year \\
\hline SST mitigated rate & $3 \mathrm{E}-11 /$ SST-year \\
\hline SST mit. \& rel. rate & N/A \\
\hline DST unmitigated rate & $6 \mathrm{E}-7 /$ DST-year \\
\hline DST mitigated rate & $3 \mathrm{E}-11 / \mathrm{DST}$-year \\
\hline DST mit. \& rel. rate & N/A \\
\hline
\end{tabular}

A11 rates assume a control is in place to preclude startup when flammable concentrations may be present. NOTE: Such a control is NOT currently in place.

Active ventilation systems typically have components such as fan motors and blowers, motor operated dampers, pressure and flow instrumentation, pressure switches, heaters, and temperature sensors. The only components located in the air stream are the blower, temperature sensors, and heaters (Scaief 1996, page 9).

Differential pressure gauges and switches are connected to the air stream via sensing Tines (Scaief 1996, page 9). The pressure switches control 120 VAC circuits and are considered to have a high capability for ignition. These switches have a probability of producing an ignition with the probability of 1.0. It is recognized that the ignition of flammable gases at the switches can not propagate back to the ventilation duct and back to the tank unless the concentration of flammable gases is high enough and may not be 
able to propagate through the sensing lines because of cooling effects of the walls of the small diameter tubing.

The motor on a motor operated damper uses a single phase 115 VAC motor (Scaief 1996, page 9). These motors have a probability of ignition 1.0 when operating. But these motors are outside the ventilation duct, and the question of the possibility of propagation of an ignited flammable gas mixture back into the ventilation duct and tank vapor space must be considered.

The blowers or fans are not made of non sparking materials except for the SY Farm primary ventilation fan. All other primary ventilation fans have some capability of being an ignition source from fan misalignment or over heating of bearings. Related to fan misalignment, the ignition source is assumed to be from fan blades contacting the fan housing due to an imbalanced system that does not cause the fan to shutdown catastrophically. This failure rate is assumed to be $3 E-5 /$ hour (Eide 1990 , page 19, ventilator fans failure to run; assuming that this failure rate could represent fan imbalance). It is assumed that the time between failure detection is 1 week (168 hours); the time the fan blades could continue striking the fan housing before it was shutdown for correction. Thus the average amount of time the fan misalignment could occur before being detected is half of a week ( 84 hours). Deflagration rates are calculated below for two possible scenarios to determine which scenario yields the dominant rate. The first scenario considers that the fan has failed such that fan blades are striking the fan housing producing sparks and then a GRE occurs. The second scenario considers that a GRE occurs and while there is a flammable gas mixture in the tank, the fan fails such that the fan blades are striking the fan housing producing sparks. For scenario 1 for an SST, the rate of deflagration is $8 \mathrm{E}-3 \mathrm{GREs} /$ year * 84 hours $/\{8760$ hours/year] * $3 \mathrm{E}-5$ /hour * 8760 hours/year [annual probability that there is an ignition source from fan misalignment] $=2.0 E-5$ per year. For scenario 2 for an SST, the rate of deflagration is $3 \mathrm{E}-5 /$ hour $* 8760$ hours/year * $1 \mathrm{E}-4$ [proportion of time above LFL, which is above concentration for Dome failure for SSTS $]=2.6 \mathrm{E}-5$ per year. It is recognized that the proportion of time value [1E-4] is based on passive ventilation and is more conservative than for active ventilation but $S-102$ does not have active ventilation and it is the representative SST. Therefore the second scenario's deflagration rate dominates.

The temperature sensors are ranked "low" as an ignition source (Scaief 1996, page 10) so it was assigned a probability of ignition of $1 E-5$ based on the discussion in section 6.1. It is assumed that a failed temperature sensor that could result in sparks would be detected in 24 hours. Deflagration rates are calculated below for two possible scenarios to determine which scenario yields the dominant rate. The first scenario considers that a temperature sensor has failed such that it is producing a continuous spark and then a GRE occurs. The second scenario considers that a GRE occurs and while there is a flammable gas mixture in the tank, a temperature sensor fails such that it sparks. For scenario 1 for an SST, the rate of deflagration is $8 E-3$ GREs/year * 24 hours/ 88760 hours/year] * 1E-5/year [annual probability that there is an ignition source from a failed temperature sensor] $=2.2 \mathrm{E}-10$ per year. For scenario 2 for an SST, the rate of deflagration is $1 \mathrm{E}-5 /$ year $* 1 \mathrm{E}-4$ [proportion of time above LFL, which is above concentration for Dome failure for SSTs] = 1E-9 per year. It is recognized that the proportion of time value [1E-4] is based on passive ventilation and is more conservative than for active ventilation but $\mathrm{S}-102$ does not have active ventilation and it is the 
representative SST. Therefore the second scenario's deflagration rate dominates.

Based on the uncertainty of design for the heater elements of the primary ventilation system, the heater elements are ranked "medium to high" as an ignition source (Scaief 1996, page 10). Since the fan and the heater elements are both ranked at least "medium" (Scajef 1996, page 10) and there is not enough information to calculate the probability of ignition for the heater elements, it is assumed that the heater elements have the same probability as the fan to produce an ignition. The heater element deflagration rate calculations will be the same as for the fan.

It is recognized that ignition sources in the active ventilation system require flammable gases in the ventilation system to result in ignition plus a high enough concentration of flammable gases is required for propagation of the ignited flammable gases back into the tank vapor space. It is assumed that the probability of propagation of deflagration from the active ventilation system to the tank has a probability of 0.01 because of the velocity of the exhaust stream. This is only applicable to times when the fan is actually operating. A start up and shutdown control should be in place to preclude providing an ignition source.

The SST unmitigated rate of deflagration related to the primary tank active ventilation system producing a spark excluding the ignition sources that are outside the ventilation duct is rounded up to $6 \mathrm{E}-7 / \mathrm{SST}$-year ( $\{3 \mathrm{E}-5 /$ hour $* 8760$ hours $/$ year $\}+1 \mathrm{E}-5 /$ year $+\{3 \mathrm{E}-5 /$ hour $* 8760$ hours $/$ year $\})$ * $1 E-4$ [proportion of time above LFL, which is above concentration for Dome failure for SSTs $]$ * 0.01 (propagation) $=5.3 \mathrm{E}-7 /$ SST-year). The SST mitigated rate of deflagration related to the primary tank active ventilation system producing a spark because the fans would be made of non-sparking materials and the heaters would be designed for flammable gas environments is $3 E-11 / S S T$-year $(1 E-5 /$ year $+1 E-5 /$ year $+1 E-5 /$ year $) * 1 E-4$ [proportion of time above $L F L$, which is above concentration for Dome failure for SSTs] $* 0.01$ (propagation) $=$ 3.0E-11/SST-year).

The DST unmitigated rate of deflagration related to the primary tank active ventilation system producing a spark is rounded up to $6 \mathrm{E}-7 / \mathrm{DST}-$ year ( $\{3 \mathrm{E}-5 /$ hour * 8760 hours $/$ year $\}+1 \mathrm{E}-5 /$ year $+\{3 \mathrm{E}-5 /$ hour $* 8760$ hours $/$ year $\})$ * IE-4 [proportion of time above LFL and concentration for Dome failure for DSTs $] * 0.01$ (propagation) $=5.3 \mathrm{E}-7 / \mathrm{DST}-\mathrm{year}$ ). The DST mitigated rate of deflagration related to the primary tank active ventilation system producing a spark is 3E-11/DST-year (1E-5/year + IE-5/year + 1E-5/year) * 1E-4 [proportion of time above LFL and concentration for Dome failure for DSTs] * 0.01

(propagation) $=3.0 \mathrm{E}-11 / \mathrm{DST}-$ year $)$. 
WHC-SD-WM-CN-041, REV, O

\subsection{FIBERGLASS LOWS AND PLASTIC RISER SLEEVES}

Summary of Deflagration Rates for Fiberglass LOWs and Plastic Riser Sleeves

\begin{tabular}{|c|l|}
\hline Deflagration Cases & Deflagration Rates (per year) \\
\hline SST unmitigated rate & $6 \mathrm{E}-3 /$ SST-year \\
\hline SST mitigated rate & $6 \mathrm{E}-5 /$ SST-year \\
\hline SST mit. \& rel. rate & $6 \mathrm{E}-7 / \mathrm{SST}$-year \\
\hline DST unmitigated rate & $6 \mathrm{E}-3 / \mathrm{DST}$-year \\
\hline DST mitigated rate & $6 \mathrm{E}-5 / \mathrm{DST}$-year \\
\hline DST mit. \& rel. rate & $6 \mathrm{E}-7 / \mathrm{DST}$-year \\
\hline
\end{tabular}

Because electrostatic charges are associated with fiberglass LOWs and plastic riser sleeves, the bounding probability of ignition in the unmitigated case is 1.0. If bonding and grounding are applied, the mitigated probability of ignition is $1 \mathrm{E}-2$. If human reliability related to bonding and grounding is brought to its best by superior procedures and independent verification, the mitigated probability of ignition with high human reliability is 1E-4. NOTE: These controls for non-conductive materials bonding and grounding do not appear to be in place as of this writing. Also, if future designs choose materials in compliance with National Fire Protection Association (NFPA) requirements, the rate could be further reduced.

Fiberglass LOWs and plastic riser sleeves that have not been in use for a period of time are not of a particular concern as far as static electricity. When monitoring is being performed in LOWs or operations are occurring in plastic riser sleeves, then there is potential for static spark concerns. Deflagration rates are calculated below for two possible scenarios to determine which scenario yields the dominant rate. The first scenario considers that monitoring work is performed in an LOW, static charge is built up, and then a GRE occurs. The second scenario considers that a GRE occurs just before LOW monitoring work begins. Information related to LOW monitoring is that monitoring is performed weekly and lasts about 0.5 hour per tank. Therefore the annual probability that static charge is available is 52 monitoring episodes/year * year $/ 8760$ hours * 0.5 hours/episode $=3 \mathrm{E}-3$ per year. The rate of static charge on yearly basis would be 52 per year.

For scenario 1 for an SST, the rate of deflagration is $8 E-3$ GREs/year * $3 E-3$ [annual probability that static charge is present] $=2.4 \mathrm{E}-5$ per year. For scenario 2 for an SST, the rate of deflagration is 52 static charges/year * 1E-4 [proportion of time above LFL, which is above concentration for Dome failure for SSTS] $=5.2 \mathrm{E}-3$ per year. Therefore the second scenario's deflagration rate dominates.

The SST unmitigated rate of deflagration is rounded up to $6 \mathrm{E}-3 / \mathrm{SST}$-year (52 static charge events/SST-year * 1E-4 [proportion of time above LFL, which is above concentration for Dome failure for SSTs $]=5.2 \mathrm{E}-3 /$ SST-year). The SST mitigated rate of deflagration is rounded up to $6 \mathrm{E}-5 / \mathrm{SST}$-year $(5.2 \mathrm{E}-3 / \mathrm{SST}$-year 
* 0.01 (human error in bonding/grounding) $=5.2 \mathrm{E}-5 / \mathrm{SST}-\mathrm{year}$ ). The SST mitigated and reliable human action rate of deflagration is rounded up to 6E-7/SST-year (5.2E-3/SST-year * 0.0001 (human error with independent verification of bonding/grounding) $=5.2 \mathrm{E}-7 / \mathrm{SST}-\mathrm{year})$.

The DST unmitigated rate of deflagration is rounded up to $6 \mathrm{E}-3 / \mathrm{DST}-\mathrm{year}$ (52 static charge events/DST-year * 1E-4 [proportion of time above LFL and above concentration for Dome failure for DSTs] $=5.2 E-3 /$ DST-year). The DST mitigated rate of deflagration is 6E-5/DST-year $(5.2 \mathrm{E}-3$ /DST-year $* 0.01$ (human error in bonding/grounding) $=5.2 \mathrm{E}-5 /$ DST-year). The DST mitigated and reliable human action rate of deflagration is rounded up to 6E-7/DST-year (5.2E-3/DST-year * 0.0001 (human error with independent verification of bonding/grounding) $=5.2 \mathrm{E}-7 /$ DST-year).

\subsection{TRANSFER PUMP}

Summary of Deflagration Rates for Transfer Pump

\begin{tabular}{|c|l|}
\hline Deflagration Cases & Deflagration Rates (per year) \\
\hline DST unmitigated rate & 2E-4/DST-year \\
\hline DST mitigated rate & 2E-6/DST-year \\
\hline DST mit. \& rel. rate & 2E-7/DST-year \\
\hline
\end{tabular}

The motors on transfer pumps are three phase induction type motors. When operating as designed they do not spark or generate high temperatures but certain failure modes could cause a spark capable of igniting a flammable mixture of gases. Assuming a transfer pump motor fails in such a way as to produce a spark at the rate of $3 \mathrm{E}-5$ /hour (Eide 1990, page 12, motor failing to run; assuming all the failures represented by this failure rate cause a spark). Based on the information related to transfers in the discussion for the tank high level detector above, 5 transfers per year for any given DST is assumed. The average transfer is assumed to occur for 8 hours.

The common cause effect of a transfer causing a GRE and an ignition source is discussed below related to the rate of deflagration. This is the dominant scenario because the transfer pump is the ignition source when energized and when it is running and energized there is the potential for a GRE. It is also recognized that ignition sources in the pump pit require flammable gases in the pump pit to result in ignition plus a high enough concentration of flammable gases is required for propagation of the ignited flammable gases back into the tank vapor space. It is assumed that the probability of propagation of deflagration from the pump pit to the tank has a probability of 0.1 .

The DST unmitigated rate of deflagration related to the transfer pump motor producing a spark is rounded up to 2E-4/DST-year (5 transfers/year * 1 GRE/transfer * $3 E-5 /$ hour $* 8$ hours $* 0.1$ (propagation) $=1.2 \mathrm{E}-4 /$ DST-year) . For the controlled situation if the flammability reading increases above 25 percent of lower flammability limit (LFL), the operating specification document for watch 1 ist tanks (OSD-T-151-00030, page 7) directs the operator to 
stop all work on the tank and place the tank in a safe configuration. It is assumed that the operator may fail to shut off power to the transfer pump with a probability of $1 E-2$. The DST mitigated rate of deflagration is

2E-6/DST-year (2E-4/DST-year * $1 \mathrm{E}-2=2 \mathrm{E}-6 / \mathrm{DST}-$ year). The DST mitigated and reliable human action rate of deflagration is $2 E-7 / D S T-y e a r$ (2E-4/DST-year * $1 E-3$ [human error with independent verification] = 2E-7/DST-year).

\subsection{VEHICLE FUEL FIRE}

\begin{tabular}{|c|l|}
\hline \multicolumn{2}{|c|}{ Summary of Deflagration Rates for Vehicle Fuel Fire } \\
\hline Deflagration Cases & Deflagration Rates (per year) \\
\hline SST unmitigated rate & $5 E-8 /$ SST-year \\
\hline SST mitigated rate & $5 E-10 /$ SST-year \\
\hline SST mit. \& rel. rate & N/A \\
\hline DST unmitigated rate & $5 E-8 / D S T-y e a r$ \\
\hline DST mitigated rate & $5 E-10 / D S T-y e a r$ \\
\hline DST mit. \& rel. rate & N/A \\
\hline
\end{tabular}

The scenario that represents this ignition source is where a vehicle driven in a tank farm collides with a riser - rupturing the fuel tank, igniting the spilled fuel by the collision or hot engine parts, and spilling of the burning fuel down the riser that was involved in the collision.

Based on two off normal (ON) reports in two subsequent years as described below, a frequency of 1 vehicle accident fuel tank rupture per year in all the tank farms is assumed.

o ON \#WHC-TANKFARM-1992-29 - - In this event a drywell monitoring van backed over a riser at 104-SX and punctured its gas tank. Two gallons of gas spilled onto the ground and five more gallons were caught in a bucket while spilling. It is important to note that the driver did a 360 degree walk-around prior to backing up and noticed the riser, but still hit the riser anyway. The riser was not opened in the accident.

- ON \#WHC-TANKFARM-1993-76 -- In this event, a drywe11 monitoring vehicle backed into a riser at 108-S. A pinhole leak in the vehicle's gas tank resulted, but the riser was not opened in the accident.

The following calculation of the vehicle fuel fire accident scenario uses the above assumption of 1 vehicle accident fuel tank rupture per year in al1 the tank farms and information in a letter report titled "Frequency Analysis of Vehicle Fuel Release Resulting in Waste Tank Fire" (Lindberg 1995). The frequency of 1 vehicle accident fuel tank rupture per year in all tank farms is put on a "per vehicle entry into the tank farm" basis by 
dividing by the estimated number of vehicle entries into a tank farm. In the letter report (Lindberg 1995, page 2) there are tank farms operations personnel estimates of the number of tank farm entries per year for single-shell tanks (SSTs) and double-shell tanks (DSTs): 1040 SST farm entries per year and 520 DST farm entries per year. Thus the probability of a vehicle collision with a riser in a tank farm per vehicle entry is $9.6 \mathrm{E}-4$ per SST farm vehicle entry (1 rupture/year * year/1040 SST farm vehicle entries = 9.62E-4/SST farm vehicle entry) and $1.9 \mathrm{E}-3$ per DST farm vehicle entry (1 rupture/year * year/520 DST farm vehicle entries $=1.92 \mathrm{E}-3 / \mathrm{DST}$ farm vehicle entry).

other factors that must be factored into the calculation to represent the described accident scenario are probability of riser breaking due to the vehicle collision, probability that the fuel is ignited by the collision or by heat from the engine, and probability that the burning fuel will enter the waste tank riser. The following probabilities are taken from the letter report (Lindberg 1995, page 3):

- probability of riser breaking due to the vehicle collision (5E-1)

0 probability that the fuel is ignited by the collision or by heat from the engine $(1 \mathrm{E}-2)$

- probability that the burning fuel will enter the waste tank riser $(1 \mathrm{E}-1)$

The SST unmitigated rate of deflagration related to a vehicle collision in a tank farm causing burning fuel to spill into a tank riser is calculated assuming 1000 SST farm vehicle entries per year. Thus the rate is rounded up to 5E-8/SST-year ( 1 fuel tank rupture/year * year/1040 SST farm vehicle entries * 1000 SST farm vehicle entries * 5E-1 * 1E-2 * $1 \mathrm{E}-1$ * $1 \mathrm{E}-4$ [proportion of time above LFL, which is above concentration for Dome failure for SSTS $]=4.8 \mathrm{E}-8 / \mathrm{SST}-$ year $)$.

The SST mitigated rate of deflagration related to a vehicle collision in a tank farm causing burning fuel to spill into a tank riser is calculated assuming 100 SST farm vehicle entries per year and controls on the design of the vehicle by mechanically protecting the fuel tank (bumpers, frame, etc.) which reduces the ruptures by an assumed factor of 10 . Thus the rate is rounded up to $5 \mathrm{E}-10 / \mathrm{SST}$-year (1E-1 fuel tank rupture/year [includes design changes that reduce rupture by factor of 10] * year/1040 SST farm vehicle entries * 100 SST farm vehicle entries * 5E-1 * $1 \mathrm{E}-2$ * $1 \mathrm{E}-1$ * $1 \mathrm{E}-4$ [proportion of time above LFL, which is above concentration for Dome failure for SSTs] = 4.8E-10/SST-year).

The DST unmitigated rate of deflagration related to a vehicle collision in a tank farm causing burning fuel to spill into a tank riser is calculated assuming 500 DST farm vehicle entries per year. Thus the rate is rounded up to 5E-8/DST-year (1 fuel tank rupture/year * year/520 DST farm vehicle entries * 500 DST farm vehicle entries * 5E-1 *1E-2 * 1E-1 * 1E-4 [proportion of time above LFL and above concentration for Dome failure for DSTs] = 4.8E-8/DST-year) .

The DST mitigated rate of deflagration related to a vehicle collision in a tank farm causing burning fuel to spill into a tank riser is calculated 
assuming 50 DST farm vehicle entries per year and controls on the design of the vehicle by mechanically protecting the fuel tank (bumpers, frame, etc.) which reduces the ruptures by an assumed factor of 10 . Thus the rate is rounded up to 5E-10/DST-year (1E-1 fue] tank rupture/year [includes design changes that reduce rupture by factor of 10] * year/520 DST farm vehicle entries * 50 DST farm vehicle entries * 5E-1 * 1E-2 *1E-1 * 1E-4 [proportion of time above LFL and above concentration for Dome failure for DSTs] = 4.8E-10/DST-year).

\subsection{HOT DRILLING CHIPS}

Summary of Deflagration Rates for Hot Drilling Chips

\begin{tabular}{|c|l|}
\hline Deflagration Cases & Deflagration Rates (per year) \\
\hline SST unmitigated rate & $2 E-3 / S S T$-year \\
\hline SST mitigated rate & $5 E-7 / S S T$-year \\
\hline SST mit. \& rel. rate & $5 E-8 / S S T$-year \\
\hline DST unmitigated rate & $2 E-3 / D S T-y e a r$ \\
\hline DST mitigated rate & $5 E-7 / D S T-y e a r$ \\
\hline DST mit. \& rel. rate & $5 E-8 / D S T-y e a r$ \\
\hline
\end{tabular}

For hot drilling chips to be an ignition source in a tank, the drilling must occur on or near an opening to the tank vapor space. The probability of any given drilling activity being performed on a riser (drilling into a riser cover while still bolted to the riser) is assumed to be lE-l. If drilling were near enough to a riser (but not directly on the riser cover) so that hot drilling chips could enter the riser if open, the probability that the riser is open is assumed to be 5E-1. Thus the probabilities of the two possible scenarios for hot drill chips entering a tank's vapor space are $1 E-1$ per drilling activity and $5 \mathrm{E}-2$ per drilling activity (1E-1 per drilling activity * $5 \mathrm{E}-1=5 \mathrm{E}-2)$. Thus the two scenarios together are $1.5 \mathrm{E}-1(1 \mathrm{E}-1+5 \mathrm{E}-2)$.

The SST unmitigated rate of deflagration related to drilling activities is calculated assuming 100 drilling activities per tank per year. Thus the rate is rounded up to $2 \mathrm{E}-3 / \mathrm{SST}$-year (100 drilling activities/SST-year * $1.5 \mathrm{E}-1$ hot drilling chips in tank per drilling activity * 1E-4 [proportion of time above LFL, which is above concentration for Dome failure for SSTs] = $1.5 \mathrm{E}-3 / \mathrm{SST}-$ year).

The SST mitigated rate of deflagration related to drilling activities is calculated assuming 3 drilling activities per tank per year and controls on how and when drilling is performed to prevent drilling chips from entering the tank. Thus the rate is rounded up to $5 E-7 / S S T-y e a r$ ( $3 \mathrm{drilling}$ activities/SST-year * $1.5 \mathrm{E}-1$ hot drilling chips in tank per drilling activity * 0.01 [human error related to preventing drilling chips from entering the tank] * $1 \mathrm{E}-4$ [proportion of time above LFL, which is above concentration for Dome failure for SSTs $]=4.5 \mathrm{E}-7 /$ SST-year) . 
The SST mitigated with reliable human action rate of deflagration related to drilling activities is the mitigated option above and a reduced human error rounded to 5E-8/SST-year (3 drilling activities/SST-year * $1.5 \mathrm{E}-1$ hot drilling chips in tank per drilling activity * 0.001 [human error with independent verification] * $1 E-4$ [proportion of time above $L F L$, which is above concentration for Dome failure for SSTs ] $=4.5 \mathrm{E}-8 /$ SST-year) .

The DST unmitigated rate of deflagration related to drilling activities is calculated assuming 100 drilling activities per tank per year. Thus the rate is rounded up to $2 E-3 / D S T-y e a r$ (100 drilling activities/DST-year * $1.5 E-1$ hot drilling chips in tank per drilling activity * 1E-4 [proportion of time above LFL and above concentration for Dome failure for DSTS] = 1.5E-3/DST-year).

The DST mitigated rate of deflagration related to drilling activities is calculated assuming 3 drilling activities per tank per year and controls on how and when drilling is performed to prevent drilling chips from entering the tank. Thus the rate is rounded up to 5E-7/DST-year ( 3 drilling activities/DST-year * $1.5 \mathrm{E}-1$ hot drilling chips in tank per drilling activity * 0.01 [human error related to preventing drilling chips from entering the tank] * 1E-4 [proportion of time above LFL and above concentration for Dome failure for DSTs] $=4.5 E-7 / D S T-y e a r)$.

The DST mitigated with reliable human action rate of deflagration related to drilling activities is the mitigated option above and a reduced human error rounded up to 5E-8/DST-year (3 drilling activities/DST-year * $1.5 \mathrm{E}-1$ hot drilling chips in tank per drilling activity $* 0.001$ [human error with independent verification] * $1 \mathrm{E}-4$ [proportion of time above LFL and above concentration for Dome failure for DSTS ] $=4.5 E-8 / D S T-y e a r)$.

\subsection{WELDING OR TORCH BURNING SLAG OR HOT METAL}

Summary of Deflagration Rates for Welding or Torch Burning Hot Slag or Metal

\begin{tabular}{|c|l|}
\hline Deflagration Cases & Deflagration Rates (per year) \\
\hline SST unmitigated rate & $3 E-3 / S S T$-year \\
\hline SST mitigated rate & $3 E-7 / S S T$-year \\
\hline SST mit. \& re]. rate & $3 E-8 / S S T$-year \\
\hline DST unmitigated rate & $3 E-3 / D S T-y e a r$ \\
\hline DST mitigated rate & $3 E-7 / D S T-y e a r$ \\
\hline DST mit. \& rel. rate & $3 E-8 / D S T-y e a r$ \\
\hline
\end{tabular}

For welding or torch activities producing burning slag or hot metal to be an ignition source in a tank, the welding or torch activities must occur on or near an opening to the tank vapor space. The probability of any given welding or torch activity being performed on a riser (welding or torch activity on a riser cover while still bolted to the riser) is estimated to be 
less than drilling so $5 \mathrm{E}-2$ per welding or torch activity. If welding or torch activities were near enough to a riser (but not directly on the riser cover) so that burning slag or hot metal could enter the riser if open, the probability that the riser is open is assumed to be $5 \mathrm{E}-1$. Thus the probabilities of the two possible scenarios for burning slag or hot metal entering a tank's vapor space are 5E-2 per welding or torch activity and 2.5E-2 per welding or torch activity (5E-2 per welding or torch activity * $5 E-1=2.5 \mathrm{E}-2$ per welding or torch activity). Thus the two scenarios together are $7.5 \mathrm{E}-2(5 \mathrm{E}-2+2.5 \mathrm{E}-2)$.

The SST unmitigated rate of deflagration related to welding or torch activities is calculated assuming 300 welding or torch activities per tank per year. Thus the rate is rounded up to $3 E-3 / S S T-y e a r$ ( 300 welding or torch activities/SST-year * 7.5E-2 burning slag or hot metal in tank per welding or torch activity * $1 E-4$ [proportion of time above LFL, which is above concentration for Dome failure for SSTS ] $=2.3 \mathrm{E}-3 / \mathrm{SST}-\mathrm{year}$ ) .

The SST mitigated rate of deflagration related to welding or torch activities is calculated assuming 3 welding or torch activities per tank per year and controls on how and when welding or torch burning is performed to prevent burning slag or hot metal from entering the tank. Thus the rate is rounded up to $3 \mathrm{E}-7 / \mathrm{SST}$-year ( 3 welding or torch activities/SST-year * 7.5E-2 burning slag or hot metal in tank per welding or torch activity $* 0.01$ [human error related to preventing burning slag or hot metal from entering the tank] * 1E-4 [proportion of time above LFL, which is above concentration for Dome failure for SSTS] $=2.3 E-7 / S S T$-year) .

The SST mitigated with reliable human action rate of deflagration related to welding or torch activities is the mitigated option above and a reduced human error and is rounded up to $3 \mathrm{E}-8 / \mathrm{SST}$-year ( 3 welding or torch activities/SST-year * $7.5 \mathrm{E}-2$ burning slag or hot metal in tank per welding or torch activity * 0.001 [human error with independent verification] * $1 E-4$ [proportion of time above LFL, which is above concentration for Dome failure for SSTs] $=2.3 \mathrm{E}-8 / \mathrm{SST}-$ year).

The DST unmitigated rate of deflagration related to welding or torch activities is calculated assuming 300 welding or torch activities per tank per year. Thus the rate is rounded up to 3E-3/DST-year $(300$ welding or torch activities/DST-year * $7.5 \mathrm{E}-2$ burning slag or hot metal in tank per welding or torch activity * $1 \mathrm{E}-4$ [proportion of time above LFL and above concentration for Dome failure for DSTs] $=2.3 \mathrm{E}-3 / \mathrm{DST}-$ year) .

The DST mitigated rate of deflagration related to welding or torch activities is calculated assuming 3 welding or torch activities per tank per year and controls on how and when welding or torch burning is performed to prevent burning slag or hot metal from entering the tank. Thus the rate is rounded up to 3E-7/DST-year (3 welding or torch activities/DST-year * $7.5 \mathrm{E}-2$ burning slag or hot metal in tank per welding or torch activity $* 0.01$ [human error related to preventing burning slag or hot metal from entering the tank] * 1E-4 [proportion of time above LFL and above concentration for Dome failure for DSTS ] $=2.3 E-7 /$ DST-year) .

The DST mitigated with reliable human action rate of deflagration related to welding or torch activities is the mitigated option above and a reduced human error and is 3E-8/SST-year ( 3 welding or torch activities 
/DST-year * 7.5E-2 burning slag or hot metal in tank per welding or torch activity * 0.001 [human error with independent verification] * $1 E-4$ [proportion of time above LFL and above concentration for Dome failure for DSTs] $=2.3 \mathrm{E}-8 /$ DST-year) .

\subsection{GRINDING}

Summary of Deflagration Rates for Grinding

\begin{tabular}{|c|l|}
\hline Deflagration Cases & Deflagration Rates (per year) \\
\hline SST unmitigated rate & $6 \mathrm{E}-4 / \mathrm{SST}$-year \\
\hline SST mitigated rate & $9 \mathrm{E}-8 / \mathrm{SST}$-year \\
\hline SST mit. \& rel. rate & $9 \mathrm{E}-9 / \mathrm{SST}$-year \\
\hline DST unmitigated rate & $6 \mathrm{E}-4 / \mathrm{DST}$-year \\
\hline DST mitigated rate & $9 \mathrm{E}-8 / \mathrm{DST}$-year \\
\hline DST mit. \& rel. rate & $9 \mathrm{E}-9 / \mathrm{DST}$-year \\
\hline
\end{tabular}

For grinding to be an ignition source in a tank, the grinding must occur on or near an opening to the tank vapor space. The probability of any given grinding activity being performed on a riser or near enough to a riser that grinding sparks could enter the riser if open is assumed to be $5 \mathrm{E}-2$. If grinding were near enough to a riser so that grinding sparks could enter the riser if open, the probability that the riser is open is assumed to be $5 E-1$. Thus the probability for grinding sparks entering a tank's vapor space is rounded up to $3 \mathrm{E}-2$ per grinding activity $(5 \mathrm{E}-2$ per grinding activity * $5 \mathrm{E}-1=$ 2.5E-2 per grinding activity).

The SST unmitigated rate of deflagration related to grinding activities is calculated assuming 200 grinding activities per tank per year. Thus the rate is $6 \mathrm{E}-4 / \mathrm{SST}-$ year (200 grinding activities/SST-year * $3 \mathrm{E}-2$ grinding sparks in tank per grinding activity * 1E-4 [proportion of time above LFL, which is above concentration for Dome failure for SSTS ] $=6.0 E-4 /$ SST-year) .

The SST mitigated rate of deflagration related to grinding activities is calculated assuming 3 grinding activities per tank per year and controls on how and when grinding is performed to prevent grinding sparks from entering the tank. Thus the rate is rounded up to 9E-8/SST-year (3 grinding activities/SST-year * $3 E-2$ grinding sparks in tank per grinding activity * 0.01 [human error related to preventing grinding sparks from entering the tank] * 1E-4 [proportion of time above LFL, which is above concentration for Dome failure for SSTs $]=9.0 E-8 / S S T-y e a r)$.

The SST mitigated with reliable human action rate of deflagration related to grinding activities is the mitigated option above and a reduced human error and is rounded up to 9E-9/SST-year (3 grinding activities/SST-year * $3 \mathrm{E}-2$ grinding sparks per grinding activity * 0.001 [human error with independent verification] * $1 E-4$ [proportion of time above $L F L$, which is above concentration for Dome failure for SSTs] $=9.0 \mathrm{E}-9 / \mathrm{SST}-$ year) . 
WHC-SD-WM-CN-041, REV, O

The DST unmitigated rate of deflagration related to grinding activities is calculated assuming 200 grinding activities per tank per year. Thus the rate is $6 E-4 / D S T-y e a r$ (200 grinding activities/DST-year * 3E-2 grinding sparks per grinding activity * $1 E-4$ [proportion of time above LFL and above concentration for Dome failure for DSTs] $=6.0 E-4 / D S T-y e a r$ ) .

The DST mitigated rate of deflagration related to grinding activities is calculated assuming 3 grinding activities per tank per year and controls on how and when grinding is performed to prevent grinding sparks from entering the tank. Thus the rate is 9E-8/DST-year ( 3 grinding activities/DST-year * $3 E-2$ grinding sparks in tank per grinding activity $* 0.01$ [human error related to preventing grinding sparks from entering the tank] * 1E-4 [proportion of time above LFL and above concentration for Dome failure for DSTs] = 9.0E-8/DST-year).

The DST mitigated with reliable human action rate of deflagration related to grinding activities is the mitigated option above and a reduced human error and is 9E-9/DST-year (3 grinding activities/DST-year * 3E-2 grinding sparks per grinding activity *0.001 [human error with independent verification] * 1E-4 [proportion of time above LFL and above concentration for Dome failure for DSTs ] $=9.0 E-9 / D S T-y e a r)$.

\subsection{ELECTRICAL EQUIPMENT USED OUTSIDE A TANK}

Summary of Deflagration Rates for Electrical Equipment Used Outside the Tank

\begin{tabular}{|c|l|}
\hline Deflagration Cases & Deflagration Rates (per year) \\
\hline SST unmitigated rate & $6 \mathrm{E}-4 / \mathrm{SST}$-year \\
\hline SST mitigated rate & $6 \mathrm{E}-6 / \mathrm{SST}$-year \\
\hline SST mit. \& rel. rate & $6 \mathrm{E}-7 / \mathrm{SST}$-year \\
\hline DST unmitigated rate & $6 \mathrm{E}-4 / \mathrm{DST}$-year \\
\hline DST mitigated rate & $6 \mathrm{E}-6 / \mathrm{DST}$-year \\
\hline DST mit. \& rel. rate & $6 \mathrm{E}-7 / \mathrm{DST}$-year \\
\hline
\end{tabular}

It is assumed that electrical equipment will be used outside of any given tank once every week during a year. For electrical equipment that is used outside a tank to be an ignition source in a tank, it is recognized that flammable gases must exist outside the tank that can be ignited plus a high enough concentration of flammable gases is required for propagation of the ignited flammable gases back into the tank vapor space. It is assumed that the probability of propagation of deflagration from outside the tank to the tank has a probability of 0.1 . The unmitigated probability of electrical equipment used outside a tank being an ignition source is 1.0 . The mitigated probability could be $1 E-2$ if the control was to not use electrical equipment near a tank but human error resulted in a failure to follow the control. The mitigated with reliable human action probability is assumed to be $1 \mathrm{E}-3$ considering human error with independent verification. 
The SST unmitigated rate of deflagration for electrical equipment that is used outside a tank is rounded up to 6E-4/SST-year (52 uses of electrical equipment/SST-year * 1E-4 [proportion of time above LFL, which is above concentration for Dome failure for SSTs] * 0.1 [probability of propagation] = $5.2 \mathrm{E}-4$ /SST-year). The SST mitigated rate of deflagration is rounded up to 6E-6/SST-year (52 uses of electrical equipment/SST-year * 1E-4 [proportion of time above LFL, which is above concentration for Dome failure for SSTs] * 0.1 [probability of propagation] * $1 \mathrm{E}-2$ [human error] $=5.2 \mathrm{E}-6 / \mathrm{SST}$-year). The SST mitigated with reliable human action rate of deflagration is rounded up to $6 \mathrm{E}-7 / \mathrm{SST}$-year (52 uses of electrical equipment/SST-year * 1E-4 [proportion of time above LFL, which is above concentration for Dome failure for SSTs] $* 0.1$ [probability of propagation] * 1E-3 [human error with independent verification] $=5.2 \mathrm{E}-7 / \mathrm{SST}-$ year) .

The DST unmitigated rate of deflagration for electrical equipment that is used outside a tank is rounded up to 6E-4/DST-year (52 uses of electrical equipment/DST-year * 1E-4 [proportion of time above LFL and above concentration for Dome failure for DSTs] * 0.1 [probability of propagation] = 5.2E-4/DST-year). The DST mitigated rate of deflagration is rounded up to $6 \mathrm{E}-6 / \mathrm{DST}$-year (52 uses of electrical equipment/DST-year * 1E-4 [proportion of time above LFL and above concentration for Dome failure for DSTs] * 0.1 [probability of propagation] * $1 \mathrm{E}-2$ [human error] $=5.2 \mathrm{E}-6 / \mathrm{DST}-$ year). The DST mitigated with reliable human action rate of deflagration is rounded up to 6E-7/DST-year (52 uses of electrical equipment/DST-year * 1E-4 [proportion of time above LFL and above concentration for Dome failure for DSTs] * 0.1 [probability of propagation] * $1 \mathrm{E}-3$ [human error with independent verification $]=5.2 \mathrm{E}-7 /$ DST-year . .

\subsection{GREENHOUSE FIRE ASSOCIATED WITH A PIT OR RISER}

Summary of Deflagration Rates for Greenhouse Fire Associated With a Pit or Riser

\begin{tabular}{|c|l|}
\hline Deflagration Cases & Deflagration Rates (per year) \\
\hline SST unmitigated rate & $3 \mathrm{E}-5 /$ SST-year \\
\hline SST mitigated rate & $3 \mathrm{E}-7 /$ SST-year \\
\hline SST mit. \& re1. rate & $3 \mathrm{E}-8 /$ SST-year \\
\hline DST unmitigated rate & $3 \mathrm{E}-5 /$ DST-year \\
\hline DST mitigated rate & $3 \mathrm{E}-7 /$ DST-year \\
\hline DST mit. \& re1. rate & $3 \mathrm{E}-8 /$ DST-year \\
\hline
\end{tabular}

It is assumed that 3 greenhouses will be used over a pit or riser for any given tank during a year. There could be many sources of ignition used in a greenhouse associated with a pit or riser but a dominant source would be electrical equipment with a probability of producing an ignition source of 1.0. It is recognized that flammable gases would need to collect in a greenhouse associated with a pit or riser that can be ignited plus a high

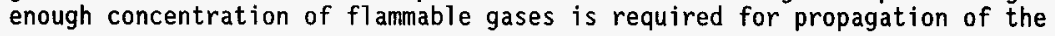


ignited flammable gases back into the tank vapor space. It is assumed that the probability of propagation of deflagration from outside the tank to the tank has a probability of 0.1 . The unmitigated probability of electrical equipment used in a greenhouse is 1.0 . The mitigated probability could be $1 \mathrm{E}-2$ if the control was to not use electrical equipment in a greenhouse associated with pit or riser but human error resulted in a failure to follow the control. The mitigated with reliable human action probability is assumed to be $1 \mathrm{E}-3$ considering human error with independent verification. These probabilities would bound the concerns related to the use of non-conductive plastics and electrostatic sparks associated with greenhouses.

The SST unmitigated rate of deflagration for electrical equipment that is used inside a greenhouse associated with a pit or riser is 3E-5/SST-year (3 greenhouses/SST-year * 1.0 [probability of ignition source in greenhouse] * 1E-4 [proportion of time above LFL, which is above concentration for Dome failure for SSTS] * 0.1 [probability of propagation] $=3.0 \mathrm{E}-5 / \mathrm{SST}$-year). The SST mitigated rate of deflagration is 3E-7/SST-year (3 greenhouses/SST-year * 1.0 [probabi] ity of ignition source in greenhouse] * $1 E-4$ [proportion of time above LFL, which is above concentration for Dome failure for SSTs] * 0.1 [probability of propagation] * $1 \mathrm{E}-2$ [human error] $=3.0 \mathrm{E}-7 / \mathrm{SST}-\mathrm{year}$ ). The SST mitigated with reliable human action rate of deflagration is $3 E-8 / S S T-y e a r$ (3 greenhouses/SST-year * 1.0 [probability of ignition source in greenhouse] * IE-4 [proportion of time above LFL, which is above concentration for Dome failure for SSTs] * 0.1 [probability of propagation] * $1 E-3$ [human error with independent verification] $=3.0 \mathrm{E}-8 / \mathrm{SST}-\mathrm{year}$ ).

The DST unmitigated rate of deflagration for electrical equipment that is used inside a greenhouse associated with a pit or riser is 3E-5/DST-year (3 greenhouses/DST-year * 1.0 * 1E-4 [proportion of time above LFL and above concentration for Dome failure for DSTS] * 0.1 [probability of propagation] = 3.0E-5/DST-year). The DST mitigated rate of deflagration is 3E-7/DST-year (3 greenhouses/DST-year * $1.0 * 1 E-4$ [proportion of time above LFL and above concentration for Dome failure for DSTs] * 0.1 [probability of propagation] * $1 \mathrm{E}-2$ [human error] $=3.0 \mathrm{E}-7 / \mathrm{DST}-\mathrm{year}$ ). The DST mitigated with reliable human action rate of deflagration is 3E-8/DST-year (3 greenhouses/DST-year * 1.0 * 1E-4 [proportion of time above LFL and above concentration for Dome failure for DSTs] * 0.1 [probability of propagation] * $1 E-3$ [human error with independent verification $]=3.0 \mathrm{E}-8$ /DST-year) . 
WHC-SD-WM-CN-041, REN, $D$

\subsection{BRUSH FIRE}

Summary of Deflagration Rates for Brush Fire

\begin{tabular}{|c|c|}
\hline Deflagration Cases & Deflagration Rates (per year) \\
\hline SST unmitigated rate & 1E-6/SST-year \\
\hline SST mitigated rate & $\begin{aligned} \text { 4E-9/SST-year } & \text { (control to remove brush from } \\
& \text { tank farm and check under } \\
& \text { vehicles for brush prior to } \\
& \text { entry into tank farm) }\end{aligned}$ \\
\hline SST mit. \& rel. rate & $4 E-9 / S S T-y e a r$ \\
\hline DST unmitigated rate & 1E-6/DST-year \\
\hline DST mitigated rate & $\begin{aligned} \text { 4E-9/DST-year } & \text { (control to remove brush from } \\
& \text { tank farm and check under } \\
& \text { vehicles for brush prior to } \\
& \text { entry into tank farm) }\end{aligned}$ \\
\hline DST mit. \& rel. rate & 4E-9/DST-year \\
\hline
\end{tabular}

There are two suggested scenarios for a brush fire caused ignition source that could propagate an ignition source into a tank. First a range fire could start outside a tank farm and burning material could enter the tank farm and an opening to the tank. Second a vehicle could collect brush under the vehicle, be driven into a tank farm, brush is ignited by hot exhaust system or engine, and burning material could enter an opening to the tank.

For a range fire that starts outside a tank farm, based on information from the Hanford Fire Department, there are range fires of up to about 5,000 acres once every 5 years. The frequency of a range fire occurring somewhere on the Hanford Site is $2 \mathrm{E}-1 /$ year (1 5,000 acre fire/5 years $=2 \mathrm{E}-1 /$ year). The Hanford Site is roughly 560 square miles in area $(358,400$ acres). So the frequency that the fire occurs in a 5000 acre section that includes a tank farm is rounded up to $3 \mathrm{E}-3 /$ year $(2 \mathrm{E}-1 /$ year * [5000acres $/ 358,400$ acres] $=$ $2.8 \mathrm{E}-3 /$ year). The probability that burning material would enter the tank when present in the tank farm is assumed to be 1E-1. In a controlled situation it is assumed that brush is cleared from the inside of a tank farm thus a probability of fire getting inside the tank farm is assumed to be $1 E-1$.

For a vehicle started brush fire, one off-normal occurred in 1992 (WHC-TANKFARM-1992-01) in which a truck at 241-TX tank farm picked up tumbleweeds on its carriage and then the tumbleweeds ignited. This off-normal represented one event in 9 years of off-normal history. The frequency of 1 vehicle brush fire per 9 years in all tank farms is put on a "per vehicle entry into the tank farm" basis by dividing by the estimated number of vehicle entries into a tank farm. In the letter report (Lindberg 1995, page 2) there are tank farm operation's personnel estimates of the number of tank farm entries per year for single-shell tanks (SSTs) and double-shell tanks (DSTs): 1040 SST farm entries per year and 520 DST farm entries per year. Thus the frequency of a vehicle brush fire in a tank farm per vehicle entry is about 1E-4 per SST farm vehicle entry (1 vehicle brush fire/9 years * year/1040 SST 
farm vehicle entries $=1.07 E-4 /$ SST farm vehicle entry) and 2E-4 per DST farm vehicle entry (1 vehicle brush fire/9 years * year/520 SST farm vehicle entries $=2.14 E-4 / D S T$ farm vehicle entry).

The SST unmitigated rate of deflagration related to brush fires is calculated assuming 1000 vehicle entries per tank per year. Thus the rate is 1E-6/SST-year ( $\{[3 E-3 / S S T-y e a r ~ * 0.1]+[1 E-4 / S S T$ farm vehicle entry * 1000 vehicle entries/tank-year * 0.1$]$ ] * IE-4 [proportion of time above LFL, which is above concentration for Dome failure for SSTs] $=1.0 \mathrm{E}-6 /$ SST-year) .

The SST mitigated rate of deflagration related to brush fires is calculated assuming controls on the number of vehicle entries and controls related to checking for brush under trucks and keeping brush out of tank farms. Thus the rate of deflagration is 4E-9/SST-year $\{[3 E-3 / S S T-y e a r * 0.1$ * 0.1 [clearing brush from tank farm] $+[1 E-4 / S S T$ farm vehicle entry * 100 vehicle entries/tank-year * $0.1 * 0.01$ [checking under trucks for brush]] * 1E-4 [proportion of time above LFL, which is above concentration for Dome failure for SSTs $]=4.0 \mathrm{E}-9 /$ SST-year) .

The SST mitigated with reliable human action rate of deflagration related to brush fires is the mitigated option above and a reduced human error and is rounded up to $4 \mathrm{E}-9 / \mathrm{SST}$-year $\{[3 \mathrm{E}-3 / \mathrm{SST}$-year $* 0.1 * 0.1$ [clearing brush from tank farm] $]+[1 E-4 / S S T$ farm vehicle entry * 100 vehicle entries/tank-year *0.1*0.001 [checking under trucks for brush with independent verification]] $* 1 E-4$ [proportion of time above LFL, which is above concentration for Dome failure for SSTs] $=3.1 E-9 /$ SST-year).

The DST unmitigated rate of deflagration related to brush fires is calculated assuming 500 vehicle entries per tank per year. Thus the rate is $1 E-6 / D S T-y e a r(\{[3 E-3 / D S T-y e a r * 0.1]+[2 E-4 / D S T$ farm vehicle entry * 500 vehicle entries/tank-year * 0.1]] * 1E-4 [proportion of time above LFL and above concentration for Dome failure for DSTs] $=1.0 \mathrm{E}-6 /$ DST-year) .

The DST mitigated rate of deflagration related to brush fires is calculated assuming controls on the number of vehicle entries and controls related to checking for brush under trucks and keeping brush out of tank farms. Thus the rate of deflagration is $4 E-9 / D S T-y e a r ~\{[3 E-3 / D S T-y e a r * 0.1$ * 0.1 [clearing brush from tank farm] + [2E-4/DST farm vehicle entry * 50 vehicle entries/tank-year * $0.1 * 0.01$ [checking under trucks for brush]] $*$ 1E-4 [proportion of time above LFL and above concentration for Dome failure for DSTs] $=4.0 \mathrm{E}-9 / \mathrm{DST}-\mathrm{year}$ ).

The DST mitigated with reliable human action rate of deflagration related to brush fires is the mitigated option above and a reduced human error and is rounded up to 4E-9/DST-year [[3E-3/DST-year * $0.1 * 0.1$ [clearing brush from tank farm] $+[2 E-4 / D S T$ farm vehicle entry * 50 vehicle entries/tank-year * $0.1 * 0.001$ [checking under trucks for brush with independent verification]] $* 1 E-4$ [proportion of time above LFL and above concentration for Dome failure for DSTs] = 3.1E-9/DST-year).

\subsection{ADJACENT TANK FIRE}

Basically this rate is the summation of the rates for all the ignition sources represented in Sections 6.2 to 6.15 but reduced by a factor of ten to 
WHC-SD-WM-CN-04I, REL, O

account for an assumed probability of propagation from one tank to another through connecting piping of 0.1 .

\subsection{LIGHTNING STRIKE}

Summary of Deflagration Rates for Lightning Strike

\begin{tabular}{|c|c|}
\hline Deflagration Cases & Deflagration Rates (per year) \\
\hline SST unmitigated rate & $3 \mathrm{E}-5 / \mathrm{SST}$-year \\
\hline SST mitigated rate & $\begin{aligned} & \text { 3E-6/SST-year } \text { (assumes a system could be } \\
& \text { provided that mitigates } 9 \text { of } 10 \\
& \text { strikes. Such a system may not } \\
& \text { be cost effective.) }\end{aligned}$ \\
\hline SST mit. \& rel. rate & $\mathbf{N} / \mathbf{A}$ \\
\hline DST unmitigated rate & 3E-4/DST-year \\
\hline DST mitigated rate & $\begin{array}{l}\text { 3E-5/DST-year (assumes a system could be } \\
\text { provided that mitigates } 9 \text { of } 10 \\
\text { strikes. Such a system may not } \\
\text { be cost effective.) }\end{array}$ \\
\hline DST mit. \& rel, rate & $N / A$ \\
\hline
\end{tabular}

Based on a lightning ground strike plot including the Hanford Site for a five year period from January 1, 1991 to January 1, 1996 documented by Global Atmospherics, Inc., a lightning strike frequency of 0.06 strikes per square kilometer per year is used as the base lightning strike frequency for this calculation (Zach 1996). A nominal sized tank farm is 0.05 square kilometers. Thus the lightning strike frequency on a nominal tank farm is $3 E-3 /$ year $(0.06$ strikes/square kilometer-year $* 0.05$ square kilometers $=3.0 \mathrm{E}-3 /$ year $)$.

It is also recognized that the low pressure systems that are associated with a lightning storm, could result in the release of gases from a tank at the same time as the ignition source is produced (common cause). Assume one out of a hundred lightning strikes on a SST tank farm results in a gas release at the same time. Since DST wastes are more fluid, assume one out of ten lightning strikes on a DST tank farm results in a gas release at the same time. Thus the rate of deflagration is composed of the part that is common cause related and the part that is random GRE related.

The SST unmitigated rate of deflagration related to lightning is taken as $3 \mathrm{E}-5 / \mathrm{SST}$-year $([3 \mathrm{E}-3 /$ year $* 0.01]+[3 \mathrm{E}-3 /$ year $* .99 * 1 \mathrm{E}-4$ [proportion of time above LFL, which is above concentration for Dome failure for SSTs] = $3.03 \mathrm{E}-5 / \mathrm{SST}-y e a r)$. The SST mitigated rate is taken as $3 \mathrm{E}-6 / \mathrm{SST}-$ year ([3E-3/year * $0.01 * 0.1$ [1ightning protection reduction]] $+[3 E-3 /$ year * .99 * 0.1 [1ightning protection reduction] * $1 \mathrm{E}-4$ [proportion of time above $L F L$, which is above concentration for Dome failure for SSTs]] $=3.03 E-6 / S S T-y e a r)$. 
WHC-SD-WM-CN-041, REN. $O$

The DST unmitigated rate of deflagration related to 1 ightning is taken as $3 \mathrm{E}-4 / \mathrm{DST}$-year $([3 \mathrm{E}-3 /$ year $* 0.1]+[3 \mathrm{E}-3 /$ year $* .9 * 1 \mathrm{E}-4$ [proportion of time above LFL and above concentration for Dome failure for DSTs] = 3.00E-4/DST-year). The DST mitigated rate is taken as 3E-5/SST-year ([3E-3/year * $0.1 * 0.1$ [lightning protection reduction]] $+\{3 \mathrm{E}-3 /$ year * .9* 0.1 [1ightning protection reduction] * $1 E-4$ [proportion of time above LFL and above concentration for Dome failure for DSTs] $=3.00 E-5 / D S T-y e a r)$.

\subsection{SEISHIC EVENT}

Summary of Deflagration Rates for Seismic Event

\begin{tabular}{|c|l|}
\hline Deflagration Cases & Deflagration Rates (per year) \\
\hline Unmitigated rate & $9 \mathrm{E}-4 /$ year \\
\hline Mitigated rate & $9 \mathrm{E}-4 /$ year \\
\hline Mit. \& rel. rate & N/A \\
\hline
\end{tabular}

It is assumed that a $0.2 \mathrm{~g}$ earthquake will cause an ignition source within the tank dome space with a probability of 1.0 due to metal striking metal or electrical faults producing continual sparks. Based on the return rate for a $0.2 \mathrm{~g}$ earthquake from a recent Hanford Site seismic hazard analysis report (WHC 1996a) of 1200 years, the rate of a $0.2 \mathrm{~g}$ earthquake at Hanford is rounded up to $9 E-4 /$ year ( 1 seismic event $/ 1200$ years $=8.3 E-4 /$ year).

It is also recognized that the seismic event, including after shocks, could result in the release of gases from a tank at the same time as the ignition source is produced or exists. Assume the rate of seismic events of $0.2 \mathrm{~g}$ is the rate of deflagration for both unmitigated and mitigated cases.

\subsection{STILL CAMERA AND LIGHTS}

Summary of Deflagration Rates for Still Camera and Lights

\begin{tabular}{|c|l|}
\hline Deflagration Cases & Deflagration Rates (per year) \\
\hline SST unmitigated rate & 1E-3/SST-year \\
\hline SST mitigated rate & $1 \mathrm{E}-9 / \mathrm{SST}$-year (camera design meets NFPA \\
requirements)
\end{tabular}


The unmitigated probability of ignition for a still camera and lights is assumed to be 1.0 because these cameras and lights were not designed to operate in a flammable gas environment and produce an electrical flash as part of operation. The mitigated probability of ignition is assumed to $1 E-5$ because of design of the camera and lights to industrial standards for flammable gas environments.

The SST unmitigated rate of deflagration related to the intrusive activity of using a still camera and lights is calculated assuming 10 camera activities per tank per year. Thus the rate is $1 \mathrm{E}-3 / \mathrm{SST}$-year (10 camera activities/SST-year * 1.0/activity [probability of ignition] * $1 E-4$ [proportion of time above LFL, which is above concentration for Dome failure for SSTs] $=1.0 \mathrm{E}-3 / \mathrm{SST}$-year .

The SST mitigated rate of deflagration related to the intrusive activity of using a still camera and lights is calculated assuming controls on the number of camera activities and controls on the design of the camera and lights to industrial standards for flammable gas environments. Thus the rate of deflagration is 1E-9/SST-year (1 camera activity/SST-year * 1E-5/activity [probability of ignition] * 1E-4 [proportion of time above LFL, which is above concentration for Dome failure for SSTS $]=1.0 E-9 /$ SST-year) .

The DST unmitigated rate of deflagration related to the intrusive activity of using a still camera and lights is calculated assuming 10 camera activities per tank per year. Thus the rate is $1 \mathrm{E}-3 / \mathrm{DST}$-year (10 camera activities/DST-year * $1.0 /$ activity [probability of ignition] * IE-4 [proportion of time above LFL and above concentration for Dome failure for DSTs ] $=1.0 \mathrm{E}-3 /$ DST-year) .

The DST mitigated rate of deflagration related to the intrusive activity of using a still camera and lights is calculated assuming controls on the number of camera activities and controls on the design of the camera and lights to industrial standards for flammable gas environments. Thus the rate of deflagration is 1E-9/DST-year (1 camera activities/DST-year * 1E-5/activity [probability of ignition] * 1E-4 [proportion of time above LFL and above concentration for Dome failure for DSTs] $=1.0 \mathrm{E}-9 / \mathrm{DST}-$ year) .

\subsection{REMOVING RISER COVER THAT DOES NOT HAVE SAMPLE PORT}

Summary of Deflagration Rates for Removing Riser Cover That Does NOT Have Sample Port

\begin{tabular}{|c|l|}
\hline Deflagration Cases & Deflagration Rates (per year) \\
\hline SST unmitigated rate & $1 E-2 / S S T-y e a r$ \\
\hline SST mitigated rate & $3 E-6 / S S T-y e a r$ \\
\hline SST mit. \& rel. rate & $3 E-8 / S S T-y e a r$ \\
\hline DST unmitigated rate & $1 E-2 / D S T-y e a r$ \\
\hline DST mitigated rate & $3 E-6 / D S T-y e a r$ \\
\hline DST mit. \& re1. rate & $3 E-8 / D S T-y e a r$ \\
\hline
\end{tabular}


The unmitigated probability of ignition from electrostatic sparks is assumed to be 1.0 because there would be no provisions for bonding and grounding in an unmitigated situation and electrostatic sparks would be expected as part of operation. The mitigated probability of ignition is assumed to be $1 E-2$ because of human error in failing to apply the bonding and grounding provisions when a procedure says to use them. If human reliability related to bonding and grounding is brought to its best by superior procedures and independent verification the mitigated probability of ignition with high human reliability is $1 \mathrm{E}-4$.

The SST unmitigated rate of deflagration related to electrostatic sparks is calculated assuming 100 riser cover removals per tank per year. Thus the rate is $1 E-2 / S S T-y e a r$ (100 riser cover removals/SST-year * $1.0 /$ activity [probability of ignition] * IE-4 [proportion of time above LFL, which is above concentration for Dome failure for SSTs] $=1.0 \mathrm{E}-2 / \mathrm{SST}-\mathrm{year}$ ).

The SST mitigated rate of deflagration related to electrostatic sparks is calculated assuming controls on the number of riser cover removal activities and controls related to bonding and grounding of risers related to tanks on flammable gas watch list. Thus the rate of deflagration is $3 \mathrm{E}-6 / \mathrm{SST}$-year $(3$ riser cover removals/SST-year $* 0.01$ [human error in failing to apply bonding and grounding provisions] * 1E-4 [proportion of time above LFL, which is above concentration for Dome failure for SSTs] = 3.0E-6/SST-year).

The SST mitigated with reliable human action rate of deflagration related to electrostatic sparks is the mitigated option above and a reduced human error and is 3E-8/SST-year (3 riser cover removals/SST-year * 0.0001 [human error in failing to apply bonding and grounding provisions with independent verification] * $1 \mathrm{E}-4$ [proportion of time above LFL, which is above concentration for Dome failure for SSTS $]=3.0 \mathrm{E}-8 /$ SST-year).

The DST unmitigated rate of deflagration related to electrostatic sparks is calculated assuming 100 riser cover removals per tank per year. Thus the rate is $1 \mathrm{E}-2 / 0 S T-y e a r$ (100 riser cover removals/DST-year * $1.0 /$ activity [probability of ignition] * 1E-4 [proportion of time above LFL and above concentration for Dome failure for DSTs] $=1.0 \mathrm{E} \sim 2$ /DST-year).

The DST mitigated rate of deflagration related to electrostatic sparks is calculated assuming controls on the number of riser cover removal activities and controls related to bonding and grounding of risers related to tanks on flammable gas watch list. Thus the rate of deflagration is $3 E-6 / D S T-y e a r$ ( 3 riser cover removals/DST-year * 0.01 [human error in failing to apply bonding and grounding provisions] * $1 E-4$ [proportion of time above LFL and above concentration for Dome failure for DSTs] $=3.0 E-6 / D S T-y e a r)$.

The DST mitigated with reliable human action rate of deflagration related to electrostatic sparks is the mitigated option above and a reduced human error and is 3E-8/DST-year (3 riser cover removals/DST-year * 0.0001 [human error in fai]ing to apply bonding and grounding provisions with independent verification] * $1 E-4$ [proportion of time above LFL and above concentration for Dome failure for DSTs] $=3.0 \mathrm{E}-8 / \mathrm{DST}-$ year). 
WHC-SD-WM-CN-041, REV.O

\subsection{REMOVING RISER COVER THAT HAS A SAMPLE PORT}

Summary of Deflagration Rates for Removing Riser Cover That Has a Sample Port

\begin{tabular}{|c|c|}
\hline Deflagration Cases & Deflagration Rates (per year) \\
\hline SST unmitigated rate & 1E-2/SST-year \\
\hline SST mitigated rate & $\begin{array}{r}\text { 3E-8/SST-year (sample port in riser } \\
\text { appreciably reduces rate) }\end{array}$ \\
\hline SST mit. \& rel. rate & 3E-9/SST-year \\
\hline DST unmitigated rate & 1E-2/DST-year \\
\hline DST mitigated rate & $\begin{array}{r}\text { 3E-8/DST-year (sample port in riser } \\
\text { appreciably reduces rate) }\end{array}$ \\
\hline DST mit. \& rel. rate & 3E-9/DST-year \\
\hline
\end{tabular}

The difference between the calculated deflagration rates between riser covers without and with sample ports is because a riser cover with a sample port can be sampled before any electrostatic spark would be introduced into the riser given the bonding/grounding were not present or was not adequate. Thus if the sample shows the a flammable gas concentration level above acceptable limits, the riser would not be opened until the level is reduced below the acceptable limits.

The unmitigated probability of ignition from electrostatic sparks is assumed to be 1.0 because there would be no provisions for bonding and grounding in an unmitigated situation and electrostatic sparks would be expected as part of operation. The mitigated probability of ignition is assumed to be the combined human error of $1 \mathrm{E}-4$ because of human error in sampling for flammable gas through the riser sample port prior to riser cover removal and human error in failing to apply the bonding and grounding provisions when a procedure says to use them. These two human errors are assumed independent because different personnel perform the two different operations of sampling and bonding/grounding. If human reliability related to bonding and grounding is brought to its best by superior procedures and independent verification the mitigated probability of ignition with high human reliability for the combined human error is $1 E-5$.

The SST unmitigated rate of deflagration related to electrostatic sparks is calculated assuming 100 riser cover removals per tank per year. Thus the rate is $1 E-2 / S S T$-year (100 riser cover removals/SST-year * $1.0 /$ activity [probability of ignition] * 1E-4 [proportion of time above LFL, which is above concentration for Dome failure for SSTs] $=1.0 \mathrm{E}-2 / \mathrm{SST}-$ year).

The SST mitigated rate of deflagration related to electrostatic sparks is calculated assuming controls on the number of riser cover removal activities and controls related to sampling for flammable gas and bonding and grounding of risers related to tanks on flammable gas watch list. Thus the rate of deflagration is 3E-8/SST-year ( 3 riser cover removals/SST-year * 
0.0001 [combined human error related to gas sampling and bonding/grounding] * $1 \mathrm{E}-4$ [proportion of time above LFL, which is above concentration for Dome failure for SSTs] $=3.0 E-8 / S S T-y e a r)$.

The SST mitigated with reliable human action rate of deflagration related to electrostatic sparks is the mitigated option above and a reduced human error and is 3E-9/SST-year (3 riser cover removals/SST-year * 1E-5 [combined human error with independent verification] * $1 \mathrm{E}-4$ [proportion of time above LFL, which is above concentration for Dome failure for SSTs] = 3.0E-9/SST-year).

The DST unmitigated rate of deflagration related to electrostatic sparks is calculated assuming 100 riser cover removals per tank per year. Thus the rate is $1 E-2 / D S T-y e a r$ (100 riser cover removals/DST-year * $1.0 /$ activity [probability of ignition] * 1E-4 [proportion of time above LFL and above concentration for Dome failure for DSTs] $=1.0 \mathrm{E}-2 /$ DST-year) .

The DST mitigated rate of deflagration related to electrostatic sparks is calculated assuming controls on the number of riser cover removal activities and controls related to bonding and grounding of risers related to tanks on flammable gas watch 1 ist. Thus the rate of deflagration is 3E-8/DST-year ( 3 riser cover removals/DST-year * 0.0001 [combined human error related to gas sampling and bonding/grounding] * $1 \mathrm{E}-4$ [proportion of time above LFL and above concentration for Dome failure for DSTs] = 3.0E-8/DST-year).

The DST mitigated with reliable human action rate of deflagration related to electrostatic sparks is the mitigated option above and a reduced human error and is 3E-9/DST-year (3 riser cover removals/DST-year * $1 E-5$ [combined human error with independent verification] * 1E-4 [proportion of time above LFL and above concentration for Dome failure for DSTs] = 3.0E-9/DST-year).

\subsection{AIR LANCING}

Summary of Deflagration Rates for Air Lancing

\begin{tabular}{|c|l|}
\hline Deflagration Cases & Deflagration Rates (per year) \\
\hline Unmitigated rate & $3 \mathrm{E}-1 / \mathrm{SST}$-year \\
\hline Mitigated rate & $\begin{array}{c}3 \mathrm{E}-4 / \mathrm{SST} \text {-year (controls on number of } \\
\text { activities and bonding \& } \\
\text { grounding) }\end{array}$ \\
\hline Mit. \& rel. rate & $3 \mathrm{E}-6 /$ SST-year \\
\hline
\end{tabular}

Since air lancing is a waste intrusive activity, the probability of air lancing producing an ignition source due to electrostatic sparks will be on a per air lancing activity basis. When air or water is moving through conduits there is a potential for build up of electrostatic charge. The unmitigated probability of an air lance producing an ignition source is 1.0 because unmitigated assumes no grounding of the air lances. The mitigated probability 
of producing an ignition source is $1 \mathrm{E}-2$ (human error to attach bonding properly). If human reliability related to bonding and grounding is brought to its best by superior procedures and independent verification the mitigated probability of ignition with high human reliability is $1 E-4$.

It is recognized that waste intrusive activities may result in gas release thus a common cause exists between gas release and ignition source. It is assumed that air lancing will cause a GRE once per every hundred air lance activities independent of whether performed in a SST or a DST (based on information in February 22, 1996 letter by Schofield). Thus two calculations are to be compared. First the random rate of GREs/year and the fraction of a year air lancing would be performed assuming 8 hours per air lance activity ( $X$ GREs/tank-year * [ $[Y$ air lance activities/year * 8 hours/activity $\} /\{8760$ hours/year $\}]=$ random rate of deflagration). Second the number of GRES induced by air lance activities per year ( $\{Y$ air lance activities/year $\} / 100=$ common cause rate of deflagration). From this comparison it can be seen that the common cause rate is larger than the random rate unless the random GREs/year are greater than about 11 GREs/year. Thus only the common cause rates of deflagration are calculated below because the random GRE/year rate is less than $1 \mathrm{GRE} /$ year.

The unmitigated rate of deflagration related to the air lancing activity is calculated assuming 30 air lancing activities per tank per year. Thus the rate is $3 E-1 /$ tank-year ([30/100 common cause GREs/tank-year $]$ * $1.0=$ 3.0E-1/tank-year).

The mitigated rate of deflagration related to the air lancing activity is calculated assuming controls on the number of air lancing activities and controls related to the bonding and grounding of the air lance. Thus the rate of deflagration is 3E-4/tank-year (3/100 common cause GREs/tank-year * 0.01 [human error to bond/ground properiy] $=3.0 \mathrm{E}-4 /$ tank-year).

The mitigated with reliable human action rate of deflagration related to the air lancing activity is the mitigated option above and a reduced human error and is 3E-6/tank-year (3/100 common cause GREs/tank-year * 0.0001 [human error with independent verification of bonding/grounding] $=3.0 \mathrm{E}-6 /$ tank-year) .

\subsection{HYDRAULIC JETTING}

Summary of Deflagration Rates for Hydraulic Jetting

\begin{tabular}{|c|c|}
\hline Deflagration Cases & Deflagration Rates (per year) \\
\hline Unmitigated rate & $3 \mathrm{E}-1 / \mathrm{SST}$-year \\
\hline Mitigated rate & $\begin{array}{c}\text { 3E-4/SST-year (controls on number of } \\
\text { activities and bonding \& } \\
\text { grounding) }\end{array}$ \\
\hline Mit. \& rel. rate & 3E-6/SST-year \\
\hline
\end{tabular}

Since hydraulic jetting is a waste intrusive activity, the probability of hydraulic jetting producing an ignition source due to electrostatic sparks 
will be on a per hydraulic jetting activity basis. When air or water is moving through conduits there is a potential for build up of electrostatic charge. The unmitigated probability of hydraulic jetting producing an ignition source is 1.0 because unmitigated assumes no grounding of the hydraulic jetting conduits. The mitigated probability of producing an ignition source is $1 \mathrm{E}-2$ (human error to attach bonding properly). If human reliability related to bonding and grounding is brought to its best by superior procedures and independent verification the mitigated probability of ignition with high human reliability is $1 \mathrm{E}-4$.

It is recognized that waste intrusive activities may result in gas release thus a common cause exists between gas release and ignition source. It is assumed that hydraulic jetting will cause a GRE once per every hundred hydraulic jetting activities independent of whether performed in a SST or a DST (based on information in February 22, 1996 letter by Schofield). Thus two calculations are to be compared. First the random rate of GREs/year and the fraction of a year hydraulic jetting would be performed assuming 8 hours per hydraulic jetting activity ( $X$ GREs/tank-year * [ $\{Y$ hydraulic jetting activities/year $\star 8$ hours/activity $\} /\{8760$ hours/year $\}]=$ random rate of deflagration). Second the number of GREs induced by hydraulic jetting activities per year ( $\{Y$ hydraulic jetting activities/year $\} / 100=$ common cause rate of deflagration). From this comparison it can be seen that the common cause rate is larger than the random rate unless the random GREs/year are greater than about 11 GREs/year. Thus only the common cause rates of deflagration are calculated below because the random GRE/year rate is less than 1 GRE/year.

The unmitigated rate of deflagration related to the hydraulic jetting activity is calculated assuming 30 hydraulic jetting activities per tank per year. Thus the rate is 3E-1/tank-year ([30/100 common cause GREs/tank-year] * $1.0=3.0 \mathrm{E}-1 /$ tank-year $)$.

The mitigated rate of deflagration related to the hydraulic jetting activity is calculated assuming controls on the number of hydraulic jetting activities and controls related to the bonding and grounding of the hydraulic jet. Thus the rate of deflagration is $3 E-4 /$ tank-year $(3 / 100$ common cause GREs/tank-year * 0.01 [human error to bond/ground properly] = 3.0E-4/tank-year).

The mitigated with reliable human action rate of deflagration related to the hydraulic jetting activity is the mitigated option above and a reduced human error and is 3E-6/tank-year (3/100 common cause GREs/tank-year * 0.0001 [human error with independent verification of bonding/grounding] = 3.0E-6/tank-year). 


\subsection{AIR LIFT CIRCULATOR}

Summary of Deflagration Rates for Air Lift Circulators

\begin{tabular}{|c|l|}
\hline Deflagration Cases & Deflagration Rates (per year) \\
\hline Unmitigated rate & $3 \mathrm{E}-1 / \mathrm{SST}$-year \\
\hline Mitigated rate & $\begin{array}{r}3 \mathrm{E}-4 / \mathrm{SST} \text {-year (controls on number of } \\
\text { activities and bonding \& } \\
\text { grounding) }\end{array}$ \\
\hline Mit. \& rel. rate & $3 \mathrm{E}-6 / \mathrm{SST}$-year \\
\hline
\end{tabular}

Since installation and operation of air lift circulators is a waste intrusive activity, the probability of this activity producing an ignition source due to electrostatic sparks will be on a per activity basis. When air or water is moving through conduits there is a potential for bujid up of electrostatic charge. The unmitiqated probability of an air lift circulator producing an ignition source is 1.0 because unmitigated assumes no grounding of the air lift circulator. The mitigated probability of producing an ignition source is 1E-2 (human error to attach bonding properly). If human reliability related to bonding and grounding is brought to its best by superior procedures and independent verification the mitigated probability of ignition with high human reliability is $1 E-4$.

It is recognized that waste intrusive activities may result in gas release thus a common cause exists between gas release and ignition source. It is assumed that installation and operation of air lift circulators will cause a GRE once every hundred installation or operation activities independent of whether performed in a SST or a DST (based on information in February 22, 1996 letter by Schofield). Thus two calculations are to be compared. First the random rate of GREs/year and the fraction of a year hydraulic jetting would be performed assuming 8 hours per air 1 ift circulator activity ( $X$ GREs/tank-year * [ $\{Y$ air lift circulator activities/year * 8 hours/act ivity $\} /\{8760$ hours/year $\}]=$ random rate of def $]$ agration $)$. Second the number of GRES induced by air lift circulator activities per year ( $Y Y$ air $\}$ ift circulator activities/year $\} / 100=$ common cause rate of deflagration). From this comparison it can be seen that the common cause rate is larger than the random rate unless the random GREs/year are greater than about 11 GREs/year. Thus only the common cause rates of deflagration are calculated below because the random GRE/year rate is less than I GRE/year.

The unmitigated rate of deflagration related to the air lift circulator activity is calculated assuming 30 air lift circulator activities per tank per year. Thus the rate is $3 \mathrm{E}-1 /$ tank-year ([30/100 common cause GREs/tank-year] * $1.0=3.0 \mathrm{E}-1 /$ tank-year $)$.

The mitigated rate of deflagration related to the air lift circulator activity is calculated assuming controls on the number of air lift circulator activities and controls related to the bonding and grounding of the air lift circulator. Thus the rate of deflagration is $3 E-4 /$ tank-year $(3 / 100$ common cause GREs/tank-year * 0.01 [human error to bond/ground properly] = 3.0E-4/tank-year). 
WHC-SD-WM-CN-041, Rev. 0

The mitigated with reliable human action rate of deflagration related to the air lift circulator activity is the mitigated option above and a reduced human error and is 3E-6/tank-year (3/100 common cause GREs/tank-year * 0.0001 [human error with independent verification of bonding/grounding] = 3.0E-6/tank-year).

\subsection{WASTE OR WATER ADDITION}

Summary of Deflagration Rates for Waste or Water Addition

\begin{tabular}{|c|c|c|}
\hline Deflagration Cases & $\begin{array}{l}\text { Waste Addition } \\
\text { Deflagration Rates } \\
\text { (per year) }\end{array}$ & $\begin{array}{l}\text { Water Addition } \\
\text { Deflagration Rates } \\
\text { (per year) }\end{array}$ \\
\hline SST unmitigated rate & $N / A$ & 3E-1/SST-year \\
\hline SST mitigated rate & $N / A$ & 3E-4/SST-year \\
\hline SST mit. \& rel. rate & $N / A$ & 3E-6/SST-year \\
\hline DST unmitigated rate & o/DST-year & 3E-1/DST-year \\
\hline DST mitigated rate & ro/DST-year & 3E-4/DST-year \\
\hline DST mit. \& rel. rate & $\mathrm{N} / \mathrm{A}$ & 3E-6/DST-year \\
\hline
\end{tabular}

Since waste or water addition to a tank is a waste intrusive activity, the probability of waste or water addition producing an ignition source due to electrostatic sparks will be on a per waste or water addition activity basis. When air or water is moving through conduits there is a potential for build up of electrostatic charge. The unmitigated probability of waste flowing into a tank producing an ignition source is essentially zero if the conductivity of the waste is greater than the conductivity of sea water. If the waste had a conductivity less than sea water, the mitigated probability of producing an ignition source for waste flow could be essentially zero if the conductivity is changed to be greater than sea water prior to the waste transfer. For water flow into a tank there may be possibilities to ground the water piping unless it is totally buried (human fallure to bond 1E-2). If bonding is possible for water addition and if human reliability related to bonding and grounding is brought to its best by superior procedures and independent verification the mitigated probability of ignition with high human reliability is $1 E-4$.

It is recognized that waste intrusive activities may result in gas release thus a common cause exists between gas release and ignition source. It is assumed that addition of waste or water will cause a GRE once every hundred additions independent of whether performed in a SST or a DST (based on information in February 22, 1996 letter by Schofield). Thus two calculations are to be compared. First the random rate of GREs/year and the fraction of a year waste or water additions would be performed assuming 8 hours per addition activity ( $X$ GREs/tank-year * [ $\{Y$ waste or water addition activities/year * 8 hours/activity $\} /\{8760$ hours/year $\}]=$ random rate of deflagration). Second the number of GREs induced by waste or water addition activities per year ( $\{Y$ addition activities/year $\} / 100=$ common cause rate of deflagration). From this 
comparison it can be seen that the common cause rate is 1 arger than the random rate unless the random GREs/year are greater than about 11 GREs/year. Thus only the common cause rates of deflagration are calculated below because the random GRE/year rate is less than 1 GRE/year.

Since most of the SSTs are isolated and no waste is to be added to SSTs, water addition is the only waste or water addition activity of concern. The SST unmitigated rate of deflagration related to the water addition activity is calculated assuming 30 waste or water addition activities per tank per year. Thus the rate is 3E-1/SST-year ([30/100 common cause GREs/SST-year] * $1.0=$ 3.0E-1/SST-year).

The SST mitigated rate of deflagration related to the water addition activity is calculated assuming controls on the number of water addition activities and controls related to the bonding and grounding of the water addition conduit. Thus the rate of deflagration is $3 E-4 / S S T-y e a r ~(3 / 100$ common cause GREs/SST-year * 0.01 [human error to bond/ground properly] = 3.0E-4/SST-year).

The SST mitigated with reliable human action rate of deflagration related to the water addition activity is the mitigated option above and a reduced human error and is 3E-6/SST-year (3/100 common cause GREs/SST-year * 0.0001 [human error with independent verification of bonding/grounding] $=$ 3. OE-6/SST-year).

The waste addition rates of deflagration were discussed in the first paragraph of this section. The DST urmitigated rate of deflagration related to the water addition activity is calculated assuming 30 waste or water addition activities per tank per year. Thus the rate is 3E-1/DST-year ([30/100 common cause GRES/DST-year] $1.0=3.0 E-1 / D S T$-year).

The DST mitigated rate of deflagration related to the water addition activity is calculated assuming controls on the number of water addition activities and controls related to the bonding and grounding of the water addition conduit. Thus the rate of deflagration is $3 E-4 / D S I-y e a r ~(3 / 100$ common cause GREs/DST-year $*$ 0.01 [human error to bond/ground proper(y] $=3.0 \mathrm{E}-4 / D S T-y e a r)$.

The DST mitigated with reliable human action rate of deflagration related to the water addition activity is the mitigated option above and a reduced human error and is 3E-6/DST-year (3/100 common cause GRES/DST-year * 0.0001 [human error with independent verification of bonding/grounding] $=3.0 \mathrm{E}-6 / \mathrm{DST}-\mathrm{year}$ ).

\subsection{INSTALLATION OF VARIOUS EQUIPMENT INTO WASTE}

Summary of Deflagration Rates for Installation of Various Equipment Into Waste

\begin{tabular}{|c|l|}
\hline Deflagration Cases & Deflagration Rates (per year) \\
\hline Unmitigated rate & $5 \mathrm{E}-1 /$ tank-year \\
\hline Mitigated rate & $1 \mathrm{E}-3 /$ tank-year \\
\hline Mit. \& rel. rate & $1 \mathrm{E}-4 /$ tank-year \\
\hline
\end{tabular}

Since installation of equipment like LOWs, MITs, etc. into a tank or push mode sampling is a waste intrusive activity, the probability of installation of equipment into the waste producing an ignition source due to electrostatic sparks or mechanical sparks will be on a per installation activity basis. The unmitigated probability of installation of equipment into 
waste in a tank producing an ignition source is assumed to be 1.0 . The mitigated probability of producing an ignition source is 0.01 because of human error to bond/ground or successfully install without producing mechanical sparks. If human reliability related to bonding and grounding is brought to its best by superior procedures and independent verification or extreme care is taken during installation the mitigated probability of ignition with high human reliability is $1 \mathrm{E}-3$.

It is recognized that waste intrusive activities may result in gas release thus a common cause exists between gas release and ignition source. It is assumed that installation of equipment into the waste will cause a GRE once every hundred installations independent of whether performed in a SST or a DST (based on information in February 22, 1996 letter by Schofield). Thus two calculations are to be compared. First the random rate of GREs/year and the fraction of a year installation activities would be performed assuming 8 hours per installation activity ( $X$ GREs/tank-year * [ $\{Y$ installation activities/year * 8 hours/activity $\} /\{8760$ hours/year $\}]=$ random rate of deflagration). Second the number of GREs induced by equipment installation activities per year ( $\{Y$ installation activities/year $\} / 100=$ common cause rate of deflagration). From this comparison it can be seen that the common cause rate is larger than the random rate unless the random GREs/year are greater than about 11 GREs/year. Thus only the common cause rates of deflagration are calculated below because the random GRE/year rate is less than 1 GRE/year.

The unmitigated rate of deflagration related to the equipment installation activity is calculated assuming 50 equipment installation activities per tank per year. Thus the rate is $5 \mathrm{E}-1 /$ tank-year ([50/100 common cause GREs/tank-year] * $1.0=5.0 \mathrm{E}-1 /$ tank-year).

The mitigated rate of deflagration related to the equipment installation activity is calculated assuming controls on the number of equipment installation activities and controls related to the bonding and grounding of the equipment being installed. Thus the rate of deflagration is $1 E-3 /$ tank-year (10/100 common cause GREs/tank-year $\star 0.01$ [human error to bond/ground properly] $=1.0 \mathrm{E}-3 /$ tank-year $)$.

The mitigated with reliable human action rate of deflagration related to the equipment installation activity is the mitigated option above and a reduced human error and is $1 E-4 /$ tank-year (10/100 common cause GREs/tank-year * 0.001 [human error with independent verification of bonding/grounding or extreme care in installation] $=1.0 \mathrm{E}-4 /$ tank-year).

\subsection{ROTARY MODE CORE DRILL OVERHEATING}

Rotary mode core drilling is not addressed in detail in this report because a very detailed safety assessment has been performed in the Los Alamos National Laboratory Safety Assessment for Rotary Mode Core Sampling (WHC $1996 \mathrm{~b}$ ) and two calculation notes (LANL 1996a and LANL 1996b). This safety assessment and the two calculation notes have much more detail than could be covered in this limited scope analysis. 
WHC-SD-WM-CN-041, REN, 0

\subsection{ROTARY MODE CORE SAMPLING TRUCK VENTILATION SYSTEM}

The rotary mode core sampling truck ventilation system is addressed in the detailed safety assessment mentioned in previous section (section 6.27 ) and thus is not addressed further in this report.

\subsection{SALT WELL PUMPING SYSTEM}

The salt well pumping system is not addressed in detail in this report because a very detailed safety assessment has been performed by Los Alamos National Laboratory and reported in a Westinghouse Hanford report (WHC 1996c). This safety assessment has much more detail than could be covered in this limited scope analysis.

\subsection{RESULTS}

The results related to rates of deflagration for flammable gas tanks are presented in a list of typical representative ignition sources and their unmitigated and mitigated rates of deflagration as shown in Tables 4 and 5 . The following estimates have been prepared to provide a basis for identifying the appropriate rate categories. The rates are "Order-of-Magnitude" estimates based on the best available information and/or informed engineering judgement. The rates are not intended to be the result of an exhaustive evaluation. The rates are intended to be good "Order-of-Magnitude" estimates to identify the appropriate rate category and indicate the efficacy of basic controls.

It is not recommended that the rates of deflagration for various pieces of instrumentation or equipment be summed together to try to generate an overall rate of deflagration per tank because of the uncertainties in the individual calculations. Rather a qualitative assessment should be made for the equipment representing a tank configuration such that a rate bin of anticipated or unlikely or extremely unlikely is chosen. For instance the design for a thermocouple tree system would indicate multiple failures must occur to result in a thermocouple causing an electrical spark sufficient to ignite flammable gas. One of the multiple failures involves the electronics for measuring the thermocouple junction voltage. This electronics supports all the thermocouples so a rate of deflagration associated with a thermocouple should not be multiplied by the number of thermocouples in a thermocouple tree to generate the total rate of deflagration for a specific tank configuration. But by looking at the differences in rate of deflagration between various pieces of equipment, instrumentation, or operations one can assess the dominant contributors to the rate of deflagration and qualitatively estimate the rate of deflagration for a specific tank configuration. 
WHC-SD-WM-CN-041, REL.O

Table 4. Deflagration Rate (Def. Rate) for Normal Storage Conditions

\begin{tabular}{|c|c|c|c|c|c|c|c|c|}
\hline $\begin{array}{l}\text { Potential Ignition Source } \\
\text { E-Electrical spark ES-Electrostatic spark } \\
\text { M-Mechanical spark T - Thermal ignition } \\
\text { Rate Categories } \\
\text { BEU - Anticipeted } \\
\text { EU - Extrend Extremely Unlikely } \\
\text { U - Unl ikely Unl ikely }\end{array}$ & $\begin{array}{l}\text { Def. Rate } \\
\text { Per SST per } \\
\text { year, } \\
\text { unnitigated }\end{array}$ & $\begin{array}{l}\text { Def. Rate } \\
\text { Per sSt per } \\
\text { year. } \\
\text { mitigated } \\
\text { (controls) }\end{array}$ & $\begin{array}{l}\text { Def. Rate } \\
\text { Per SST per } \\
\text { year, } \\
\text { assuning } \\
\text { highly } \\
\text { reliable } \\
\text { human } \\
\text { actions }\end{array}$ & $\begin{array}{l}\text { Def. Rate } \\
\text { Per DST per } \\
\text { year. } \\
\text { urmitigated }\end{array}$ & $\begin{array}{l}\text { Def. Rate } \\
\text { Per DST per } \\
\text { year. } \\
\text { mi tigated } \\
\text { (controls) }\end{array}$ & $\begin{array}{l}\text { Def. Rate } \\
\text { Per DST per } \\
\text { year. } \\
\text { assuming } \\
\text { highly } \\
\text { reliable } \\
\text { human } \\
\text { actions }\end{array}$ & $\begin{array}{l}\text { Number of } \\
\text { Operations } \\
\text { per Tank } \\
\text { per Year, } \\
\text { Unmit/Mit }\end{array}$ & $\begin{array}{l}\text { Section } \\
\text { of } \\
\text { Report } \\
\text { Where } \\
\text { Calcula- } \\
\text { tion is } \\
\text { Located }\end{array}$ \\
\hline \multicolumn{9}{|l|}{ NORMALLY INSTALLED IHSTRUMENTATION \& EQUIPMENT: } \\
\hline Thermocouple Style A (E) & $\underline{1 E-9}$ & $\underline{\text { 1E-9 }}$ & $N / A$ & $\underline{1 E-9}$ & $\underline{1 E-9}$ & $\underline{N / A}$ & & 6.2 \\
\hline Thermocouple style B (E) & $\underline{1 E-9}$ & $\underline{1 E-9}$ & $\underline{N / A}$ & $\underline{1 E-9}$ & $\underline{1 E-9}$ & $\underline{N} / \mathbf{A}$ & & 6.2 \\
\hline Thermocouple Type $K$ (E) & $\underline{1 E-9}$ & $\underline{\text { IE-9 }}$ & $N / A$ & & & & & 6.2 \\
\hline Resistance Temperature Detector (E) & $\underline{1 E-9}$ & $\underline{1 E-9}$ & N/A & & & & & 6.2 \\
\hline Multifunction Instrument Tree (MIT) (E) & & & & 1E-9 & 1E-9 & N/A & & 6.2 \\
\hline Miscellaneous waste temperature sensor (E) & $\underline{1 E-9}$ & 1E-9 & $\underline{N} / \mathbf{A}$ & $\underline{1 E-9}$ & $1 \mathrm{E}-9$ & $\underline{\mathbf{N} / \mathbf{A}}$ & & 6.2 \\
\hline ENRAf level gauge (M) & $\underline{1 E-9}$ & $\underline{1 E-9}$ & $\underline{N} / A$ & $\underline{1 E-9}$ & $\underline{1 E-9}$ & N/A & & 6.2 \\
\hline FIC reel type conductivity gauge ( $E, M)$ & $\underline{1 E-9}$ & $\underline{1 E-9}$ & $\underline{N / A}$ & $\underline{1 E-9}$ & $\underline{1 E-9}$ & N/A & & 6.2 \\
\hline $\begin{array}{l}\text { Manual tape with portable conductivity } \\
\text { meter (E, M) }\end{array}$ & $\underline{1 E-9}$ & $\underline{1 E-9}$ & $\underline{N / A}$ & $\underline{1 E-9}$ & $1 \mathrm{E}-9$ & $\mathbf{N} / \mathbf{A}$ & & 6.2 \\
\hline standard hydrogen moni toring systen (E) & $\underline{1 E-9}$ & $\underline{1 E-9}$ & $\underline{N} / \mathrm{A}$ & 1E-9 & $\underline{1 E-9}$ & N/A & & 6.2 \\
\hline Differential pressure transmitter (E) & & & & 1E-9 & 1E-9 & N/A & & 6.2 \\
\hline $\begin{array}{l}\text { Tank high level sensing probe - } \\
\text { conductivity (E) }\end{array}$ & & & & $\underline{6 E-3}$ & 6E-5 & $\underline{\mathbf{0}}$ & & 6.3 \\
\hline Video canera and lights (E, M) & . & & & $\underline{4 E-3}$ & 4E-8 & $\underline{W / A}$ & & 6.4 \\
\hline Pump pit leak detector - conductivity (E) & $\underline{2 E-7}$ & $\underline{9 E-12}$ & $\underline{N / A}$ & $\underline{3 E-4}$ & 6E-9 & N/A & & 6.5 \\
\hline $\begin{array}{l}\text { Primary tank active ventilation system } \\
\text { (E, M, ES, T) }\end{array}$ & $6 E-7$ & $\underline{3 E-11}$ & W/A & 6E-7 & $\underline{3 E-11}$ & $\underline{H / A}$ & & 6.6 \\
\hline $\begin{array}{l}\text { Fiberglass LOWs and plastic riser sleeves } \\
\text { (ES) }\end{array}$ & $\underline{6 E-3}$ & $6 \mathrm{E}-5$ & $\underline{6 E-7}$ & $\underline{6 E-3}$ & $\underline{6 E-5}$ & $\underline{6 E-7}$ & & 6.7 \\
\hline $\begin{array}{l}\text { COMBINED RATE FOR NORMALLY } \\
\text { INSTALLED INSTRUMENTATION \& EQUIPMENT- }\end{array}$ & $u$ & EU & BEU & $\begin{array}{l}\text { A (see } 6.3 \\
6.4 .86 .7)\end{array}$ & $\begin{array}{c}U(\sec 6.3 \& \\
6.7)\end{array}$ & BEU & & \\
\hline
\end{tabular}


WHC-SD-WM-CN-041, BEN, O

Table 4. Deflagration Rate (Def. Rate) for Normal Storage Conditions (Continued)

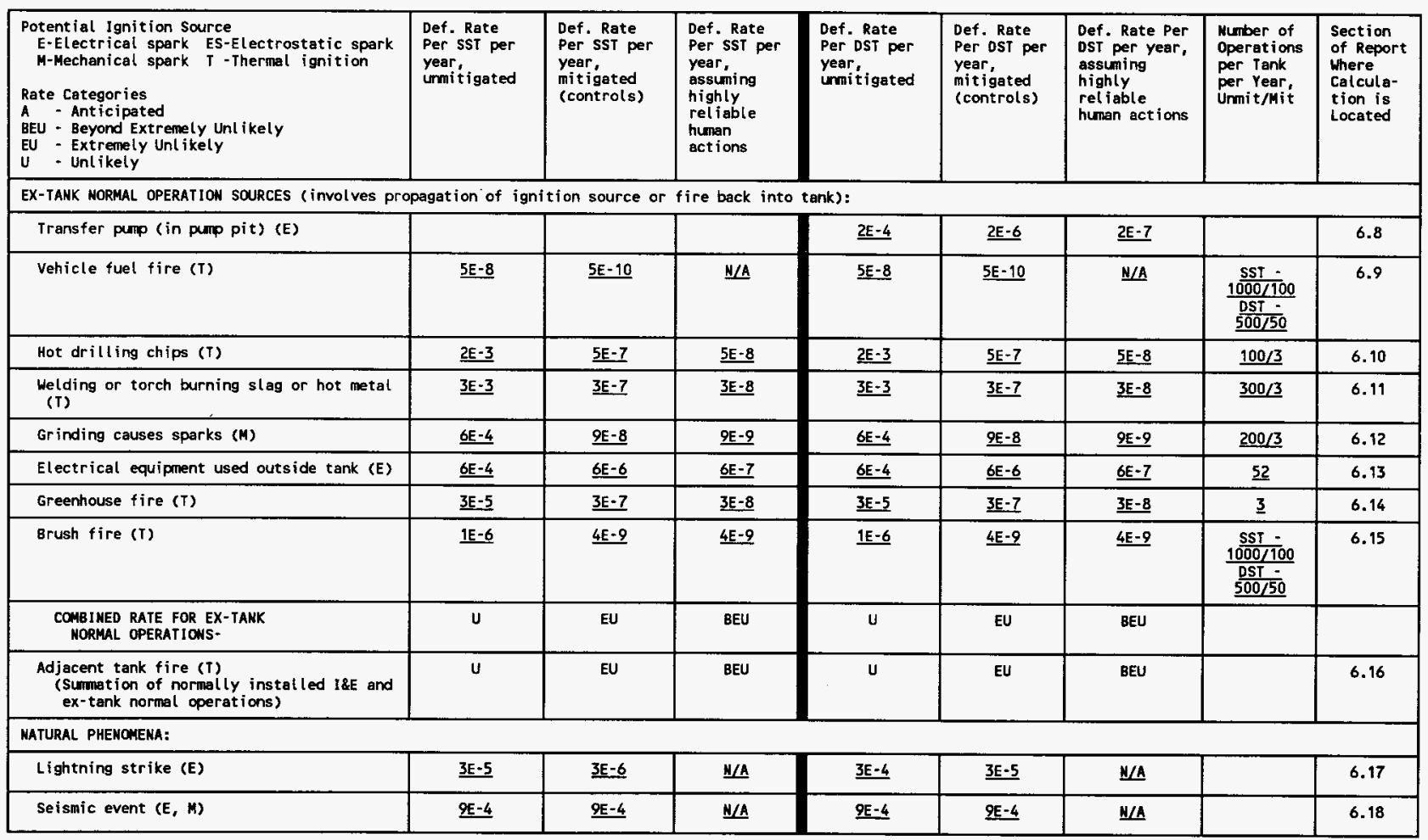


Table 5. Deflagration Rate (Def. Rate) for Intrusive Operations

\begin{tabular}{|c|c|c|c|c|c|c|c|c|}
\hline $\begin{array}{l}\text { Potential Ignition Source } \\
\text { E-Electrical spark ES-Electrostatic spark } \\
\text { M-Mechanical spark T-Thermal ignition } \\
\text { Rate Categories } \\
\text { B - Anticipated } \\
\text { BEU - Beyond Extremely Unlikely } \\
\text { EU - Extremely unlikely } \\
U \text { - Unl ikely }\end{array}$ & $\begin{array}{l}\text { Def. Rate } \\
\text { Per SsT per } \\
\text { year, } \\
\text { unmitigated }\end{array}$ & $\begin{array}{l}\text { Def. Rate } \\
\text { Per SsT per } \\
\text { year, } \\
\text { mitigated } \\
\text { (controls) }\end{array}$ & $\begin{array}{l}\text { Def. Rate } \\
\text { Per SST per } \\
\text { year, } \\
\text { assuming } \\
\text { highly } \\
\text { rel iable } \\
\text { human } \\
\text { actions }\end{array}$ & $\begin{array}{l}\text { Def. Rate } \\
\text { Per DST per } \\
\text { year, } \\
\text { umitigated }\end{array}$ & $\begin{array}{l}\text { Def. Rate } \\
\text { Per DST per } \\
\text { year, } \\
\text { mitigated } \\
\text { (controls) }\end{array}$ & $\begin{array}{l}\text { Def. Rate } \\
\text { Per DST per } \\
\text { year, } \\
\text { assuming } \\
\text { highly } \\
\text { reliable } \\
\text { human } \\
\text { actions }\end{array}$ & $\begin{array}{l}\text { Munber of } \\
\text { Intrusive } \\
\text { Operations } \\
\text { per Tank } \\
\text { per Year. } \\
\text { Unmit/Mit }\end{array}$ & $\begin{array}{l}\text { Section } \\
\text { of Report } \\
\text { inere } \\
\text { Calcula- } \\
\text { tion is } \\
\text { Located }\end{array}$ \\
\hline \multicolumn{9}{|l|}{ VAPOR INTRUSIVE: } \\
\hline Still camera and lights (E, M) & $\underline{1 E-3}$ & $\underline{1 E-9}$ & N/A & $\underline{1 E-3}$ & $1 E-9$ & $\mathrm{~N} / \mathrm{A}$ & $10 / 1$ & 6.19 \\
\hline $\begin{array}{l}\text { Removing riser cover that does not have } \\
\text { gas sample port (ES) }\end{array}$ & $\underline{1 E-2}$ & $3 E-6$ & $\underline{3 E-8}$ & $\underline{1 E-2}$ & $\underline{3 E-6}$ & $3 E-8$ & $100 / 3$ & 6.20 \\
\hline $\begin{array}{l}\text { Removing riser cover that has gas sample } \\
\text { port (ES) }\end{array}$ & $\underline{1 E-2}$ & $\underline{3 E-8}$ & $\underline{3 E-9}$ & $\underline{1 E-2}$ & $\underline{3 E-8}$ & $3 E-9$ & $\underline{100 / 3}$ & 6.21 \\
\hline $\begin{array}{l}\text { COMBINED RATE FOR VAPOR INTRUSIVE } \\
\text { OPERATIONS- }\end{array}$ & A & EU & BEU & $A$ & EU & BEU & & \\
\hline \multicolumn{9}{|l|}{ MASTE INTRUSIVE: } \\
\hline Air lance operation (ES, M) & $\underline{3 E-1}$ & $\underline{3 E-4}$ & $\underline{\underline{E}-6}$ & $\underline{3 E-1}$ & $3 E-4$ & $3 E-6$ & $\underline{30 / 3}$ & 6.22 \\
\hline Hydraul ic jetting operation (ES, M) & $\underline{\underline{3 E-1}}$ & 3E-4 & $\underline{3 E-6}$ & $\underline{3 E-1}$ & $3 \mathrm{EE}-4$ & $\underline{3 E-6}$ & $30 / 3$ & 6.23 \\
\hline Air Lift circulator operation(ES, M) & 3E-1 & $\underline{3 E-4}$ & $\underline{3 E-6}$ & $\underline{\underline{E}=-1}$ & 3E-4 & $\underline{3 E-6}$ & $\underline{30 / 3}$ & 6.24 \\
\hline Waste addition (ES) & $\mathrm{N} / \mathrm{A}$ & $\underline{m / A}$ & N/A & $\underline{\underline{0}}$ & $\therefore \quad \underline{0}$ & M/A & $30 / 3$ & 6.25 \\
\hline Water addition (ES) & $3 \mathbf{E}-1$ & $3 E-4$ & $\underline{3 E-6}$ & $3 \mathrm{E}-1$ & $3 \underline{E}-4$ & $\underline{3 E-6}$ & $\underline{30 / 3}$ & 6.25 \\
\hline $\begin{array}{l}\text { Installation of equipment and push mode } \\
\text { sampl ing }\end{array}$ & $\underline{5 E-1}$ & $\underline{1 E-3}$ & $\underline{1 E-4}$ & $\underline{5 E-1}$ & $\underline{1 E-3}$ & $\underline{1 \mathrm{E}-4}$ & $\underline{50 / 10}$ & 6.26 \\
\hline $\begin{array}{l}\text { COMBINED RATE FOR MASTE INTRUSIVE } \\
\text { OPERATIONS. }\end{array}$ & A & $\bar{u}$ & U & A & u & u & & \\
\hline $\begin{array}{l}\text { COMBINED RATE FOR VAPOR AND WASTE } \\
\text { INTRUSIVE OPERATIOWS- }\end{array}$ & A & $\bar{U}$ & u & $A$ & u & $u$ & & \\
\hline
\end{tabular}




\subsection{CONCLUSIONS}

The conclusions are as follows:

- There is at least an order of magnitude uncertainty in the calculations due to the scoped level of effort. Additional effort may reduce uncertainty for some values; others may be constrained by lack of appropriate data.

\section{Normal Storage Conditions with No Activities}

- Application of standard industrial practice related to the design of the 1) tank high level sensing probe, 2) video camera and lights, and 3 ) pump pit leak detector reduces the individual rates of deflagration from Unlikely to at least Extremely Unlikely.

- Non-conductive equipment - replace a1l equipment (riser sleeves, LOWs, etc.) containing non-conductive materials with a design that can be effectively bonded and grounded to mitigate electrostatic sparks. Replacing this non-conductive equipment will reduce the individual rates of deflagration in a given tank from Unlikely to Extremely UnTikely.

\section{Ex-Tank Operations}

Use of following controls will reduce the combined rate of deflagration from Unlikely to Extremely Unlikely.

- Transfer pump - replacing the transfer pump with one designed to meet NFPA standards.

- Drilling into a riser cover, riser, or equipment in tank boundary - limiting drilling on components that cannot be removed from the tank boundary and when drilling on the tank boundary use procedures to mitigate ignition sources (e.g., use a new drill bit, cooling water used on drill bit while drilling, etc.).

o Welding/Burning/Grinding near tank - use cutter or chisel where possible when component cannot be removed from tank boundary.

- Limit the number of operations. Careful planning of activities will minimize the number of tank entries and will result in reduced rate of deflagration. 


\section{Iank Intrusive Activities}

- Continuous monitoring and shutdown (stopping all operations when elevated levels of flammable gas are observed) will reduce the individual rates of deflagration from Anticipated to Unlikely (except for waste addition) when the following additional controls are implemented:

\section{Vapor Intrusive}

- Still camera - replacing the still camera with one designed to meet NFPA standards reduces the rate of deflagration from Unlikely to at least Extremely Unlikely.

- Riser covers - in all tanks, the first time a non-ported riser cover is removed, replace it with a ported riser cover to permit vapor sampling and continuous monitoring prior to breaking containment. This will reduce the rate for those tanks that are presently not considered flammable but may have a pocket of flammable gas or may be flammable in the future. In addition, limiting the number of intrusive activities and bonding/grounding will reduce the rate of deflagration from Anticipated (Unlikely) to Extremely Unlikely.

\section{Waste Intrusive}

- Application of bonding and grounding per NFPA guidelines will reduce the individual rates of deflagration from Anticipated to Unlikely for installation and operation of passive equipment. 
WHC-SD-WM-CN-041, REL, O

\subsection{REFERENCES}

Braun, D. J., 1992, Risk Assessment of Nitrogen Purge System for Rotary Mode Sampling Truck, WHC-SD-WM-RA-006, Westinghouse Hanford Company, Richland, Washington.

Eide, S. A., S. V. Chmielewski and T. D. Swantz, 1990, Generic Component Failure Data Base for Light Water and Liquid Sodium Reactor PRAs, EGG-SSRE-8875, Idaho National Engineering Laboratory, Idaho Falls, Idaho.

Hanton, B. M., 1996, Waste Tank Summary Report for Month Ending February 29, 1996, WHC-EP-0182-95, Westinghouse Hanford Company, Richland, Washington.

IEEE 352-1975, An American National Standard, IEEE Guide for General Principles of Reliability Analysis of Nuclear Power Generating Station Protection Systems, The Institute of Electrical and Electronics Engineers, Inc., New York, New York. (Also called referenced as ANSI N41.4-1976)

LANL, 1995, A Safety Assessment for Proposed Pump Mixing Operations to Mitigate Episodic Gas Releases in Tank 241-SY-101: Hanford Site, Richland, Washington, LA-UR-92-3196, Rev. 14, Los Alamos National Laboratory, Los Alamos, New Mexico.

LANL, 1996a, Reliability of Systems for Rotary Mode Core Sampling, Calc-Note Number TSA10-CN-WT-SA-HAZ-004, Los Alamos National Laboratory, Los Alamos, New Mexico.

LANL, 1996b, Quant ification of Accident Sequences for Rotary Mode Core Sampling, Calc-Note Number TSA10-CN-WT-SA-TH-089, Los Alamos National Laboratory, Los Alamos, New Mexico.

Lindberg, S. E., 1995, Frequency Analysis of Vehicle Fuel Release Resulting in Waste Tank Fire, (internal letter 8M400-SEL-95008 to W. L. Cowley, J. M. Grigsby, and A. B. Webb, November 9, 1995), Westinghouse Hanford Company, Richland, Washington.

Postma, A. K., 1994, Safety Analysis of Exothermic Reaction Hazards Associated with the Organic Liquid Layer in Tank 241-C-103, WHC-SD-WM-SARR-001, REV. 0, Westinghouse Hanford Company, Richland, Washington.

Scaief, C. C. III, 1991, Hydrogen Ignition Capability of Tank Farm Instrumentation and Electrical Equipment, WHC-SD-WM-ES-176, REV. 0, Westinghouse Hanford Company, Richland, Washington.

Scaief, C. C. III, 1996, Tank Farm Potential Ignition Sources, WHC-SD-WM-ES-362, REV. 1, Westinghouse Hanford Company, Richland, Washington.

Schofield, J. S., 1996, Evidence of Release Events During Waste Intrusive Activities in Flammable Gas Watch List (FGWL) and Proposed FGWL Tanks, 
(internal letter 75210-96-006, Revision 1 to W. B. Barton, February 22), Westinghouse Hanford Operations, Richland, Washington.

Sullivan, L. H., 1995, A Safety Assessment for Proposed Pump Mixing Operations to Mitigate Episodic Gas Releases in Tank 241-SY-101: Hanford Site, Richland, Washington, LA-UR-92-3196, Rev. 14, Los Alamos National Laboratory, Los Alamos, New Mexico.

WHC, 1996a, Probabilistic Seismic Hazard Analysis DOE Hanford Site, Washington, WHC-SD-W236A-TI-002, Rev.1, Prepared by Geomatrix Consultants for Westinghouse Hanford Company, Richland, Washington.

WHC, 1996b, A Safety Assessment of Rotary Mode Core Sampling in Flammable Gas Single Shell Tanks: Hanford Site, Richland, Washington, WHC-SD-WM-SAD-035, Rev. 0, Prepared by Los Alamos National Laboratory for Westinghouse Hanford Company, Richland, Washington.

WHC, 1996c, A Safety Assessment of Salt Well Pump Operations in Tank 241-A-101: Hanford Site, Richland, Washington, WHC-SD-WM-SAD-034, Rev. 0 , Prepared by Los A7amos National Laboratory for Westinghouse Hanford Company, Richland, Washington.

Zach, 1996, Probability, Consequences, and Mitigation for Lightning Strikes at Hanford High Level Waste Tanks, WHC-SD-WM-ES-387, Rev. 0, West inghouse Hanford Company, Richl and, Washington. 


\section{CHECKLIST FOR PEER REVIEW}

Document Reviewed: WHC-SD-WM-CN-041, Tank Farm Deflagration Rates Due to Various Ignition Sources

Scope of Review: Complete detailed review of all 117 pages

$\frac{\text { Yes No NA }}{[x][][] *}$

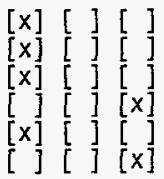

[x] [ ] [ ]

[x] [ ] [ ]

[x] [ ] [ ]

$\left[\begin{array}{lll}] & {[} & {[x]} \\ ] & {[}\end{array}\right]\left[\begin{array}{ll}x \\ 0\end{array}\right]$

[x] [ ] [ ]

$[x]\left[\begin{array}{l}{[} \\ {[x]}\end{array}\right]\left[\begin{array}{l}3 \\ {[}\end{array}\right]$

[x] [ ] [ ]

[x] [ ] [ ]

Prevtous reviews complete and cover analysis, up to scope of this review, with no gaps.

Probiem completely defined.

Accident scenarios developed in a clear and logical manner. Necessary assumptions explicitiy stated and supported. Computer codes and data files documented.

Data used in calculations explicitly stated in document.

Data checked for consistency with original source information as applicabie.

Mathematical derivations checked including dimensional consistency of results.

Models appropriate and used within range of validity or use outside range of established validity justified.

Hand calculations checked for errors. Spreadsheet results should be treated exactly the same as hand calculations. Software input correct and consistent with document reviewed. Software output consistent with input and with results reported in document reviewed.

Limits/criteria/guideines applied to analysis results are appropriate and referenced. Limits/criteria/guidelines checked against references.

Safety margins consistent with good engineering practices. Conclusions consistent with analytical results and applicable 7 imits.

Results and conclusions address all points required in the problem statement.

Format consistent with appropriate NRC Regulatory Guide or other standards

[ ] [x]* Review calculations, comments, and/or notes are attached.

\section{[x] [ ] [ ] Document approved.}

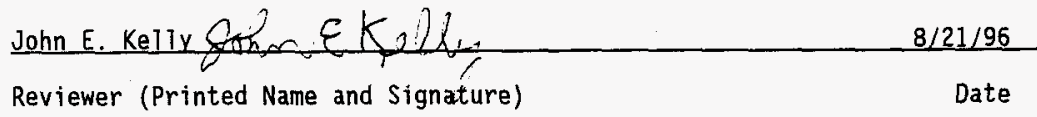

* Any calculations, comments, or notes generated as part of this review should be signed, dated and attached to this checklist. Such material should be labeled and recorded in such a manner as to be intelligible to a technically qualified third party.

$$
\text { GEF } 321
$$


WHC-SD-WM-CN-041, REV,O

\section{APPENDIX A}

PNNL Letter Report TWSFG96.24 
WHC-SD-WM-CN-041, REV. $O$

Letter Report Approvals PNNL Tank Waste Safety Projects

Date: Aug 9, 1996

Lead Author: Paul Whitney

Project Name: Waste Behavior Data Evaluation Report Title: Estimates of the Frequency of Potentially Hazardous

Signatures

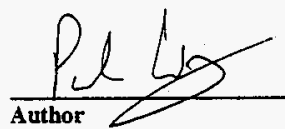

$$
\frac{9 \text { A j } 96}{\text { Date }}
$$
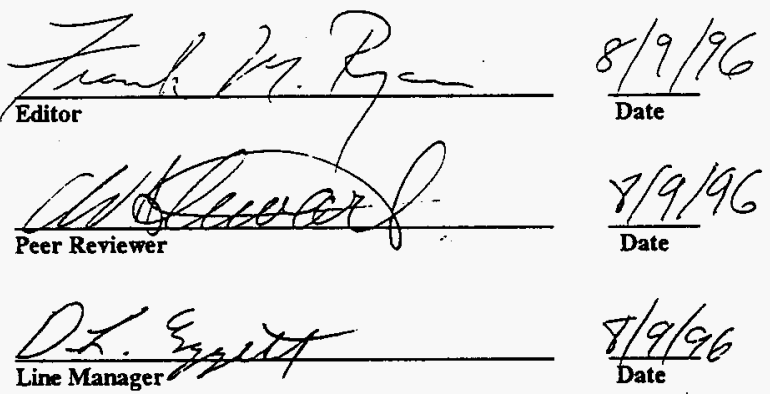

$\frac{\text { Qu broth }}{\text { project Manager }} \quad \frac{8 / 9 / 96}{\text { Date }}$

WHC Flammable Gas Safety Assessment

Date

WHC Flammable Gas Project Management

Date

70 of 117 
WHC-SD-WM-CN-041, REV. O

TWSFG96.24

Estimates of the Frequency of Potentially Hazardous Gas Releases from Hanford Tank Waste

M.E. Brewster

P.D. Whitney

August 1996

Pacific Northwest National Laboratory

Richland, Washington 99352 


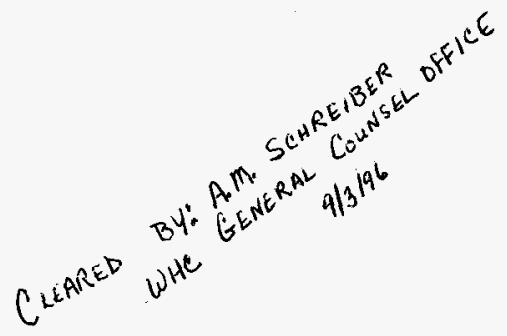

\section{LIMITED DISTRIBUTION NOTICE}

This document is made available to Westinghouse Hanford Company in confidence solely for use in performance of work under contracts with the U.S. Department of Energy. This document is not to be published or referenced in another publication, nor its contents otherwise disseminated or revealed or used for purposes other than specified above, without determination of final review authority. If the information contained herein is incorporated in a Westinghouse Hanford Company document, such document shall receive appropriate clearance. 


\section{Executive Summary}

The Hanford site is home to 177 large, underground nuclear waste storage tanks. These tanks and their contents are the subject of numerous safety and environmental concerns. One such concern is the propensity for the waste in these tanks to generate and trap flammable gases, and then intermittently release these gases into the tank headspace. This report describes a methodology to estimate the fraction of time during which a tank headspace might be hazardous because of a gas release from the tank waste, and provides order of magnitude estimates on the frequency of hazardous gas releases, based on the current level of knowledge of the Hanford tanks contents and behavior. The specific hazard considered is tank dome failure caused by the pressure from burning the released gas: The work reported was done at the request of Westinghouse Hanford Company to support the final safety analysis report (FSAR).

An additional aspect of the request was that frequency estimates be provided which are suitable for two scenarios.

1. An ignition source exists continuously over some time span, and during that time span a sufficiently large gas release occurs so that the tank dome fails.

2. During a time when the headspace concentration contains enough gas to fail the tank dome, a spark occurs which ignites the gas.

For each of the above scenarios, the sparik source and the gas release are assumed to occur independently; as opposed, say, to having a common cause (such as an earthquake).

For selected tanks, this report provides order of magnitude frequency estimates which can be used to evaluate the chance of tank dome failure due to a flammable gas burn in the above two scenarios. For Tanks 241-AN-105 and 241-S-102, our current best estimate on the frequency of hazardous gas releases are 0.004 and 0.008 per year, respectively. While no formal uncertainty analysis has been done for these estimates, it is the opinion of the authors that the uncertainties in these estimates are large; indeed, the models used to obtain these estimates are not, strictly, self-consistent. However, the estimates are believed to be indicative of the values which might be supportable.

Finally, this document is appearing well ahead of some of the anticipated supporting documents. Thus, the numerical inputs (e.g. for waste yield strength, amount of retained gas in single shell tanks, and waste gas composition), and even some of the models (single shell tank gas release mechanisms, amount of gas released by earthquakes, tank dome failure), are subject to change. 


\section{Contents}

Executive Summary

1 Introduction 1

2 Applicability of the Estimates 4

3 Strategy for Obtaining the Estimates $\quad 5$

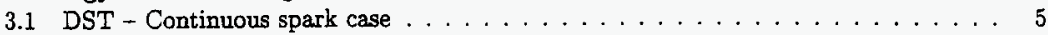

3.2 DST - Random spark case . . . . . . . . . . . . . . . . 5

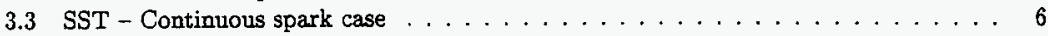

3.4 SST - Random spark case . . . . . . . . . . . . . . . 6

4 Detailed Calculations and Supporting Data $\quad 7$

4.1 Rollover Contribution $f_{r o} \ldots \ldots \ldots \ldots \ldots \ldots \ldots \ldots$

4.2 Maximum Released Volume from Rollover in a DST . . . . . . . . . . . . . . 9

4.3 Fast Release Fraction for a Rollover Event . . . . . . . . . . . . . . . . . . . . . . . . . . . . . . . . . .

4.4 The Frequency of Intrinsic Releases from a SST: $f_{\text {int }} \ldots \ldots \ldots \ldots$

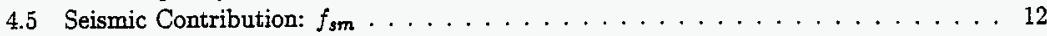

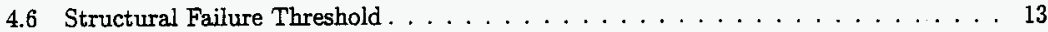

4.7 Estimated Gas Inventory $V_{\text {ret, } \max } \ldots \ldots \ldots \ldots \ldots \ldots \ldots \ldots \ldots$

4.8 Pressure $P_{g}$ at which the Gas is Held in the Tank Waste . . . . . . . . . . . 14

4.9 Gas Retention Rate Estimates . . . . . . . . . . . . . . . . 15

4.10 Headspace Volumes for the Tanks . . . . . . . . . . . . . . . . . 16

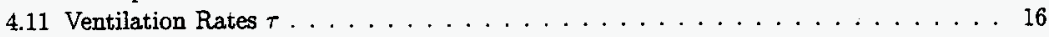

4.12 Plume Releases in SSTs . . . . . . . . . . . . . . . 19

4.13 Gas Compositions . . . . . . . . . . . . . . . . . . . 19

4.14 Combined Contributions from Intrinsic and Seismic Releases . . . . . . . . . 20

5 Potential for Improving the Results 21

References $\quad 22$

A Observed Rates of Level Change $\quad 24$

B Using Gas Retention Rate to Bound Gas Release Hazard 38

B.1 Estimating the Proportion of Time the Tank Headspace is Hazardous . . . . . . . 38

B.2 Estimating the Frequency of Hazardous Gas Releases . . . . . . . . . . . . . 41 


\section{WHC-SD-WM-CN-041, REV. O}

\section{Figures}

1 Tank AN-105 level response to a gas release event $\ldots \ldots \ldots \ldots$

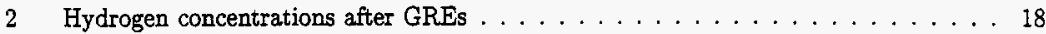

3 Tank S-107 waste level measurements . . . . . . . . . . . . . . . 25

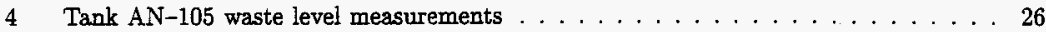

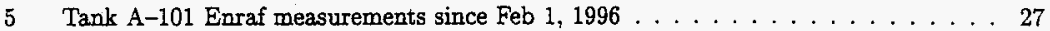

6 Tank A-101 waste level measurements since $1981 . \ldots \ldots \ldots \ldots$

7 Tank A-101 waste level measurements and average rate of level rise for 1981 FIC measurements . . . . . . . . . . . . . . . . . . . . . . 29

8. Tank AN-105 waste level measurements and average rate of level rise. . . . . . . 30

9 Tank S-102 waste level measurements and average rate of level rise. . . . . . . . 31

10 Tank S-103 waste level measurements and average rate of level rise. . . . . . . . . 32

11 Tank S-106 waste level measurements and average rate of level rise. . . . . . . . . 33

12 Tank SY-101 waste level measurements and average rate of level rise for $1990 . \quad$. . 34

13 Tank SY-101 waste level measurements and average rate of level rise for 1993. . . . 35

14 Tank SY-103 waste level measurements and average rate of level rise for 1990 . . . 36

15 Tank SY-103 waste level measurements and average rate of level rise for $1995 . \quad \ldots 37$

16 Amount of gas in tank waste as a function of time . . . . . . . . . . . . 39

17 Theoretical decay curve for hydrogen concentration in tank headspace . . . . . . . 40

18 Frequency of release, duration of hazard and proportion of time in hazardous state,

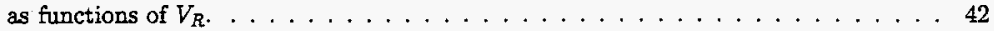

\section{Tables}

1 Order of magnitude estimated frequency of gas release events which could lead to tank dome failure . . . . . . . . . . . . . . . . . . . 3 Observed gas release volumes $\left(\right.$ in $\left.\mathrm{situ}, \mathrm{m}^{3}\right) \ldots \ldots \ldots \ldots \ldots$

3 Estimated frequencies $f_{\text {ro }}$ of hazardous rollover gas releases (per year) $\ldots \ldots \ldots$

4 Description of SST waste release mechanisms . . . . . . . . . . . . . 10

5 Probability of release fraction required for flammable headspace from each SST waste

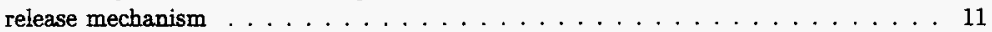

6 Probability of release fraction required for dome faihure from each SST waste release

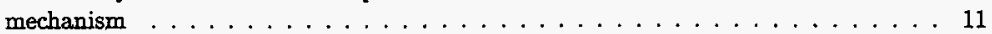

7 Probability of fast release to achieve specified hazard. . . . . . . . . . . 11

8 Seismic contributions to tank dome failure . . . . . . . . . . . . . 13

9 Minimum waste gas volumes which could, if ignited, result in tank dome failure. . . 14

10 Estimated retained gas volumes $V_{\text {ret, } \max } \ldots \ldots \ldots \ldots \ldots \ldots \ldots$

11 Pressure $P_{g}$ at which the gas is held in the tank waste . . . . . . . . . 14

12 Estimated rates of level rise and gas retention rates $\ldots \ldots \ldots \ldots$

13 Tank, tank waste, and headspace volumes . . . . . . . . . . . 16

14 Estimated characteristic times $\tau$ for passively ventilated tanks . . . . . . . . . 17

15 Estimated characteristic times in Tank SY-103 headspace . . . . . . . . . . . . 19

16 Ventilation time constants for each tank . . . . . . . . . . . . . . . 19

17 Plume release contribution to dome failure . . . . . . . . . . . . . . . 19

18 Lower flammability limit and hydrogen equivalent fuel value . . . . . . . . . . 20

19 Combined estimated frequency (per year) of hazardous gas releases . . . . . . . . . 20 


\section{Introduction}

The Hanford site is home to 177 large, underground nuclear waste storage tanks. These tanks and their contents are the subject of numerous safety and environmental concerns. One such concern is the propensity for the waste in these tanks to generate and trap flammable gases, and then periodically release these gases into the tank headspace. This report describes a methodology and provides order of magnitude estimates on the fraction of time during which a tank headspace might be hazardous because of a gas release from the tank waste, and provides order of magnitude estimates on the frequency of hazardous gas releases, based on the current level of knowledge of the Hanford tanks contents and behavior. The specific hazard considered is tank dome failure caused by the pressure from burning the gas. For the rest of this report, a "hazardous" gas release for a tank refers to a release large enough to fail the tank, if the gas were ignited. The work reported was done at the request of Westinghouse Hanford Company to support the facility safety analysis report (FSAR).

An additional aspect of the request was that the frequency estimates provided be applicable for two scenarios. These scenarios are: 1) enough gas is released from the tank waste so that the entire headspace is above the lower flammability limit (LFL), and the tank dome would fail if the gas were ignited; 2) enough gas is released as a "plume" so that if the plume were ignited the tank dome would fail. For the second scenario to be credible without the first criteria being met, it's necessary to assume that either the cause of the plume is also the cause of ignition, or that a continuous ignition source is available in the tank headspace; see section 4.12 .

The following equations outline how the probability of tank dome failures from these scenarios might be calculated, and demonstrate how the information provided in this report contributes to the calculations.

Let $f_{1}$ be the frequency (per year) of sufficiently large gas release events and assume that the gas release is independent of the spark source. Then, supposing that sometime during the year a continuous spark source occurs, and that the continuous spark lasts for a time span $T_{S}$,

Prob(tank dome failure during a year under the continuous spark scenario)

$\approx \operatorname{Prob}$ (gas release during $T_{S} \mid$ continuous spark for $T_{S}$ occurs during the year)

$\times$ Prob(continuous spark for $T_{S}$ occurs during the year)

$\approx\left(1-\exp \left(-f_{1} T_{S}\right)\right) \times \operatorname{Prob}\left(\right.$ continous spark for $T_{S}$ occurs during the year)

$\approx f_{1} T_{S} \times$ Prob(continous spark for $T_{S}$ occurs during the year)

For the scenario in which a random spark ignites gas in the tank headspace and then fails the tank dome (and assuming that the gas release is independent of the spark source). Let $f_{1}$ be the frequency of sufficiently large gas releases (per year), let $T_{G}$ denote the subsequent time span for which the tank headspace contains a hazardous amount of flammable gas, and let $f_{I}$ denote the frequency of point ignitions (per year), then

$$
\begin{aligned}
& \text { Prob(tank dome failure during a year under the random spark scenario) } \\
& \approx \text { Prob(ignition during } T_{G} \mid \text { large gas release occurs during a year) } \\
& \quad \times \text { Prob(large gas release occurs during a year }) \\
& \approx\left(1-\exp \left(-f_{I} T_{G}\right)\right) \times\left(1-\exp \left(-f_{1} 1 \mathrm{yr}\right)\right) \\
& \approx\left(f_{I} T_{G}\right) \times\left(f_{1} 1 \mathrm{yr}\right)
\end{aligned}
$$

A key objective of this report is to estimate the quantity $f_{1}$ in Equation $(1)$ and $\left(f_{1} T_{G}\right)$ in Equation (2); obtaining these estimates contributes to the calculation of the chance of dome failure. 


\section{WHC-SD-WM-CN-041, REV. $O$}

Specifically, this report describes "order of magnitude" estimates for these, and related quantities. The quantity $f_{\mathrm{l}}$ is constructed as a combination of two gas release frequencies; the first is an "intrinsic" release frequency and the second is a frequency of seismic induced gas releases; the seismic induced releases are hypothetical. For DSTs, the intrinsic releases modeled are the observed rollovers. For the SSTs, the intrinsic releases are hypothesized releases, which have not been observed yet.

The key data required to obtain the estimates on the fraction of time that a tank headspace is in a hazardous state and on the frequency of large gas release events includes:

- the expected amount of gas retained in the tank waste,

- the gas retention and release history, or anticipated release mechanisms, of the tank waste,

- the composition of the released gas,

- the ventilation rate of the headspace,

- the anticipated size and frequency of earthquakes at the Hanford site, and

- tanik structural failure limits.

The safety analyses in the FSAR are based on "representative" double and single sheil tanks. However, to make the task in this report more concrete, a subset of the Hanford tanks were selected as the focus of this study. The double shell tanks examined in this study are 241-AN-105 (AN-105), 241-SY-101 (SY-101) and 241-SY-103 (SY-103). These tanis are currently on the flammable gas watchlist; see Hanion (1996) for a description of the flammable gas watch list. Information and estimates presented in this report for Tank SY-101 are based on the state of the tank prior to the installation and use of the mixer pump. The estimates are included for the purpose of comparison with the other tanks and are not intended for use in a safety analysis of the current state of the Hanford tanks. The SSTs in the study are 241-S-102 (S-102), 241-S-103 (S-103) and 241-S-106 (S-106). Tank S-102 is also on the flammable gas watchlist, while the other two tanks are not. All three of these tanks are of significant concern because they exhibit a long term rising waste level, which might indicate increasing amounts of gas trapped in the tank waste. These three tanks also show a consistent level change in response to fluctuations in atmospheric pressure; this response also indicates that gas is trapped in the tants waste.

For Tanks AN-105, S-102, S-103, S-106, SY-101 and SY-103, Table 1 shows order of magnitude estimates for the gas release frequencies which could, if ignited, lead to tank dome failure. In particular, the column in Table 1 with the heading Random Spark Case contains order of magnitude estimates of $f_{1}$ in Equation (1) and the column with the heading Continuous Spark Case contains order of magnitude estimates of a quantity that can be used for $\left(f_{1} T_{G}\right)$ in Equation (2).

Section 2 discusses the applicability of these estimates in the FSAR. Section 3 describes the modeling and the data used to obtain the bounds on hazardous phenomena. Section 4 discusses the potential for improving the estimates. Appendix A discusses how average rates of level rise for the tank wastes were obtained. Appendix B presents another strategy for obtaining bounds on $f_{1}$ and related quantities. The bounds are obtained by first using "best estimate" data, and then varying the volume of gas released per gas release event to determine the worst case bound. While these bounds were not used in this report, aspects of the mathematic development were used. 
Table 1: Order of magnitude estimated frequency of gas release events which could lead to tank dome failure

\begin{tabular}{|lcc|}
\hline & $\begin{array}{c}\text { Continuous Spark Case } \\
\text { (\# per year) }\end{array}$ & $\begin{array}{c}\text { Random Spark Case } \\
\text { (Proportion of Time) }\end{array}$ \\
\hline Double Shell Tanks & & \\
AN-105 & $4 \mathrm{E}-3$ & $1 \mathrm{E}-4$ \\
SY-101 (historical) & $2 \mathrm{E}-1$ & $4 \mathrm{E}-3$ \\
SY-103 & 0 & 0 \\
Single Shell Tanks & & \\
S-102 & $8 \mathrm{E}-3$ & $1 \mathrm{E}-4$ \\
S-103 & $7 \mathrm{E}-4$ & $6 \mathrm{E}-6$ \\
S-106 & $2 \mathrm{E}-2$ & $9 \mathrm{E}-5$ \\
\hline
\end{tabular}




\section{Applicability of the Estimates}

It is perhaps worth making a few comments on the safety analysis methodology employed in this document. An estimate of the risk due to flammable gas consists of an estimate of both the consequence (in terms of dose) of a given scenario and its frequency. A large degree of conservatism, by some estimates 3 orders of magnitude, is built into the consequence estimates. Therefore sufficient safety factors have been included so that a large amount of conservatism is unnecessary in the estimation of frequencies.

There is a great deal of uncertainty in these frequency estimates since the seismic induced releases and the hypothesized large releases in SSTs have not been observed. Therefore these estimates are order-of-magnitude (that is, probably accurate to within multiple factors of $10^{ \pm 1}$ or $10^{ \pm 2}$ ) estimates only.

As a final caveat, the concept of a representative tank is not clearly defined in this report, nor in the FSAR in general. However, there are some tanks for which these estimates are clearly not representative. For instance, conclusions based on pre-mixer pump SY-101 data are clearly not representative of any current Hanford tanks, since this state does not exist at this time, nor are any other tanks behaving as SY-101 did. Frequencies based on calculations for burping tanks are not representative of non-burping tanks. SST saltcake tanks are probably not representative of SST siudge tanks. SSTs that have not been saltwell pumped are not representative of drained or nearly empty saltcake tanks.

The tanks that we suggest as representative tanks in this work, AN-105 for DSTs and S-102 for SSTs are on this basis representative for at most 6 DSTs and roughly 30 SSTs. There are a few DSTs (notably AW-104) which fall outside the boundaries of this comparison because they are not burping tanks, but they do retain some gas and are full. 


\section{WHC-SD-WM-CN-041, REV, O}

\section{Strategy for Obtaining the Estimates}

The fundamental hazard, dome failure due to a gas burn, is estimated by first estimating how much gas is needed to generate the necessary pressure failure, and then estimating how often (if ever) that amount of gas might be released from the tank waste. The rest of this section discusses the calculations and results for the four main categories of the calculation.

\subsection{DST - Continuous spark case}

The representative value of $f_{1}(\mathrm{AN}-105)$ is approximately $4 \mathrm{E}-3$ gas release events per year. The dominant contribution is the seismic frequency: it is estimated that a seismic event with return frequency of $1 \mathrm{E}-2$ per year (i.e. 1 in 100 years) is sufficient to release roughly $50 \%$ of the retained gas from DST sludge; see Section 4.5. The contribution from rollovers is smaller than the seismic frequency by at least an order of magnitude. This is due to the predominance of observed rollovers that have a small release volume relative to that required to produce dome failure if ignited.

There are no direct observations of gas release from a seismic event, and none of the 100-year magnitude earthquakes have occurred since the tanks were built. The frequency estimates related to seismic events are based on physical models, laboratory experiments and expert judgment ${ }^{1}$.

Deterministic frequency calculations for SY-103 result in zero, since the estimated amount of retained gas in SY-103, and its energy content, are below the threshold necessary to produce dome failure even if all the retained gas were to be released and ignited.

\subsection{DST - Random spark case}

The representative value $(\mathrm{AN}-105)$ for the fraction of time the headspace is in a hazardous state is approximately 1E-4. The correspondence to the frequency of gas release calculated above is through an additional factor (of roughly $2 \mathrm{E}-2$ years) estimating the duration of the hazard after a gas release event.

Active ventilation systems are assumed to not operate after a seismic event; however, we do assume that passive ventilation at a rate similar to that modeled and observed in SSTs would be present. The hazard is of shorter duration than the time necessary to clear the dome by passive ventilation ( 10 to 30 days) because not much dilution is required to reduce the burn energy of the expected release below that necessary to fail the dome.

The gas release volume needed to produce dome failure is based on an extrapolation procedure presented in Pasamehmetoglu (1995), and postulating a linear dependence of peak pressure on gas release volume. This formula was used to be consistent with calculations being performed to close the unresolved safety question (USQ) and and ease of use (since it is parameterized with respect to hydrogen equivalent fuel). An accuracy check was made between the extrapolation procedure and the adiabatic burn procedure described in Van Vleet (1996), assuming the same equivalent fuel values in each case. The difference was determined to be at most $20 \%$, and this error was greatest at pressures far from the failure threshold.

${ }^{1}$ H.R. Reid, P.A. Meyer and J. Phillips, May 1996. Waste Tank Sludge Yielding Estimates with Design base Earthquake Spectrum Shock Analyses, presented at the Flammable Gas Quarterly Review Meeting, PNNL, Richland WA 


\subsection{SST - Continuous spark case}

The representative frequency of hazardous gas releases (S-102) is approximately $8 \mathrm{E}-3$ gas release events per year. There is a roughly equal contribution from the seismic frequency and intrinsic release by certain credible but somewhat unlikely mechanisms, including failure of a pressure seal and release of large bubble. A seismic event of frequency 1 in 100 years is assumed to be sufficient to release roughly $10 \%$ of the retained gas from SST waste. Note that this is a lower release fraction than that assumed for DSTs, since the SST waste is assumed to have a higher yield strength than DST waste. On the other hand, SSTs have a lower structural failure threshold and hence require a smaller burn to achieve dome failure. A conservation of mass argument is employed to estimate the frequency of intrinsic releases, together with expert judgment on the likelihood of these release mechanisms; see section 4.4 .

\subsection{SST - Random spark case}

The representative value (S-102) for the fraction of time that the headspace is in a hazardous state is approximately $1 \mathrm{E}-4$. This value corresponds roughly to the frequency of gas release event, calculated above, multiplied by the duration of the hazard per release. The duration is roughly the dome clearing time, around 30 days or $1 \mathrm{E}-1$ yr. 


\section{WHC-SD-WM-CN-041, REV O}

\section{Detailed Calculations and Supporting Data}

In DSTs, there are two potentially significant contributions to the frequency of a flammable gas release event of sufficient magnitude to cause dome failure if ignited. These are the rollovers, which are observed to occur regularly in certain DSTs, and releases induced by seismic events. Thus,

$$
f_{1}=f_{r o}+f_{s m}
$$

where $f_{1}$ is the overall frequency of hazardous gas releases, $f_{\text {ro }}$ is the frequency of hazardous gas releases due to roliovers and $f_{s m}$ is the frequency of hazardous gas releases due to seismic events.

For SSTs, the potential contributors to the frequency of hazardous gas releases are a hypothesized "fast" intrinsic release and a seismic induced gas release. Letting $f_{\text {int }}$ denote the frequency of such a gas release, the overall frequency of a hazardous gas release is

$$
f_{1}=f_{\text {int }}+f_{s m}
$$

The remainder of this section presents how these quantities are calculated, as well as providing details about the inputs to these calculations.

\subsection{Rollover Contribution $f_{\text {ro }}$}

The DSTs in this study have been observed to retain and then periodically release gas from their tank waste. Table 2 lists the estimated size of the gas releases observed in these tanks. The data are from the references ${ }^{2}$ (Brewster et al. 1995, Shepard et al. 1995).

The observed gas release data was used to estimate the frequency of rollovers, $f_{\text {roL }}$ as the observed numbed of releases divided by the period of observation. Then,

$$
f_{\text {ro }}=f_{\text {roL }} \times \operatorname{Prob}\left(\text { rollover volume }>V_{D}\right)
$$

where $V_{D}$ is the amount of gas required so that, if it were ignited, the tank dome would fail; see section 4.6 for a more detailed discussion of this quantity. The probability distribution on the rollover volumes was obtained by fitting a shifted Weibull distribution to the observed release volumes. The distribution was truncated at a maximum release equal to the maximum undissolved retained gas release possible by rollover.

In the cases of SY-103 and $\mathrm{AN}-105$, the estimated gas inventories were sufficiently small that the distribution was truncated below the amount of gas required to fail the dome, $V_{D}$. Therefore a frequency of 0 is calculated. A careful probabilistic implementation of this calculation would include a distribution on the truncation point, and would also account for the uncertainty in the model for the maximum release via rollover. Since such model distributions tend to have quite wide distributions and the truncation level is fairly close to the burn failure threshold $V_{D}$, this calculation would be expected to produce a small non-zero value for the frequency contribution from rollovers, $f_{\text {ro. }}$.

The values we use for the rollover contribution to frequency of gas release events which would produce the consequence of concern, dome failure, are given in Table 3.

These values range from a minimum of 0 for Tank SY-103 to 0.02 for Tank SY-101 as it was in its pre-mixer pump state. The value for $S Y-101$ is not representative of the present state of the Hanford tanks, so we recommend using the estimates for Tank AN-105 as representative values for

\footnotetext{
${ }^{2}$ Stewart, C., Alzheimer, J., Shepard, C., Terrones, G., Chen, G. and Wilkins, N. 1996, In Situ Determination of Rheological Properties and Void Fraction: Hanford Waste Tank 241-AN-105, CW Stewart, PNNLMIT:021696
} 
Table 2: Observed gas release volumes (in situ, $\mathrm{m}^{3}$ ). The observations were taken over 4.2 years for $\mathrm{SY}-101,4.8$ years for $\mathrm{SY}-103$ and 8.6 years for $\mathrm{AN}-105$.

\begin{tabular}{|c|c|c|c|}
\hline Tank & $\begin{array}{c}\text { SY-101 } \\
\text { (historical) }\end{array}$ & $S Y-103$ & $A N-105$ \\
\hline & $5.00 \mathrm{E}+01$ & $9.40 \mathrm{E}+00$ & $9.20 \mathrm{E}+00$ \\
\hline & $5.20 \mathrm{E}+01$ & $1.04 \mathrm{E}+01$ & $9.40 \mathrm{E}+00$ \\
\hline & $5.30 \mathrm{E}+01$ & $1.04 \mathrm{E}+01$ & $9.90 \mathrm{E}+00$ \\
\hline & $5.70 \mathrm{E}+01$ & $1.04 \mathrm{E}+01$ & $1.23 \mathrm{E}+01$ \\
\hline & $6.70 \mathrm{E}+01$ & $1.04 \mathrm{E}+01$ & $1.35 \mathrm{E}+01$ \\
\hline & $6.90 \mathrm{E}+01$ & $1.15 \mathrm{E}+01$ & $1.48 \mathrm{E}+01$ \\
\hline & $7.50 \mathrm{E}+01$ & $1.25 \mathrm{E}+01$ & $2.18 \mathrm{E}+01$ \\
\hline & $7.50 \mathrm{E}+01$ & $1.25 \mathrm{E}+01$ & $2.22 \mathrm{E}+01$ \\
\hline & $8.00 \mathrm{E}+01$ & $1.30 \mathrm{E}+01$ & $2.92 \mathrm{E}+01$ \\
\hline & $8.40 \mathrm{E}+01$ & $1.46 \mathrm{E}+01$ & $3.00 \mathrm{E}+01$ \\
\hline & $8.80 \mathrm{E}+01$ & $1.56 \mathrm{E}+01$ & \\
\hline & $9.30 \mathrm{E}+01$ & $1.56 \mathrm{E}+01$ & \\
\hline & $1.01 \mathrm{E}+02$ & $1.77 \mathrm{E}+01$ & \\
\hline & $1.16 \mathrm{E}+02$ & $1.88 \mathrm{E}+01$ & \\
\hline & $1.35 \mathrm{E}+02$ & $1.98 \mathrm{E}+01$ & \\
\hline & $1.38 \mathrm{E}+02$ & $2.08 \mathrm{E}+01$ & \\
\hline
\end{tabular}




\section{WHC-SD-WM-CN-041, REN,O}

DSTs. These are order of magnitude estimates, and should only be used as such. Certainty within an order of magnitude is sufficient for most safety analysis purposes. The zero value for $A N-105$ is not expected to persist under a careful probabilistic implementation. However the release volumes are conservative (since they were not adjusted for the fast release fractions; see section 4.3); hence, the actual non-zero value is expected to be negligible compared to the seismic contribution discussed in section 4.5 .

Table 3: Estimated frequencies $f_{\text {ro }}$ of hazardous rollover gas releases (per year)

\begin{tabular}{|c|c|c|}
\hline AN-105 & SY-101 (historical) & SY-103 \\
\hline 0.00 & 0.02 & 0.0 \\
\hline
\end{tabular}

Only in the case of SY-101 (historical) did the threshold fall within the tail of the distribution where the distribution of observed releases is extrapolated via a truncated Weibull with the endpoint set to be the maximum possible rollover release according to measurement of retained gas voiume. See Johnson et al. (1994) for a thorough discussion of the Weibull distribution.

\subsection{Maximum Released Volume from Rollover in a DST}

The rollover mechanism requires a gas-retaining portion of the sludge with gas at pressure $P_{g}$ to become buoyant and rise to the surface. Gas is released until buoyancy is lost. Therefore, the fraction of retained gas released from the sludge participating in rollover is $\left(P_{g}-1\right) / P_{g}$. For example, if the gas is held at 2 atm, $50 \%$ must be released from the sludge to return to neutral buoyancy when the gas pressure is reduced to 1 atm during rollover. The maximum undissolved retained gas release possible by rollover, $V_{\text {ro,max }}$ is therefore

$$
V_{\text {ro, } \max }=V_{\text {ret, } \max } \times\left(P_{g}-1\right) / P_{g}
$$

where $V_{\text {ret,max }}$ is the retained gas volume in the tank waste.

It is presumed that dissolved ammonia is released from the tank waste when the tank waste is disturbed by a rollover. However, the release volumes were estimated by tank waste level drops and so did not measure the release of dissolved ammonia, resulting in under-predicting the released gas. The release of dissolved ammonia is accounted for in our calculation by multiplying the observed release of undissolved gas, computed from level drop, by a factor $(1+\delta)$ where $\delta$ is the ratio of dissolved to undissolved gas.

The maximum gas release possible by rollover, $V_{\text {rel, max }}$, is therefore

$$
V_{\text {rel,max }}=V_{\text {ro, } \max } \times(1+\delta)
$$

To be consistent with Van Vleet (1996), the default value for $\delta$ is chosen so that $15 \%$ of the released gas volume is from dissolved ammonia.

\subsection{Fast Release Fraction for a Rollover Event}

Only a fraction of the gas released as calculated from level drops in the cited references was released at a sufficiently rapid rate to accumulate in the headspace. A fast release fraction, $F_{a s t}$, of $70 \%$ was assumed, following (Pasamehmetoglu 1995). Thus, for a rollover release of undissolved gas of size $w$, the resulting "fast fraction" released, $v_{f r o}$, is

$$
v_{\text {fro }}=w \times F_{\text {ast }}
$$




\section{AN105 Surface Level Measurements from 5-1-94 to 5-31-94}

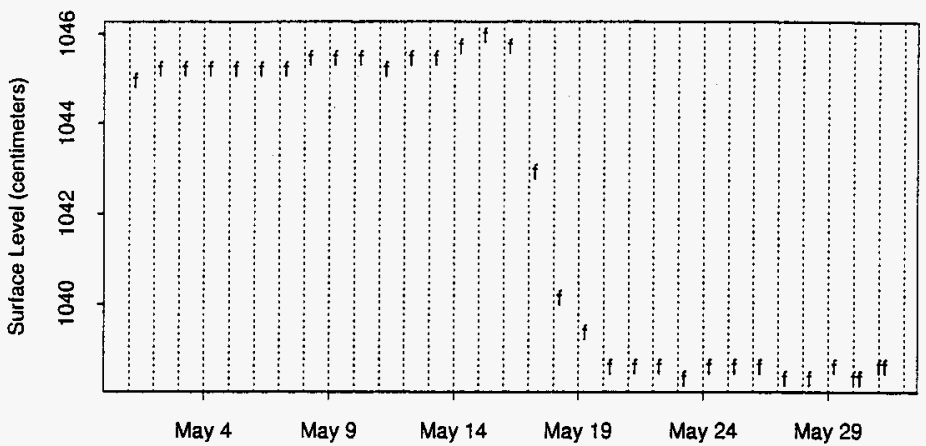

Figure 1: Tank AN-105 level response to a gas release event. The " $\mathrm{f}$ "s on the plot mark the tank waste level measurements. The vertical lines mark the beginning of each day.

Figure 1 shows the tank waste level response during a gas release which began on May 16, 1994 in Tank AN-105. The level takes 4 days to drop completely, and the initial drop is less than half of the entire gas release for this event.

\subsection{The Frequency of Intrinsic Releases from a SST: $f_{\text {int }}$}

In the expert elicitation conducted for tank waste characterization study ${ }^{3}$, four different intrinsic release mechanism from SST waste were identified. These mechanisms are listed in Table 4, along with their nominal values of release duration, 50-th percentile release fractions, and relative probability for the mechanism in a saltcake waste type. In Tables 5 and 6 , we list for each tank the probability of the release fraction required for a flammable headspace dome failure being released by the specified mechanism.

Table 4: Description of SST waste release mechanisms

\begin{tabular}{|l||c|c|c|}
\hline Release mechanism & Duration of release & Nominal Release Fraction & Probability \\
\hline \hline 1. failure of pressure seal & $100 \mathrm{~min}$ & $15 \%$ & 0.05 \\
\hline 2. large bubble release & $10 \mathrm{~min}$ & $10 \%$ & 0.05 \\
\hline 3. simple percolation & 100 days & $5 \%$ & 0.89 \\
\hline 4. weak sludge release & $10 \mathrm{~min}$ & $30 \%$ & 0.01 \\
\hline
\end{tabular}

${ }^{3}$ Colson, S., Brewster, M., Gephart, R., Hill, J., Hunter, V., Janata, J.and Morgan, L. 1996 , Draft - OutcomeBased Strategy for Tank Waste Management: A Risk, Technical andEconomic Basis for Characterization of Hanford Site Tank Wastes, TechnicalReport PNNL-11231, Pacific Northwest National Laboratory 
Table 5: Probability of release fraction required for flammable headspace from each SST waste release mechanism

\begin{tabular}{|l||c|c|c|}
\hline Release mechanism & S-102 & S-103 & S-106 \\
\hline Release Fraction Req. for Flammable Headspace & $22 \%$ & $89 \%$ & $24 \%$ \\
\hline \hline 1. failure of pressure seal & 0.21 & 0 & 0.15 \\
\hline 2. large bubble release & 0.11 & 0 & 0.09 \\
\hline 3. simple percolation & 0.04 & 0 & 0.03 \\
\hline 4. weak sludge release & 0.67 & 0 & 0.63 \\
\hline
\end{tabular}

Table 6: Probability of release fraction required for dome failure from each SST waste release mechanism

\begin{tabular}{|l||c|c|c|}
\hline Release mechanism & S-102 & S-103 & S-106 \\
\hline Release Fraction Required for Dome Failure & $23 \%$ & $68 \%$ & $14 \%$ \\
\hline \hline 1. failure of pressure seal & 0.18 & 0 & 0.59 \\
\hline 2. large bubble release & 0.10 & 0 & 0.33 \\
\hline 3. simple percolation & 0.04 & 0 & 0.12 \\
\hline 4. weak sludge release & 0.65 & 0.17 & 0.83 \\
\hline
\end{tabular}

All release mechanisms except simple percolation give a release duration which is fast compared to the characteristic ventilation time of SSTs (about 20 days). Therefore the probability of mechanisms 1,2 and 4 are added together, weighted by the factors in the last column of Table 4, to provide the probability of fast release of the specified release fraction. These are listed in Table 7 .

Table 7: Probability of fast release to achieve specified hazard.

\begin{tabular}{|l||c|c|c|}
\hline Release mechanism & S-102 & S-103 & S-106 \\
\hline \hline Probability of Release Req. for Flammable Headspace & $2 \mathrm{E}-2$ & $1 \mathrm{E}-4$ & $2 \mathrm{E}-2$ \\
\hline Probability of Release Req. for Dome Failure & $2 \mathrm{E}-2$ & $2 \mathrm{E}-3$ & $5 \mathrm{E}-2$ \\
\hline
\end{tabular}

The frequency of release is obtained by a conservation of mass argument; see Appendix B for details. This argument is technically only appropriate for a long-time duration, including many gas release events. This situation applies to no actual SSTs at present; however in the absence of other arguments, it is sufficient to obtain an order-of-magnitude estimate for the release frequency that does not contradict physical principies. Some tanks may have exhibited the simple percolation release, at which point they achieve a steady-state with zero net retention. Tanks such as S-106 show a continual growth with no level drops. Such tanks are likely to have a first release when they reach a percolation threshold which is appropriate for that waste type (10-40\%). That release is most likely to be the slow release associated with percolation however, and to not pose any hazard for a build-up of flammable gas provided passive ventilation is in effect. The most likely mechanisms for the hazard of flammable dome space or dome failure are failure of a pressure seal 


\section{WHC-SD-WM-CN-041, REV.O}

and a large bubble release. These are about equally likely to occur at any time in the overall tank retention/release cycle, so the frequency associated with the conservation of mass principle (see Appendix B, especially Equation (17)) times the probability of that mechanism on a volume basis is taken to be the frequency at which that gas release event occurs. If the release fraction required is greater than $100 \%$, we assign a frequency of zero to that gas release. The probability of this event occurring could easily change if there is steady gas growth so that greater retained gas volume are achieved. Such tanks should be monitored at a rate which allows this change in the risk to be detected and accounted for appropriately.

The expert elicitation process ${ }^{4}$, which followed industry-accepted procedures established in (NRC 1989, Keeney \& Winterfeldt 1991), has the weakness that the elicitation was not initially intended for safety analysis purposes, and was limited by availability of only 1 expert to contribute on the particular parameter set that we employed in this report (i.e. probabilities of particular gas release mechanisms in SSTs). In the case of a single expert, the elicitation process serves to allow this expert's reasoning to be challenged by the elicitation team for both technical and probabilistic correctness. However, the opportunity to incorporate or aggregate over a spectrum of expert judgments is lost. Therefore we recommend that additional elicitation on the frequencies of both intrinsic and seismic release mechanisms be conducted for the case of SSTs.

\subsection{Seismic Contribution: $f_{s m}$}

As an order of magnitude estimate, seismic events with frequency 0.01 to 0.001 (per year) have been shown to have a potential to release a significant fraction of the retained gas in the waste ${ }^{5}$. Seismic events with a frequency of 0.01 per year are expected to release about $10 \%$ of the gas in a DST; seismic events with a frequency of 0.001 per year are expected to cause the release of $50 \%$ of the retained gas. These studies are considered highly conservative because of missing attenuation factors. Also there is large uncertainty in the seismic release calculations because of a lack of knowledge of the physical phenomenology of the waste.

A placeholder functional relationship between release fraction and return rate of seismic event is used to introduce a decrease in the estimated seismic frequency if a larger release fraction is required to fail the dome: the release fraction is linear in the log of the frequency of seismic events (with a negative slope). Wesnousky (1994) discusses the observed relation between frequency and magnitude of seismic events. The relation between release fraction and frequency is not exact, however, the magnitude of the errors on the $10 \%$ and $50 \%$ release fraction estimates used to create the relationship are expected to overwheim any dependence on the release fraction. The uncertainty in these points is due primarily to model uncertainties in the structural analysis of the response of the tank and its contents to a seismic event. Significant improvements to this relationship and a decrease of conservatism would be possible, but are well outside the scope of this report.

Perhaps a more significant functional dependence which we also include to some extent in our model is a dependence of the release fraction on the physical properties of the waste. Modeling and laboratory studies at PNNL have shown that weak sludges (weaker than is expected for a typical DST or SST sludge or saltcake) that can retain a significant quantity of gas will probably release a large fraction of the retained gas quickly in a weak, and hence frequent seismic event. Thus

\footnotetext{
${ }^{4}$ Colson, S., Brewster, M., Gephart, R., Hill, J., Hunter, V., Janata, J.and Morgan, L. 1996 , Draft -OutcomeBased Strategy for Tank Waste Management: A Risk, Technical andEconomic Basis for Characterization of Hanford Site Tank Wastes, TechnicalReport PNNL-11231, Pacific Northwest National Laboratory

${ }^{5}$ Reid, H., Meyer, P. and Phillips, J.May 1996, 'Waste Tank Sludge Yielding Estimates with DesignBase Earthquakes Spectrum Shock Anaiyses', Presentation at The Flammable GasQuarterly Review Meeting, Richland, Washington.
} 
there is a certain regime of material strength (strong enough to retain, weak enough to yield in a seismic event) that is especially hazardous and care should be taken to avoid creating such a waste configuration.

A simultaneous release of ammonia from the dissolved phase can be expected to occur, and the governing mechanism may be quite analogous to rollover. We assume that the amount of dissolved ammonia released in a seismic event is the same as for a rollover. Due to lack of other information, the gas release is assumed to be instantaneous.

The values we use for the seismic contribution to frequency of gas release events which would produce the consequence of concern, dome failure, are given in Table 8 .

Table 8: Seismic contributions to tank dome failure

\begin{tabular}{|c||c|c|c|c|c|c|}
\hline & AN-105 & SY-101 (historical) & SY-103 & S-102 & S-103 & S-106 \\
\hline$f_{s m}$ (per year) & $4 \mathrm{E}-3$ & $4 \mathrm{E}-2$ & 0 & $5 \mathrm{E}-3$ & $5 \mathrm{E}-4$ & $7 \mathrm{E}-3$ \\
\hline
\end{tabular}

Although ventilation is normally considered a vaiuable mitigation option for reducing the hazard from tlammable gas, it is important to note that in the case of a seismic release, the ventilation fan and the exhaust pathway must both be designed to survive and operate effectively following large seismic events.

The presence of a power source to operate any mitigative equipment after a seismic event would also be in doubt because of the potential need to power down to avoid ignition sources from electrical equipment damaged in the seismic event. A further complication in seismic events is the likelihood of hazardous release in several tanks simultaneously.

\subsection{Structural Failure Threshold}

The pressure produced by a flammable gas burn in a DST tank headspace is calculated based on an extension of the extrapolation procedure recommended in (Pasamehmetoglu 1995). In this report, an equivalence is proposed between waste gas concentration and the amount of hydrogenequivalent fuel energy per volume of headspace. The concentration shown in detailed coupled combustion/structural dynamics simulations for SY-101 to produce dome failure was $8650 \mathrm{ft}^{3}$ of $S Y-101$ waste gas in a headspace of $43,000 \mathrm{ft}^{3}$. The equivalent fuel value of $S Y-101$ waste gas is $63 \%$ $\mathrm{H}_{2}$ combusted in air. Thus a dome concentration of $\chi_{D F}=12.7 \%$ equivalent $\mathrm{H}_{2}$ combusted in air is the threshold at which a burn is expected, under somewhat conservative assumptions described in (Pasamehmetoglu 1995), to achieve structural failure of a DST. Equivalently, the volume of a particular waste gas with equivalent fuel value ( $H_{2}$ combusted in air) of $\chi_{B}$ required to produce dome failure if burned in a headspace of volume $V_{H S}$ is

$$
V_{D}=V_{H S} \chi_{D F} / \chi_{B}
$$

The peak burn pressure $P_{B}$ that produces this failure in a DST is 3 bar (gauge) (Sullivan 1995). Therefore a crude linearization for the dependence of the peak burn pressure $P_{B}$ on release gas volume produces a formula:

$$
P_{B}=P_{1} w \chi_{B} / V_{H S}
$$

where $P_{1}=23.4 \mathrm{bar}, w$ is the release gas volume $\chi_{B}$ is the equivalent fuel ( $H_{2}$ combusted in air) of the release gas $V_{H S}$ is the headspace volume. 
This extension is used to estimate the release gas threshold in SSTs where the failure threshold is 0.82 bar (gauge) (Julyk 1995). This calculation shows that the volume necessary to produce a flammable headspace in an SST sufficient, but in the same range, as that required to achieve the failure pressure. However, there is an implicit assumption of complete combustion in this calculation, which is unlikely to be accurate at concentrations near the flammability limit. Thus there is an opportunity for significant improvement in the technical basis of the combustion model in the case of SSTs and the potential to remove some conservatism as well.

The waste gas volume, $V_{D}$, necessary to burn (as a defiagration) to cause dome failure was calculated following the extrapolation procedure suggested in (Pasamehmetoglu 1995), outlined above. Table 9 presents the resulting estimates of $V_{D}$.

Table 9: Minimum waste gas volumes which could, if ignited, resuit in tank dome failure.

\begin{tabular}{|c||c|c|c|c|c|c|}
\hline & $\mathrm{AN}-105$ & $\mathrm{~S}-102$ & $\mathrm{~S}-103$ & $\mathrm{~S}-106$ & $\mathrm{SY}-101$ & $\mathrm{SY}-103$ \\
\hline$V_{D}\left(\mathrm{~m}^{3}\right.$ at STP $)$ & 155 & 95 & 135 & 76 & 232 & 384 \\
\hline
\end{tabular}

\subsection{Estimated Gas Inventory $V_{\text {ret, max }}$}

For the double shell tanks, the retained gas $V_{\text {ret, max }}$ is based largely on the void fraction measurements. For the single shell tanks, the estimated retained gas inventories were estimated using the relationship between retained gas volume and the change in waste level that occurs as a result of changes in atmospheric pressure (Whitney 1995).

Table 10: Estimated retained gas volumes $V_{\text {ret, } \max }$

\begin{tabular}{|l||c|c|c|c|c|c|}
\hline & AN-105 & S-102 & S-103 & S-106 & SY-101 (historical) & SY-103 \\
\hline$V_{\text {ret, } \max }\left(\mathrm{m}^{3}\right.$ at STP) & 202 & 420 & 204 & 550 & 880 & 228 \\
\hline
\end{tabular}

\subsection{Pressure $P_{g}$ at which the Gas is Held in the Tank Waste}

The pressure at which the gas is held in the tank waste is estimated for the DSTs as the effective pressure based on the void fraction and ball rheometer data presented in the reports ${ }^{6}$ (Stewart et al. 1995, Shepard et al. 1995). For the SSTs, there are no similar direct measurements. Instead, the value of 1.5 atmospheres for Tank S-106 used in Hodgson et al. (1995); pressure values for the remaining SSTs were crudely estimated based on their respective waste volumes (listed in Table 13). These "gas pressure" values in this table are probably accurate to within 0.5 atm.

Table 11: Pressure $P_{g}$ at which the gas is heid in the tank waste

\begin{tabular}{|l||c|c|c|c|c|c|}
\hline & AN-105 & S-102 & S-103 & S-106 & SY-101 (historical) & SY-103 \\
\hline Gas pressure (atm) & 2.3 & 1.5 & 1.5 & 1.5 & 2.0 & 1.9 \\
\hline
\end{tabular}

\footnotetext{
${ }^{B}$ Stewart, C., Alzheimer, J., Shepard, C., Terrones, G., Chen, G. and Wilkins, N. 1996, In Situ Determination of Rheological Properties and Void Fraction: Hanford Waste Tank 241-AN-105, CW Stewart, PNNLMIT:021696
} 
More accurate estimates of the pressures for the SSTs might be obtained by estimating densities of liquid, salt, and sludge for each tank; assuming that these "phases" are layered in the tank with liquid on top, saltcake next, and sludge at the bottom. Then the volume estimates from (Hanlon 1996) can be used to compute the vertical pressure profile. Indeed, this is the methodology used to obtain the gas pressure estimates in Hodgson et al. (1995). However, since the location of the gas in these tanks is not currently known, it's not clear that this strategy would improve the estimates in Table 11.

\subsection{Gas Retention Rate Estimates}

The average gas retention rate is estimated from the average rate of increase in tank waste level, and an assumed pressure at which the gas is held in the tank waste.

The estimated rates of level increase for the tanks in question are shown in Figures 8 through 15 in Appendix A. In each of these figures the actual rate of level increase is not constant over the time span shown; the average rates of level increase (the slope of the diagonals appearing on each of these figures) is shown in the caption. Assuming the waste level increases are due to changes in trapped gas volume, the rate of gas retention $R_{R}$ can be obtained from the rate of change in level $\mathrm{d} L / \mathrm{d} t$, once this rate of level change has been scaled by $A P / P_{0}$, where $P$ is the pressure at which the gas is held, $P_{0}$ is standard pressure, and $A$ is the cross sectional area of the tank ${ }^{7}$. A retention rate can be estimated from:

$$
R_{R}(t)=\left(P / P_{0}\right) A \frac{\mathrm{d} L}{\mathrm{~d} t}
$$

Three main sources of uncertainty arise in using the rate of change in waste level as an estimate of gas retention rate:

1. Liquid has been known to "leak into" the Hanford tanks; additionally, some tank operations involve the addition of water into the tanks (e.g., installation of liquid observation weils, installation of thermocouple trees, and flushing of measurement devices which come into contact with the tank waste).

2. Evaporation is possibly occurring from many of the Hanford tanks.

3. The pressure at which the gas is held in the waste is not known.

The first two of these sources of uncertainty relate to the addition and deletion of liquid phase to or from the tanks. The third is related to the location of the gas in the tank waste.

Some of the level rise in the Hanford tanks may be due to liquid entering the tanks from the outside. For instance, the April 1995 monthly status report, Hanlon (1995), points out that the level rise in Tanks B-202, BX-101, BX-103 and BY-106 may all be due, in part, to intrusion. The visual appearance of the waste surface is cited in support of intrusion from the surface to the tank contents (i.e., liquid portion apparently increasing).

The single sheil Tanks C-106, SX-101, SX-102, SX-103, SX-104, SX-105 and SX-106 all have decreasing waste levels, presumably due to evaporation. Liquid in the double shell Tank AZ-101 is also believed to be evaporating. Note that these tanks are actively ventilated. Finally, some tank waste is believed to be hygroscopic. We are not currently able to quantify the uncertainties

\footnotetext{
${ }^{7}$ All the tanks in this report have a circular cross section and a radius of 37.5 feet
} 


\section{WHC-SD-WM-CN-041, REN. ?}

related to evaporation or intrusion. In this work, these sources of uncertainty are ignored (some data-based work along these lines has been reported ${ }^{8}$ ).

Table 12 lists the the rates of level increase in the tanks and the corresponding rates of gas retention for the SSTs in this report. Note that a useful validation exercise would be to compare these retention rates with estimated gas generation rates, where the generation rates are obtained by means other than the waste level data.

Table 12: Estimated rates of level rise and gas retention rates

\begin{tabular}{|l||c|c|c|}
\hline Tank & S-102 & S-103 & S-106 \\
\hline $\begin{array}{l}\text { Average Waste Level Growth } \\
\text { (m per year) }\end{array}$ & 0.03 & 0.02 & 0.03 \\
$\begin{array}{l}\text { Retention Rate (m } \\
\text { year) }\end{array}$ & 17 & 11 & 18 \\
\hline
\end{tabular}

\subsection{Headspace Volumes for the Tanks}

Estimates of tank headspace volumes are listed in Table 13; the waste volumes are from (Hanlon 1996) and the tank volumes are taken from the spreadsheets used in (Hodgson et al. 1995).

Table 13: Tank, tank waste, and headspace volumes

\begin{tabular}{|c|c|c|c|c|c|c|c|}
\hline & Tank & AN-105 & $S-102$ & $S-103$ & $S-106$ & $S Y-101$ & $S Y-103$ \\
\hline Tank Volume $\left(\mathrm{m}^{3}\right)$ & & 5337 & 3981 & 3981 & 3981 & 5337 & 5337 \\
\hline Waste Volume $\left(\mathrm{m}^{3}\right)$ & & 4270 & 2078 & 939 & 1813 & 4270 & 2816 \\
\hline Headspace Volume $\left(\mathrm{m}^{3}\right)$ & & 1067 & 1903 & 3043 & 2168 & 1067 & 2521 \\
\hline
\end{tabular}

\subsection{Ventilation Rates $\tau$}

In addition to the frequency of the release, the duration of the hazard after the release must be calculated. The duration of the hazard depends on how quickly the hazardous gas is ventilated from the tank headspace. Using a standard exponential decay model for the concentration of gases in the tank headspace, the duration for which the tanik beadspace is hazardous, $\tau_{\text {ro }}$ is

$$
\tau_{\text {ro }}= \begin{cases}\tau \ln \left(V_{\text {ro }} / V_{D}\right) & \text { provided } V_{\text {ro }}>V_{D} \\ 0 & \text { otherwise }\end{cases}
$$

This duration is calculated based on an exponential relaxation of the initial release $V_{\text {ro }}$ using the characteristic time $\tau$ appropriate for the flow rates normally observed in the tank.

\footnotetext{
${ }^{8}$ Whitney, P., Wilkins, N., Miller, N., Meyer, P. and Brewster, M. 1996, Flammable gas Data Evaluation Progress Report, Letter Report WTSFG96.1.
} 
Most of the single shell tanks are not actively ventilated; Tanks S-102, S-103 and S-106 are not actively ventilated. For these tanks, the average ventilation flow rate (due to atmospheric pressure changes) is often assumed to be 0.45 volume percent per day (Hopkins 1994). The value 0.45 volume percent per day corresponds to a time constant $\tau=1 / 0.0045=222$ (days) for passive ventilation. However, standard hydrogen monitors were recently placed on some of the passively ventilated tanks. Brown (1996) reports slight hydrogen releases from the waste in some these tanks during a large pressure swing in December 1995. The decay in hydrogen concentration from these releases was used to estimate the ventilation rate for four of the single shell tanks. Figure 2 shows the natural $\log$ of the Hydrogen concentrations versus time for the passively ventilated Tanks S111, U-103, U-105 and U-108. A broad time window is shown for each of these tanks to provide some perspective on the hydrogen release and decay. The points marked as "•" in each plot were used to estimate the parameter $\tau$ using previously developed methodology ${ }^{9}$. The report presents two methods: one based on ordinary least squares and the other based on a more "robust" line fitting procedure. In each of the four plots, the solid lines are the robust fits; the dashed lines are the least squares fits.

Table 14 summarizes the estimates of $\tau$ for each tank and method. The table shows that for each tank there is not much difference in the $\tau$ 's estimated by the least squares and the robust linear fits. Based on the values in this table, we used a value of $\tau=21$ (days) for the three passively ventilated tanks in this study.

Table 14: Estimated characteristic times $\tau$ for passively ventilated tanks. The units of $\tau$ and for the corresponding $95 \%$ confidence intervals (CIs) is are days.

\begin{tabular}{|l|cccc|}
\hline Tank & Robust $\tau$ & Robust CI & Least Squares $\tau$ & Least Squares CI \\
\hline S-111 & 21.6 & $(20.7,22.6)$ & 21.3 & $(20.4,22.4)$ \\
U-103 & 11.9 & $(11.4,12.4)$ & 11.8 & $(11.4,12.2)$ \\
U-105 & 23.6 & $(20.7,26.9)$ & 22.1 & $(19.9,24.9)$ \\
U-108 & 19.7 & $(18.7,20.7)$ & 19.5 & $(18.6,20.6)$ \\
\hline
\end{tabular}

The ventilation rate for actively ventilated tanks is observed to vary, even for the same tank. Estimated ventilation rates for Tank SY-103 were obtained from the observed decay of hydrogen subsequent to a gas release ${ }^{10}$. These estimates are summarized in Table 15.

For Tank AN-105, the vent flow rates of $0.4-0.8 \mathrm{cmm}$ (cubic meters per minute) matched the concentration decay rate following the August 1995 gas release, see (Stewart et al. 1996). The vaiue $0.6 \mathrm{cmm}$ was used to estimate $\tau$ for this tank. For Tank SY-101, the flow rate of $550 \mathrm{~cm}$, reported in Hopkins (1994), was used to estimate $\tau$.

Table 16 summarizes the characteristic time values, $\tau$, used in the calculations in this report.

Finally, as noted above, a possible outcome of a seismic event is the shutdown of the active ventilation systems. Accordingly, the characteristic time for a passively ventilated SST was used for the characteristic time of ventilation in DSTs subsequent to an earthquake.

\footnotetext{
${ }^{9}$ Neerchal, N. and Whitney, P. 1995 Letter Report "Measurement Responses to Gas Release Events in Tank 241-SY-103"

${ }^{10}$ ibid.
} 

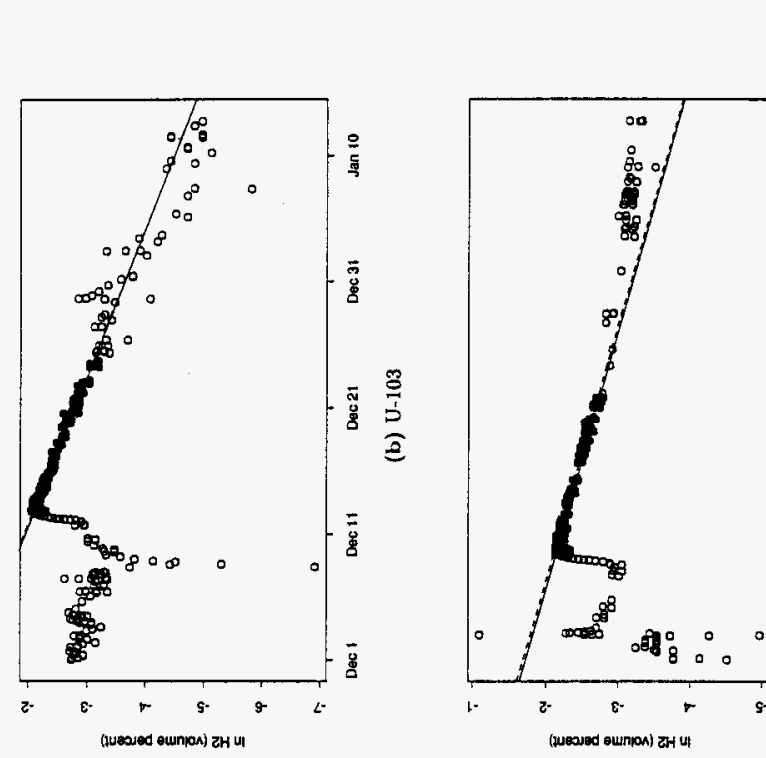

矛

况

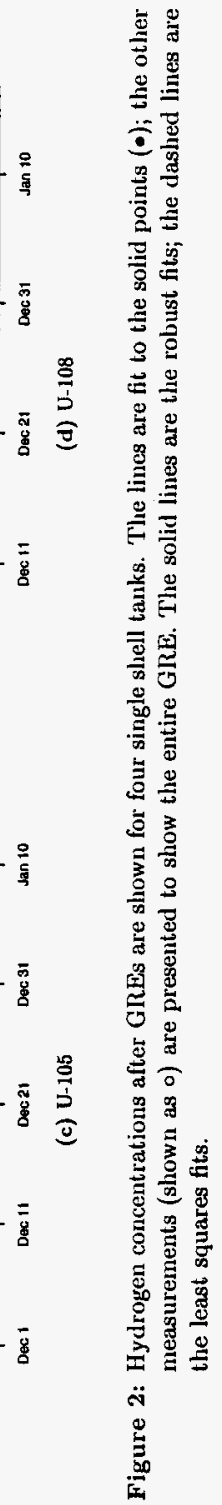


Table 15: Estimated characteristic times in Tank SY-103 headspace. A characteristic time estimate was obtained based on the decay of hydrogen concentration subsequent to the GRE.

\begin{tabular}{|l||c|}
\hline GRE Start Date & $\tau$ (days) \\
\hline $12-27-94$ & 1.6 \\
$1-22-95$ & 1.1 \\
$3-02-95$ & 1.5 \\
$5-02-95$ & 2.3 \\
\hline
\end{tabular}

Table 16: Ventilation time constants for each tank

\begin{tabular}{|r||c|c|c|c|c|c|}
\hline Tank & AN-105 & S-102 & S-103 & S-106 & SY-101 & SY-103 \\
\hline$\tau$, Characteristic Time (days) & 1.2 & 20 & 20 & 20 & .05 & 2.3 \\
\hline
\end{tabular}

\subsection{Plume Releases in SSTs}

A plume release is a rapid release of waste gas which is ignitable before it has an opportunity to thoroughly mix with the air in the headspace. In SSTs, a release volume with sufficient energy to fail the dome can be smaller than the column necessary to make the headspace flammable. Thus, such a release has a potentially greater frequency than the releases which make the headspace flammable; but the hazard from these releases is of limited duration because the characteristic mixing time is very short; on the order of 10 minutes. ${ }^{11}$ This contribution dominates the fraction of time and space flammable in Tanis $\mathrm{S}-103$ because the release fraction necessary to achieve a flammable headspace is greater than $100 \%$. The contribution itself is very small, on the order of IE-9. Table 17 summarizes the calculated contributions.

Table 17: Plume release contribution to dome failure

\begin{tabular}{|l||c|c|c|}
\hline & S-102 & S-103 & S-106 \\
\hline Eraction of time and space flammable & $2 \mathrm{E}-7$ & $1 \mathrm{E}-8$ & $3 \mathrm{E}-7$ \\
\hline
\end{tabular}

\subsection{Gas Compositions}

The composition of the gas trapped in the tank waste can be estimated for various Hanford tanks, based on the relative proportions of non-atmospheric gas species measured in grab samples from tank headspaces. Based on such estimates, lower flammability limits for the gas mixtures can be calculated. The lower flammability limit formula (from Hopkins (1994)) is:

$$
\frac{1}{\left[\mathrm{H}_{2}\right] / .04+\left[\mathrm{CH}_{4}\right] / .055+\left[\mathrm{NH}_{3}\right] / .15}
$$

\footnotetext{
${ }^{11}$ Antoniak, Z. and Recknagle, K. 1996. Letter report Modeling of Hydrogen Plume Concentrations in a Single-Shell Tonk Dome TWSFG96.6
} 


\section{WHC-SD-WM-CN-041, REN, O}

The pressure that would result from burning this gas was calculated in two steps. The first step, as described in Appendix C in LANL (1996), is to calculate the amount of hydrogen which leads to an equivalent hydrogen fuel value. The formula for this transformation is:

$$
3.32 \times\left[\mathrm{CH}_{4}\right]+1.32 \times\left[\mathrm{NH}_{3}\right]+\left[\mathrm{H}_{2}\right]
$$

Then, this amount of "equivalent hydrogen" is used as input to the hydrogen burn model, described in section 4.6, to determine the resulting pressure in the tank headspace.

Table 18 contains the the lower flammability limits of the gas in air, and the hydrogen equivalent fuel values for the flammable gas mixture. These values are taken from (Van Vleet 1996), except for Tanks SY-101 and SY-103; these two tank's values are from (Pasamehmetoglu 1995). Lower flammability limits for DST slurry gas are not tabulated; for every case calculated so far, if enough gas is present to fail the tank dome, then the mixture is flammable.

Table 18: Lower flammability limit and hydrogen equivalent fuel value

\begin{tabular}{|l||c|c|c|c|c|c|}
\hline \multicolumn{1}{|r|}{ Tank } & AN-105 & S-102 & S-103 & S-106 & SY-101 & SY-103 \\
\hline LFL in Air for Slurry Gas & - & 0.048 & 0.060 & 0.060 & - & - \\
Hydrogen Equivalent Fuel Value & 0.88 & 0.70 & 1.03 & 1.00 & 0.63 & 0.84 \\
\hline
\end{tabular}

\subsection{Combined Contributions from Intrinsic and Seismic Releases}

The values we use for the total contribution to frequency of gas release events, $f_{1}$, which would produce the consequence of concern, dome failure, are given in Table 19. Annual Frequencies range from 0 for $\mathrm{SY}-103$ to $4 \mathrm{E}-3$ for $\mathrm{AN}-105$ (representative) to $2 \mathrm{E}-1$ for $\mathrm{SY}-101$ (historical, not representative) Note that the contribution due to seismic releases is of equal magnitude or greater than the rollover (for DSTs) or hypothesized "natural" (for SSTs) releases.

Table 19: Combined estimated frequency (per year) of hazardous gas releases

\begin{tabular}{|c||c|c|c|c|c|c|}
\hline & AN-105 & SY-101 (historical) & SY-103 & S-102 & S-103 & S-104 \\
\hline$f_{1}$ & $4 \mathrm{E}-3$ & $2 \mathrm{E}-1$ & 0 & $8 \mathrm{E}-3$ & $7 \mathrm{E}-4$ & $2 \mathrm{E}-2$ \\
\hline
\end{tabular}

Seismic events in general are likely to be common-cause ignition mechanisms, however this ignition is not guaranteed. Therefore seismic events ignited by uncorrelated sparks are still an important scenario to consider.

Also note that seismic events are likely to produce flammable gas releases in many tanks simultaneously, and therefore represent a greater hazard when consider on a multi-tank basis because of the potential for a single ignition event leading to failure of more than one tank structure.

The estimates produced here are considered conservative. Modeling of the effects of large seismic events has been based on fairly simple models that do not capture some expected ameliorating effects, such as the actual attenuation of the vibrations in the soil surrounding the tanks. 


\section{Potential for Improving the Results}

An additional level of effort would be required to quantify the uncertainties in the bounds; we strongly recommend this effort. The important benefits of this effort would be 1) an understanding of how good the estimates are and 2) a ranking of the importance of refining the various inputs to the estimates.

The remainder of this section lists phenomena which may affect the estimates, and have not yet been accounted for.

Background flammability of tank headspace We are ignoring whatever steady state of $\mathrm{H}_{2}$ concentration may be present in the tank headspace. Ignoring the steady state gas is consistent with the available data: most grab sample measurements to date support this hypothesis.

Liquid intrusions Tank operations and rainwater/snowmelt can contribute to the waste level in Hanford tanks; if this phenomenon exists and is not accounted for, then the gas retention rate estimates in this report are high, and the hazard is overstated.

Evaporation Liquid leaving the tank would result in artificially low gas retention rate estimates.

No nitrogen in gas No nitrogen component was assumed for the slurry gas; a consequence of this is that the gas is estimated as a richer mixture than actual, and so we're overestimating the hazard associated with the gas retention rate.

Complete burn of combustible gas We're assuming a complete burn of the released gas to calculate the pressure in response to the burn. As the burn is not expected to be complete; this assumption overstates the hazard.

Pressure increase due to gas release The temporary pressure increase resulting from a gas release is ignored; this effect is expected to be small.

Anticipated decrease in gas generation rate As the waste in the Hanford tanks ages, it cools and many of the contributors to gas generation are used up. This decrease in generation rate is ignored; and so the hazard is overstated.

Dissolved ammonia releases The actual release of ammonia from dissolved gas is expected to be nonlinearly dependent on the volume of release from undissolved gas, and the quantity will not be identical for rollover and seismic releases. Further, the time profile of ammonia release is different than the profile of bubble release, thus the ammonia fraction in the release gas varies with time. These effects could significantly affect. burn energy estimates but are not expected to significantly affect flammability estimates. Therefore, more detailed modeling of the release of dissolved ammonia could be valuable for the DST calculations. Dissolved ammonia release could be included in SSTs and better estimates for ammonia release could be incorporated in DST modeis. 


\section{References}

Brewster, M., Gallagher, N. B., Hudson, J. D. \& Stewart, C. W. (1995), The Behavior, Quantity and Location of Undissolved Gas in Tank 241-SY-101, Technical Report PNL-10681, Pacific Northwest Laboratory, Richland, Washington.

Brown, R. G. (1996), Compilation of Hydrogen Data for 22 Single Shell Flammable Gas Watch List Tanks, Technical Report WHC-SD-WM-ER-576, Westinghouse Hanford Company, Richland, Washington.

Hanlon, B. (1995), Waste Tank Summary Report for Month Ending April 30, 1995, Technical Report WHC-EP-0182-85, Westinghouse Hanford Company, Richland, Washington.

Hanlon, B. (1996), Waste Tank Summary for Month Ending October 31, 1995, Technical Report WHC-EP-0182-91, Westinghouse Hanford Company, Richland, Washington.

Van Vleet, R. (1996), Summary of Flammable Gas Hazards and Potential Consequences in Tank Waste Remediation system Facilities at the Hanford Site, Technical Report WHC-SD-WMTI-753, Westinghouse Hanford Company, Richland, Washington.

Hodgson, K., Anantamula, R., Barker, S., K.D.Fowler, Hopkins, J., Lecheit, J. \& Reynolds, D. (1995), Evaluation of Hanford Tanks for Trapped Gas, Technical Report WHC-SD-WM-ER526, Rev. 0, Westinghouse Hanford Company, Richland, Washington.

Hopkins, J. (1994), Proposed Criteria for Flammable Gas Watch List Tanks, Technical Report WHC-EP-0702 Rev. 0, Westinghouse Hanford Company, Richland, Washington.

Johnson, N., Kotz, S. \& Balakrishnan, N. (1994), Continuous Univariate Distributions, 2nd edn, John Wiley \& Sons, New York.

Julyk, L. (1995), Static Internal Pressure Capacity of Hanford Singe-Shell Waste Tanks, Technical Report WHC-SD-WM-TI-623, Westinghouse Hanford Company.

Keeney, R. \& Winterfeldt, D. V. (1991), 'Eliciting Probabilities from Experts in Complex Technical Problems', IEEE Transactions on Engineering Management 38, 191-201.

LANL (1996), A Safety Assessment of Rotary Mode Core Sampling in Flammable Gas Single Shell Tanks: Hanford Site, Technical Report WHC-SD-WM-SAD-035 Rev. 0, Westinghouse Hanford Company, Richland, Washington.

NRC (1989), Severe Accident Risks: An Assessment of Five U.S. Nuclear Power Plants, Technical Report NUREG-1150, Nuclear Regulatory Commission, Washington, DC.

Pasamehmetoglu, K. (1995), Maximum Allowable Gas Release Estimate for Tank 103-SY, Technical report, Los Alamos National Laboratory.

Shepard, C., Stewart, C., Alzheimer, J., Terrones, G., Chen, G. \& Wilkins, N. (1995), In Situ Determination of Rheological Properties and Void Fraction: Hanford Waste Tank 241-SY-103, Technical Report PNL-10865, Pacific Northwest Laboratory.

Stewart, C., Alzheimer, J., Shepard, C., Terrones, G., Chen, G. \& Wilkins, N. (1996), In Situ Determination of Rheological Properties and Void Fraction: Hanford Waste Tank 241-AN-105, CW Stewart, Technical Report Letter Report PNNLMIT:021696, Pacific Northwest National Laboratory. 
Stewart, C., Shepard, C., Alzheimer, J., Stokes, T. \& Terrones, G. (1995), In Situ Determination of Rheological Properties and Void Fraction in Hanford Waste Tank 241-SY-101, Technical Report PNL-10682, Pacific Northwest Laboratory, Richland, Washington.

Sullivan, H. (1995), A Safety Assessment for Proposed Pump Mixing Operations to Migitage Episodic Gas Releases in Tank 241-SY-101, Technical Report LA-UR-92-3196, Los Alamos National Laboratory.

Tingey, J., Bredt, P. \& Shade, E. (1994), The Effects of Heating and Dilution On the Rheological and Physical Properties of Tank 241-SY-101 Waste, Technical Report PNL-10198, Pacific Northwest Laboratory, Richland, Washington.

Wesnousky, S. G. (1994), 'The Gutenberg-Richter or Characteristic Earthquake Distribution, Which Is It?', Bulletin of the Seismological Society of America 84(6), 1940-1959.

Whitney, P. (1995), Screening the Hanford Tanks for Trapped Gas, Technical Report PNL-10821, Pacific Northwest Laboratory, Richland, Washington. 


\section{A Observed Rates of Level Change}

Various options were considered and calculated to obtain the rates of level increase for the tanks in this study. The initial issue considered was: what should be the "target" of the estimate? We considered the following options:

- The recent rate of level increase

For instance, base the estimate on the last 6-12 months of level data

- The maximum observed rate of level increase for the level data

For instance, search the level data since 1981 for the largest consistent rate of level increase

- The average of the observed rates of level increase for the level data

A difficulty with the first option is that there are instances where a tank's rate of level increase is Hat, or nearly flat, over large time spans; and subsequently the rate of increase resumes at a larger value. Figure 3 shows that the waste level of Tank S-107 rose relatively rapidly from 1981 to 1985; the level was almost flat for a year beginning in mid-1988. Subsequently, the rate of level rise increased, and is currently at a value similar to the value in 1982 (i.e., the rate of increase in level, not the level). Tank AN-105 waste levels are shown in Figure 4; the tanis appears to have had a cycle of level rises and rapid gas releases in 1986 and 1987. The level rise during 1988 was followed by about two years during which the tank did not appear to undergo any rapid releases. Subsequently, in 1991 the pattern of level rises followed by rapid level falls resumed (interpreted as increasing amounts of gas trapped in the tank waste, followed by rapid releases).

A difficulty with the second option is that the largest observed rate of increase for SSTs typically occurs during the first year or so of tank waste level measurements. The rate of gas generation might be expected to decrease as the tanks age, due to cooling of the waste and to gradual exhaustion of the "fuel" for gas creation. Note that the cooling may improve the gas retention properties of the tank waste; see (Tingey et al. 1994).

Finally, an advantage of the third option is that it points more directly to the average retention rate $\bar{R}_{R}$ in Equation (15) in Appendix B. However, there is no assurance that the time span for which we have tank data is adequate to provide an accurate estimate of gas retention in the tank waste. Also note that, for tanks whose tank waste level appears to have become more or less constant, the average rate of level increase will be much smaller than the maximum rate of increase observed during the early part of the tank level history.

Considering these factors, we investigated the following four parameters to estimate the average rate of waste level increase:

- The median of the slopes obtained from linear least squares fits to stretches of well-conditioned data.

- The median of the slopes obtained by calculating the change in level vs. the change in time at the extreme time ranges of stretches of well-conditioned data

- The median of the first derivatives of a smoothing spline fit to waste level data

- The median of the positive first derivatives of a smoothing spline fit to waste level data

The stretches of well-conditioned data appearing in the first two options were those obtained by the break detection scheme used in (Whitney 1995); it turned out that the break detection scheme 


\section{S107 Surface Level Measurements from 1-5-81 to 4-2-96}

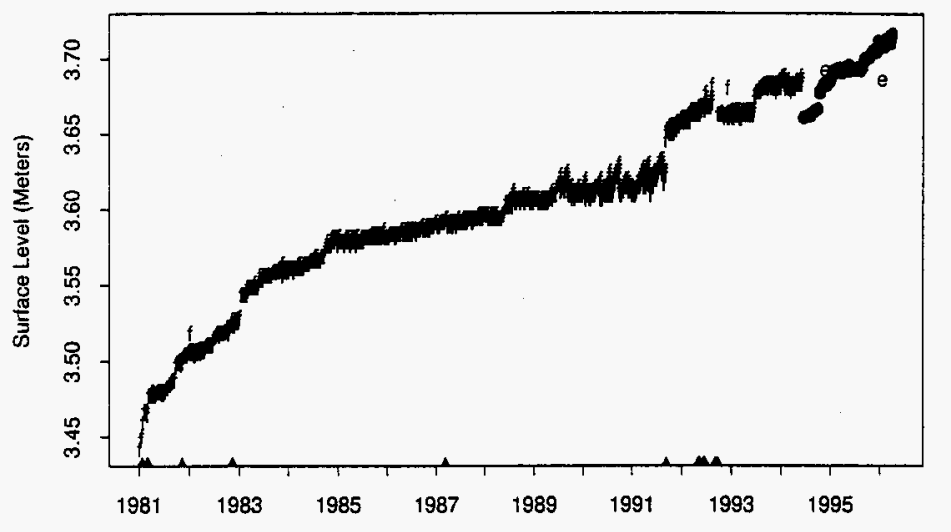

PNL Thw Apr 11 09:33:43 POT 1896

Figure 3: Tank S-107 waste level measurements

was not adequate to detect all the changes in rates which appear throughout the tank level data. For this reason, the first two options were rejected.

The third option gives equal weight to a week in which the waste level falls (perhaps due to gas release, temperature changes, or instrumentation) and to a week in which the waste level rises. Since our interest is in the retention rate, we used the fourth option. Finally, note that the median was selected (rather than the average) so that the occasional anomalous data point or level change would not influence the estimate.

The estimates obtained are shown in Figures 8 through 15. These plots show the raw data on which the average rate of level rise was based; the diagonal lines drawn across these figures show the estimated rate of level rise. Thus, a "visual" check of the estimated rates is to see to what extent the rising portions of the level data are parallel to the diagonal lines. The actual rate of level rise values used in the calculations are shown at the bottom of each figure. Finally, note that calculations were done for two different years for Tanks SY-101 and SY-103; the most recent data was used from each of these calculations.

Note that Tank A-101 is an unusual case. The current trend in the waste levels obtained by Enraf measurements in this tank (see Figure 5) is downward, as is the broad trend shown in the manual tape measurements (see Figure 6). However, the early data record shows a tendency for the level to rise (see Figure 7). If one averages this early rate of increase (0.18 meters per year) together with a zero rate of level increase for the subsequent times, a rate of 0.017 meters per year is obtained:

$$
\frac{(0.18) 1.5}{16}+\frac{0(14.5)}{16}=0.017
$$


AN105 Surface Level Measurements from 1-6-86 to 4-3-96

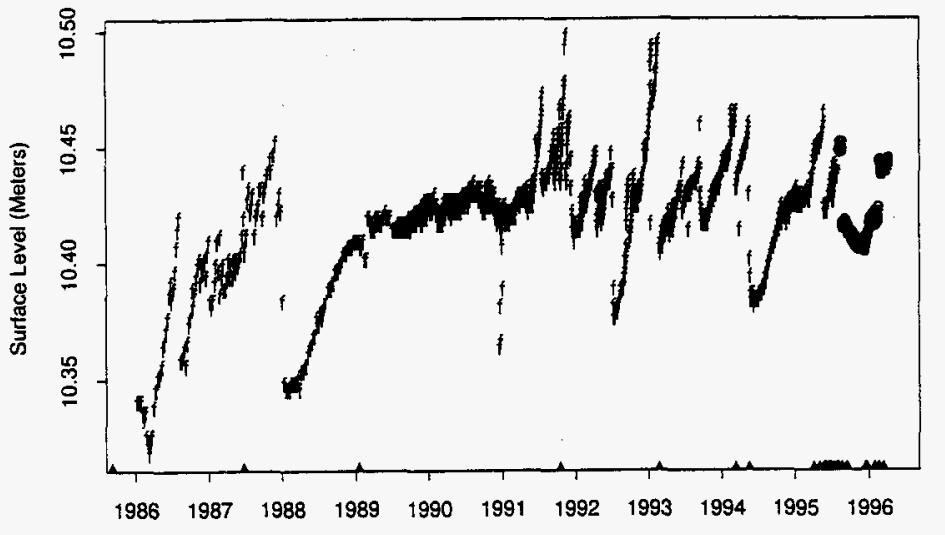

PNL ThL Apr 11 09:33:52 POT 1996

Figure 4: Tank AN-105 waste level measurements

A possible explanation for the historically decreasing trend is evaporation; the waste temperature is $60^{\circ} \mathrm{C}$, well above ambient. Another explanation is a slow leak. Since we are not quantitatively considering evaporation or leakage, and since one of these factors may dominate the calculation, we cannot do a reasonable calculation for Tank A-101. 
$\angle I I$ to $20 \mathrm{I}$

$2 z$

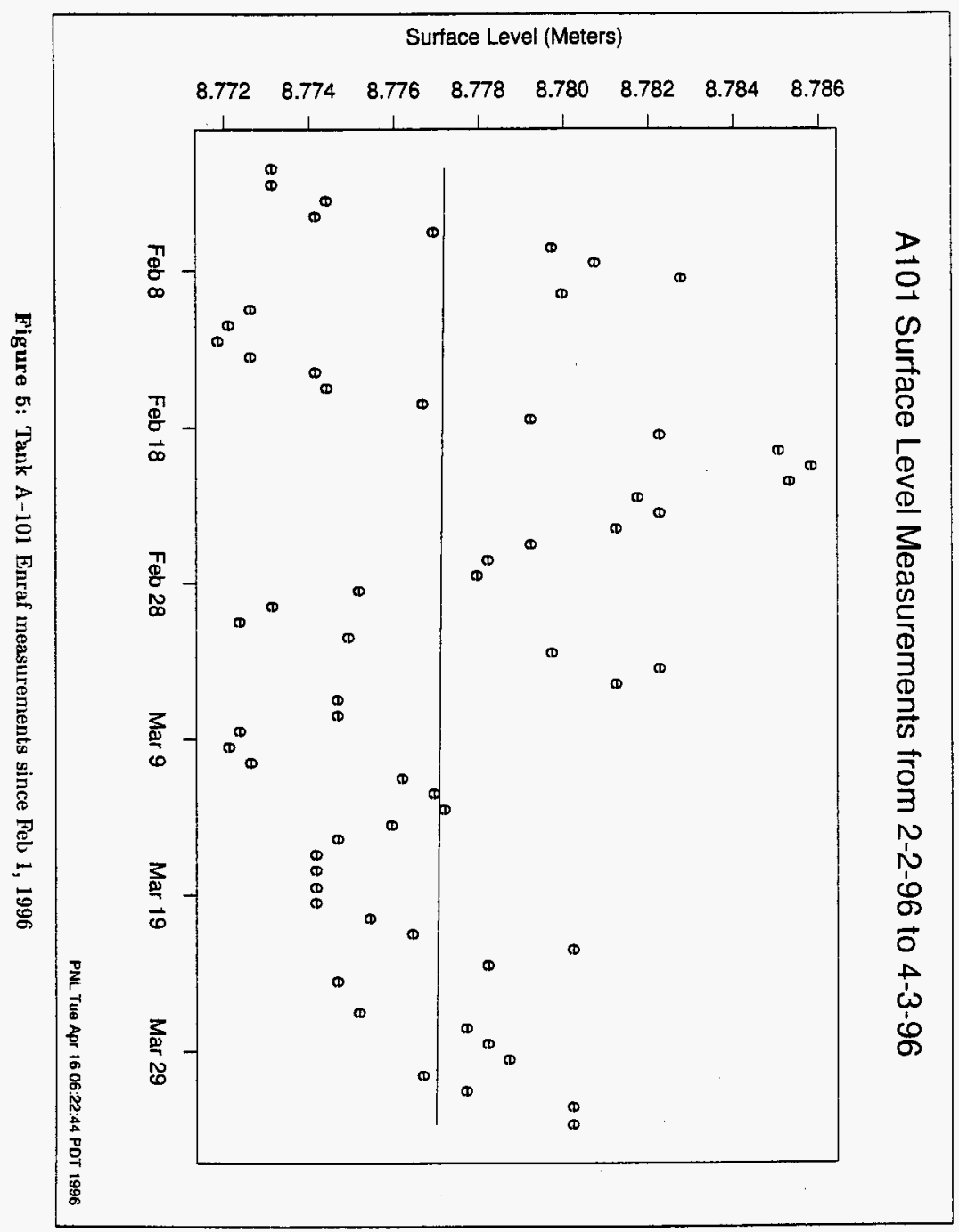


WHC-SD-WM-CN-041, REN. O

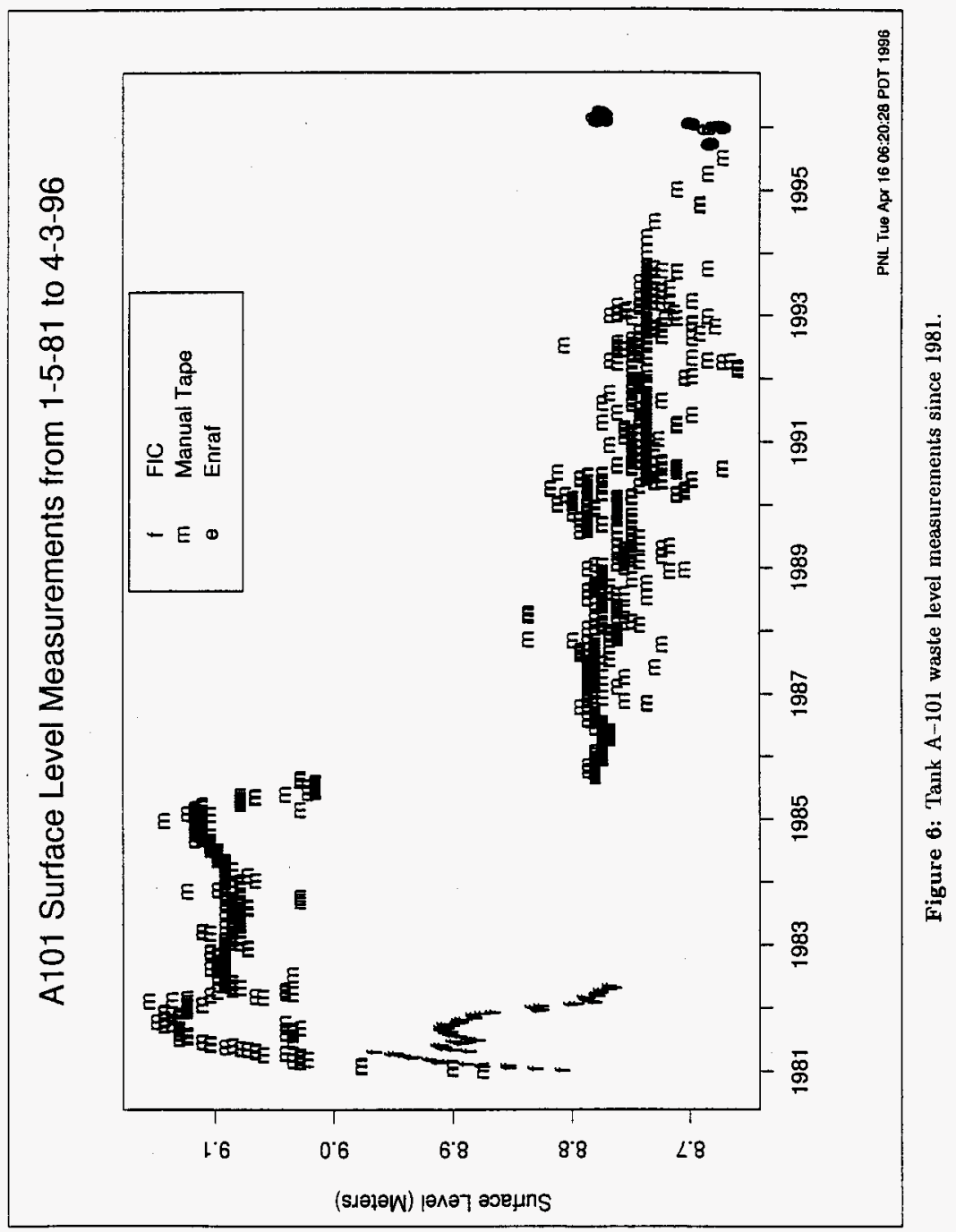




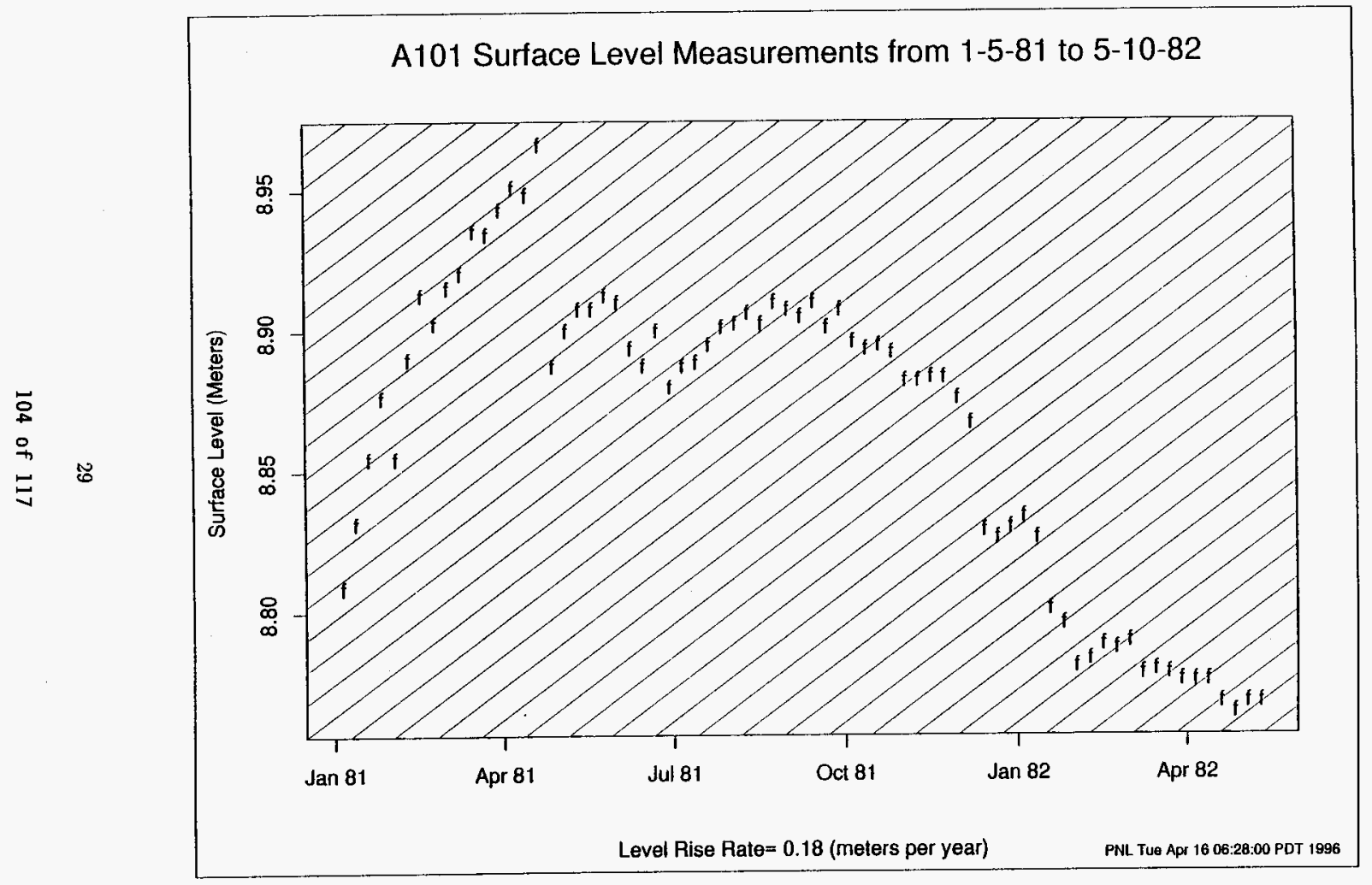

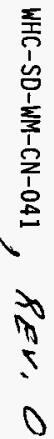

Figure 7: Tank A-101 waste level measurements and average rate of level rise for 1981 FIC measurements 


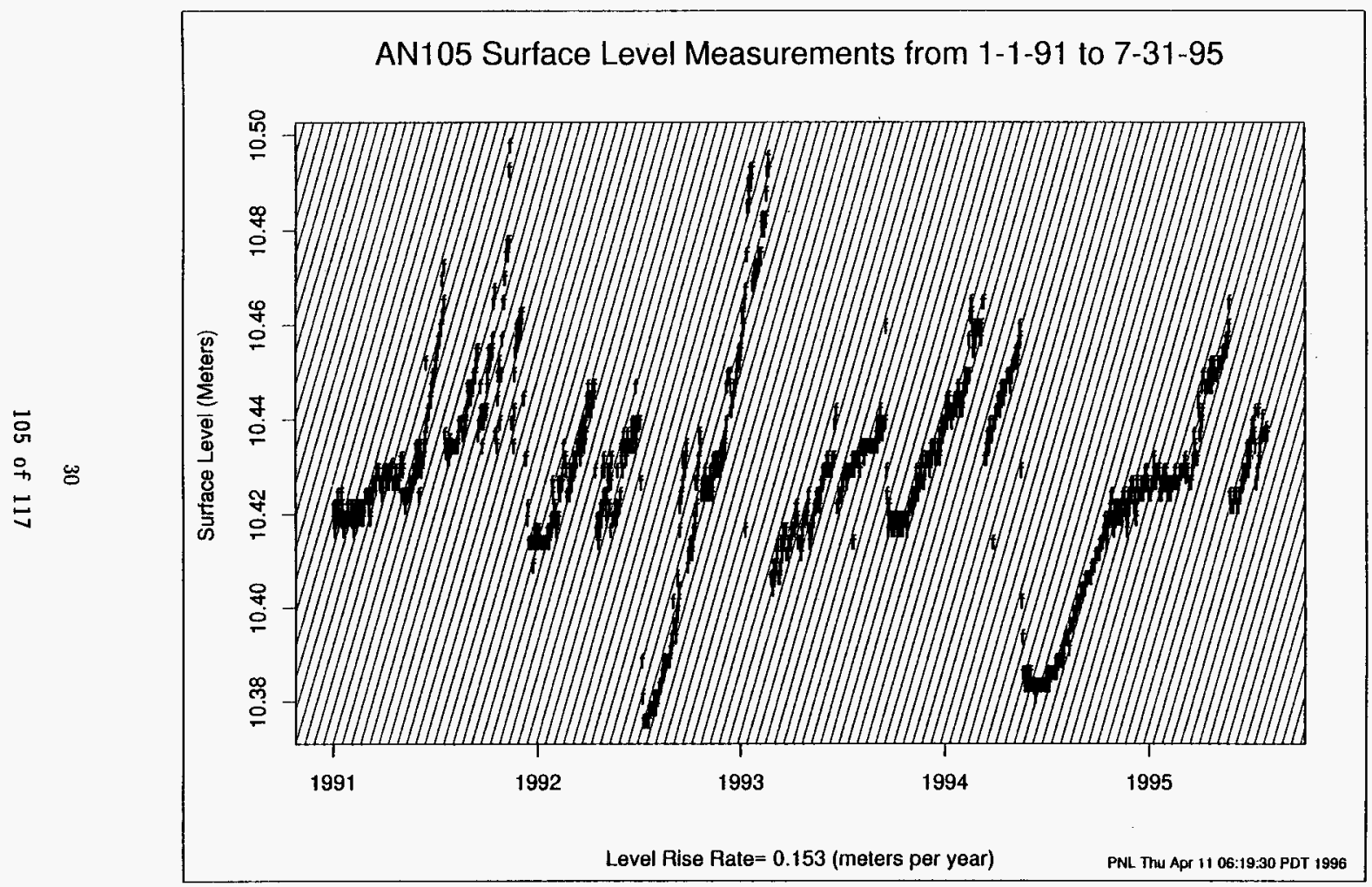

Figure 8: Tank AN-105 waste level measurements and average rate of level rise. 
WHC-SD-WM-CN-041, REV, O

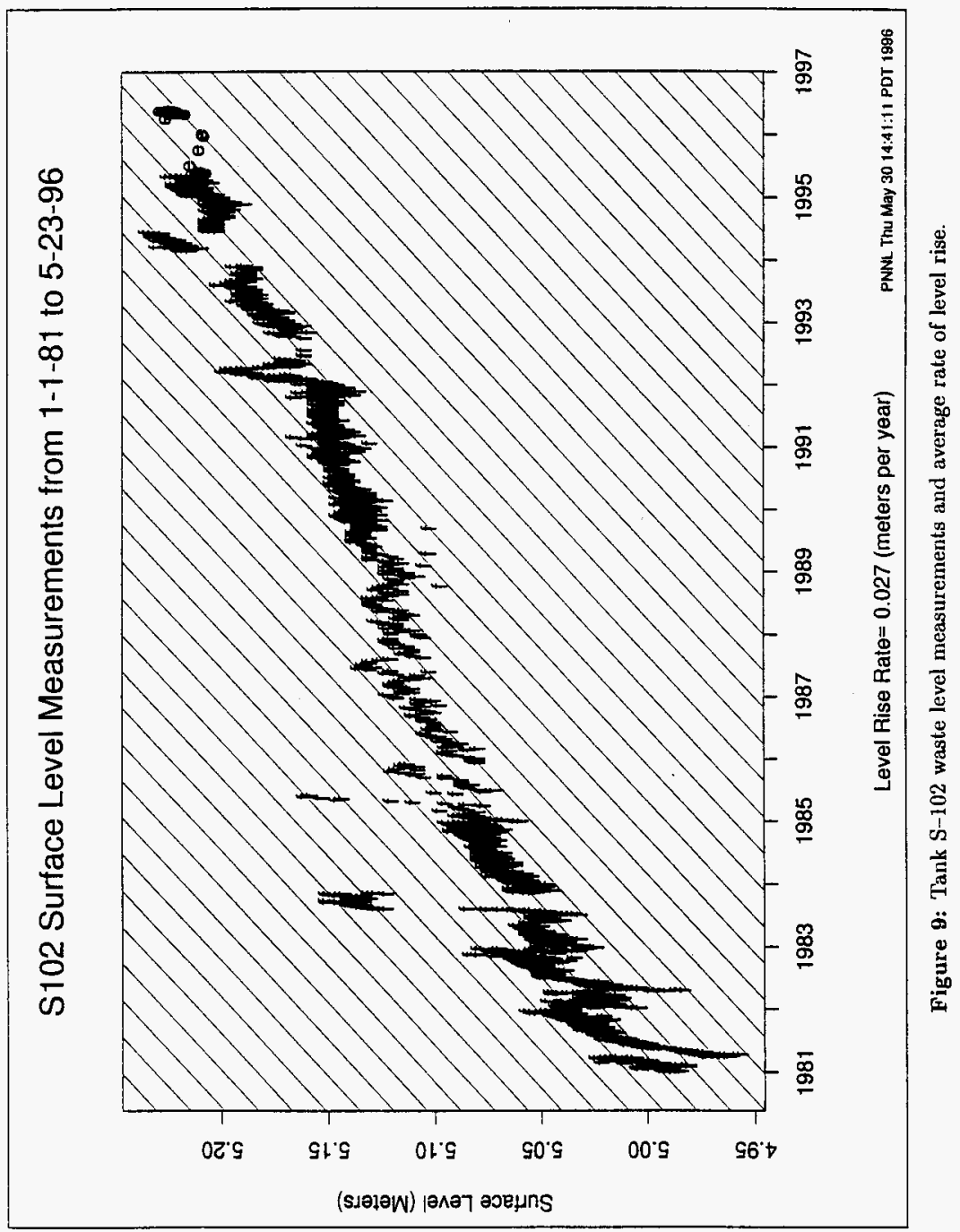




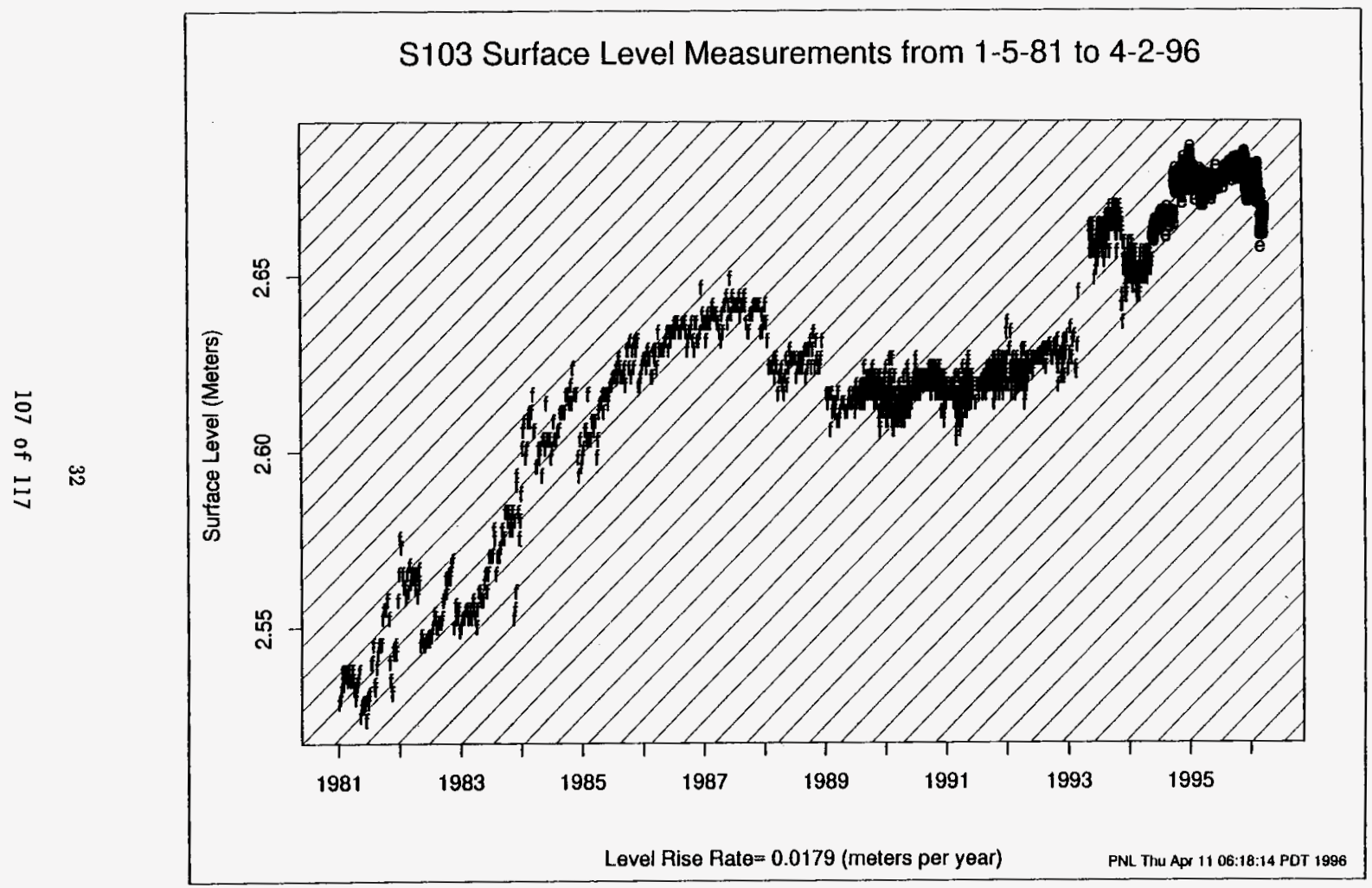

Figure 10: Tank S-103 waste level measurements and average rate of level rise. 


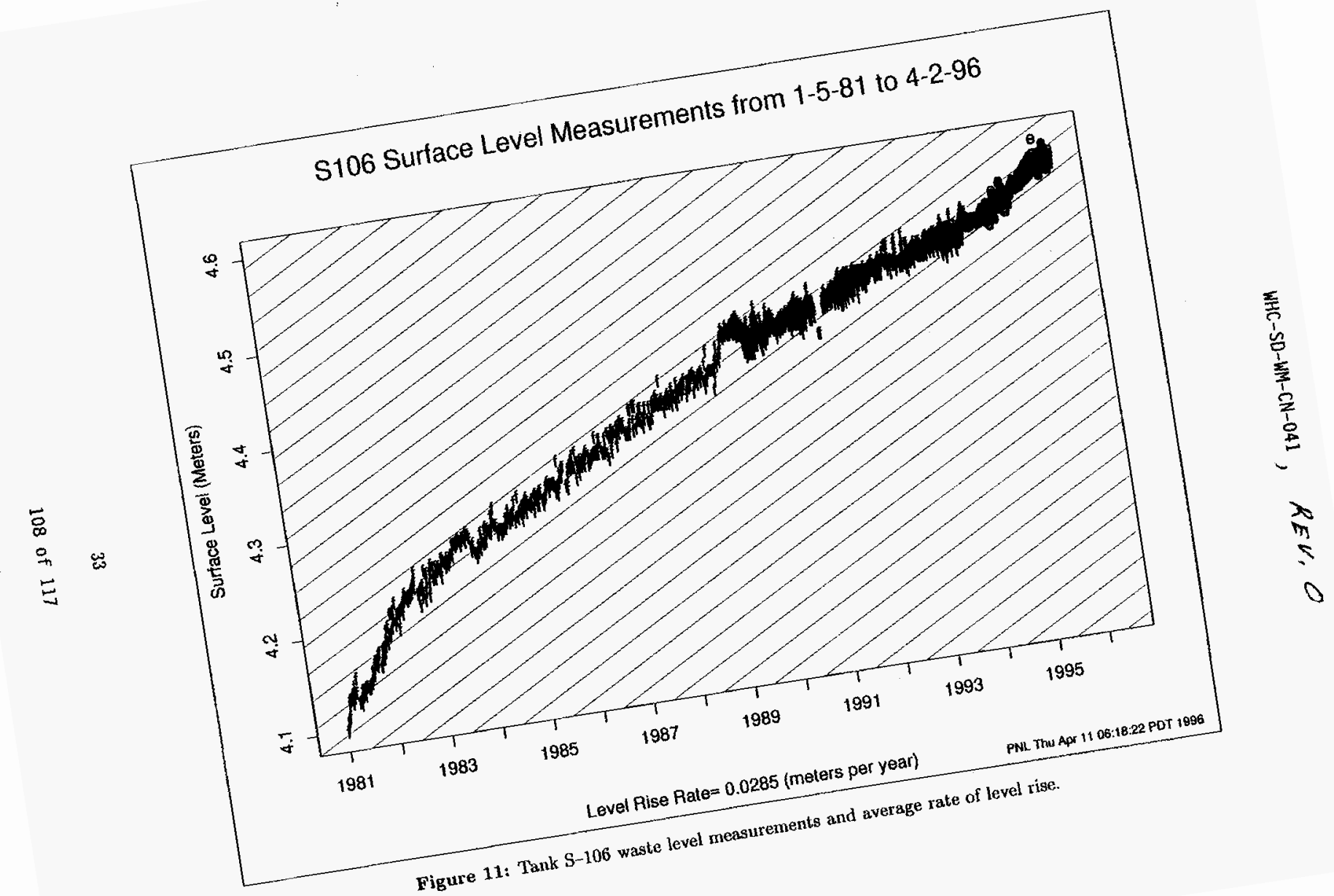




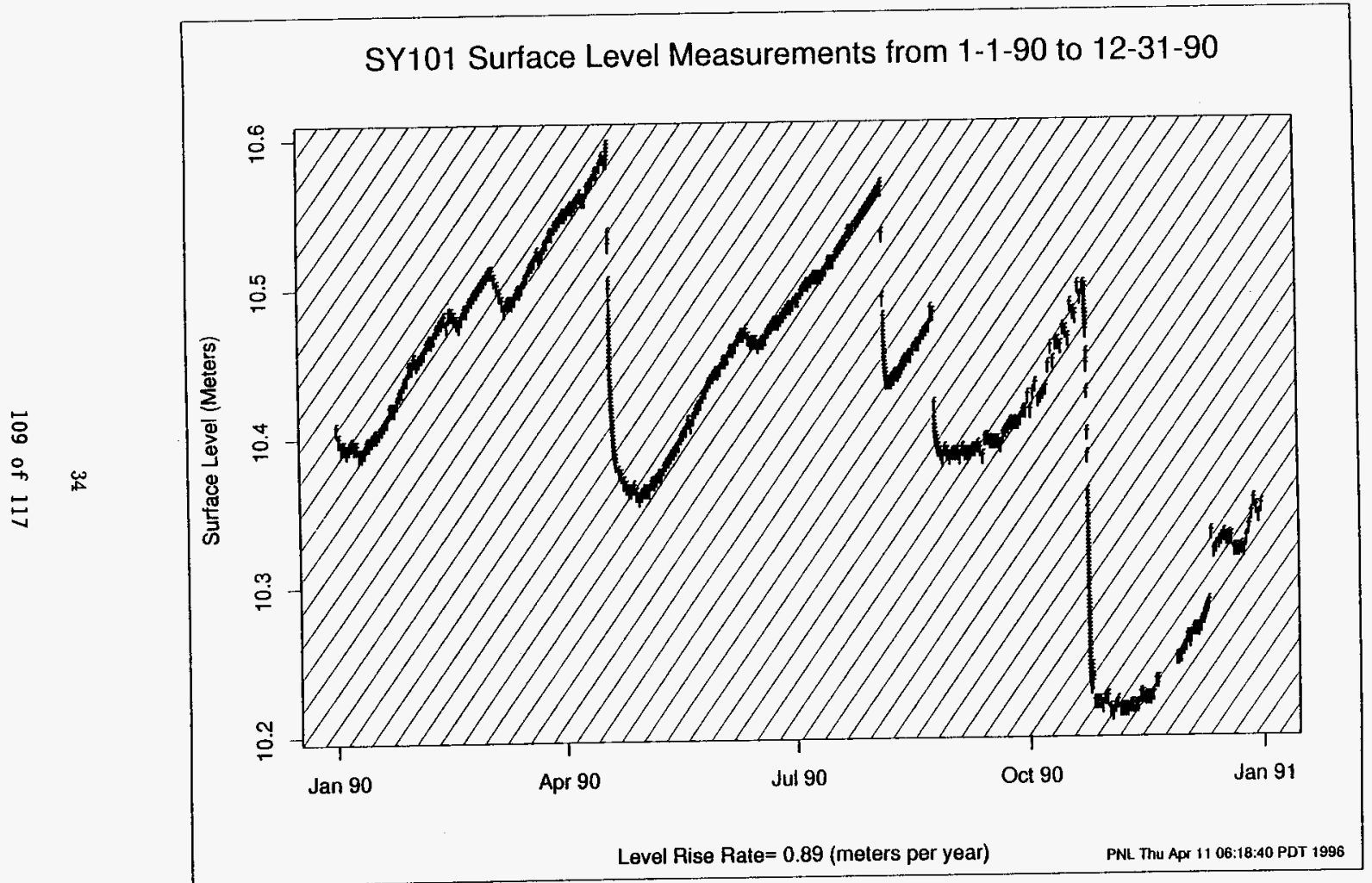

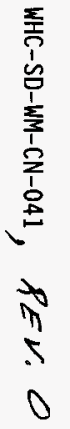

Figure 12: Tank SY-101 waste level measurements and average rate of level rise for 1990 
WHC-SD-WM-CN-041, REV.O

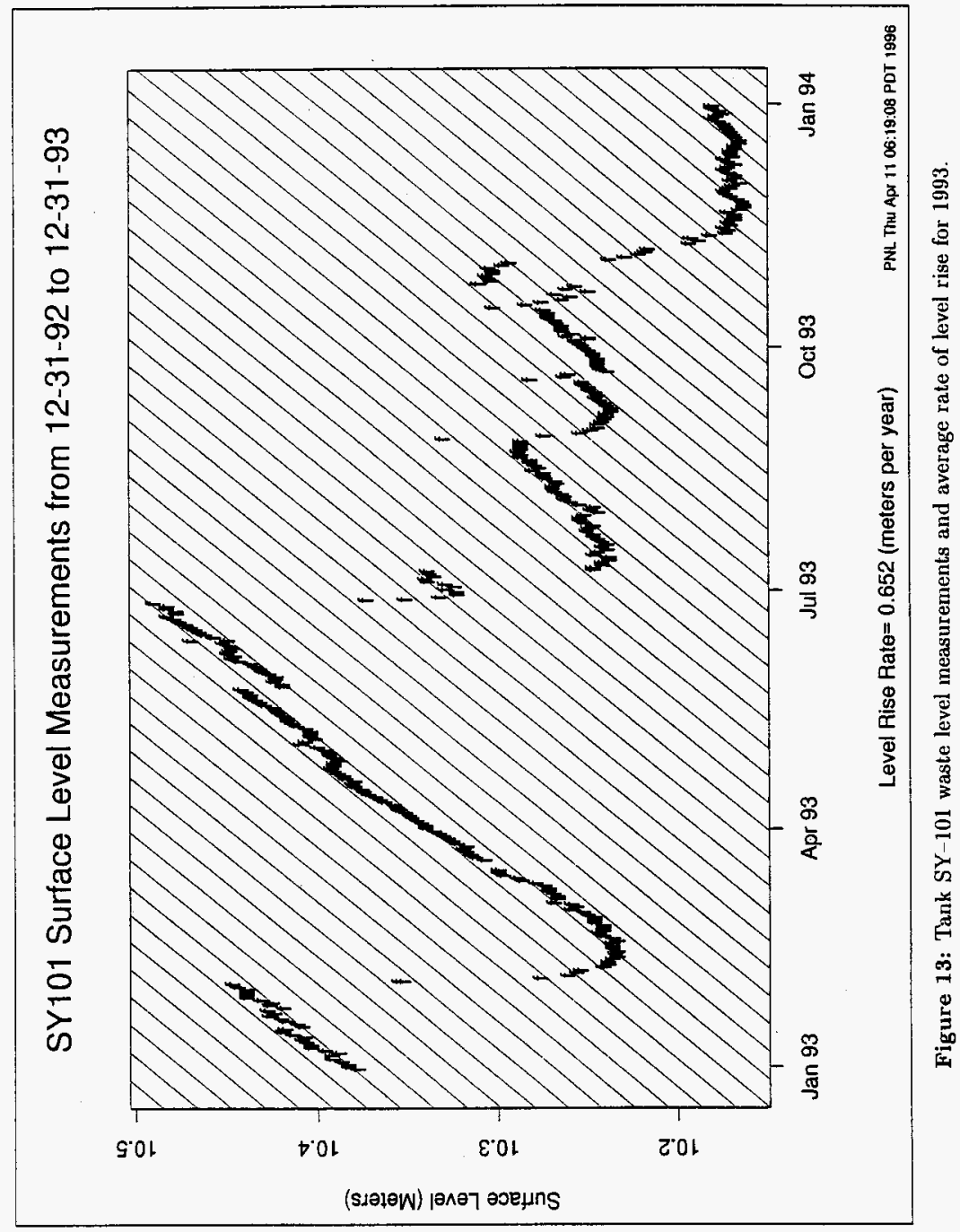




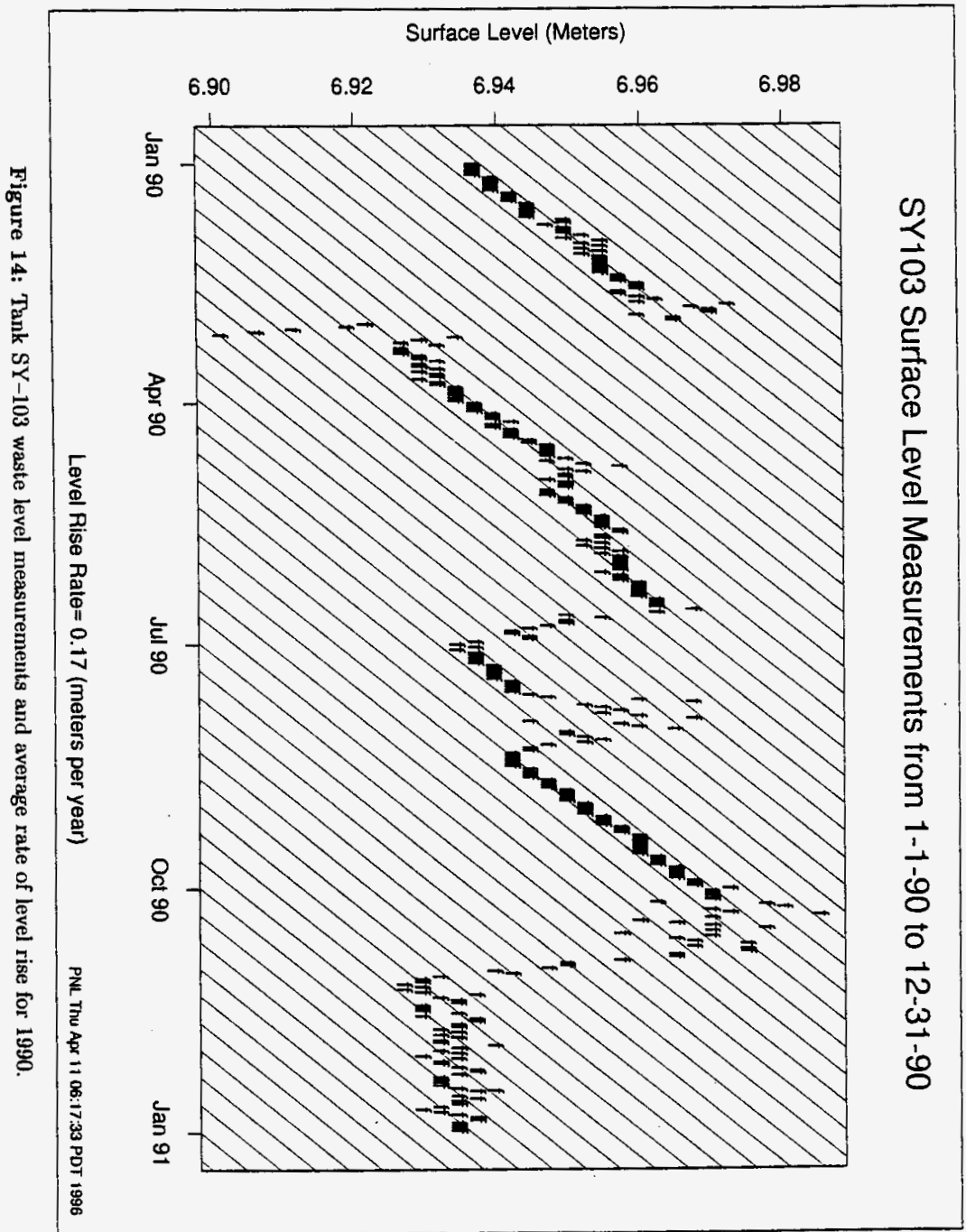




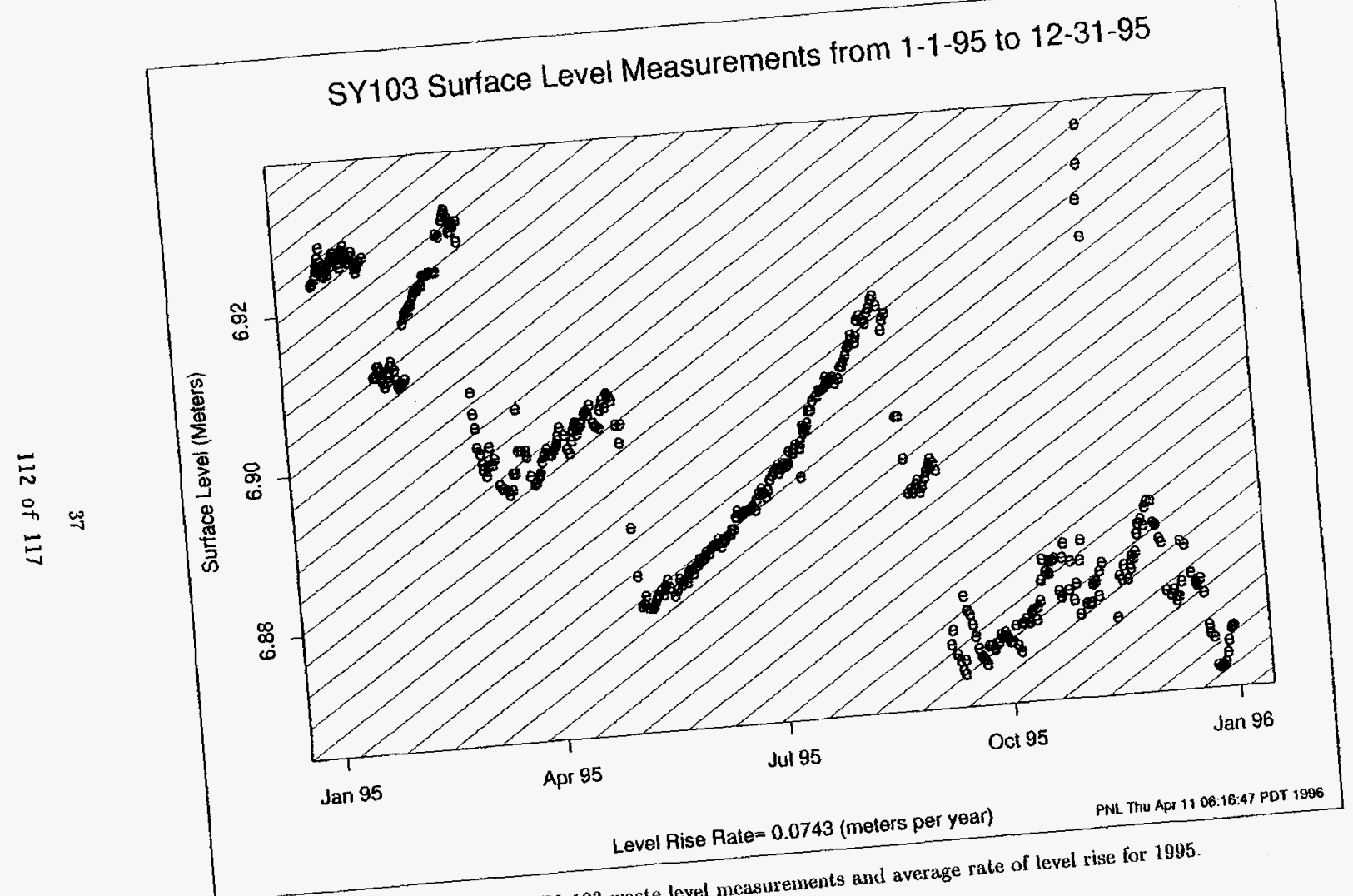

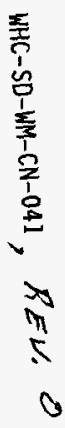

SY-103 waste level measurements and average rate of level rise for 1995. 


\section{B Using Gas Retention Rate to Bound Gas Release Hazard}

This appendix describes how one could obtain "worst case" bounds on the following quantities:

1. the fraction of time that a Hanford waste tank headspace is in a hazardous state; and

2. the frequency of large gas release events (GREs) that result in a hazardous state.

The methods described in this section are not the methods used in the report; however, some of the model developments in this appendix are used in Section 4.4.

Bounds are obtained by first using "best estimate" data, and then varying the volume of gas released per GRE to determine the worst case bound. Note that the amount of gas release corresponding to the worst case for the proportion of time that the tank headspace is hazardous is not the same as the amount of gas release corresponding to the worst case for the frequency of hazardous gas releases.

The bounding estimate of the proportion of time that the tank headspace is hazardous is derived in Section B.1. The bounding estimate of the frequency of hazardous gas releases is derived in Section B.2.

\section{B.1 Estimating the Proportion of Time the Tank Headspace is Hazardous}

Many of the Hanford waste tanks which are of potential concern for flammable gas show a waste level rise over time. It's hypothesized that this level rise is due to an increasing amount of retained gas. This section presents a mathematical argument which shows how an estimated gas retention rate, a tank headspace ventilation rate, and a "threshold" headspace concentration can be used to bound the long-run proportion of time the headspace is in a hazardous condition; i.e. that the headspace concentration is above the threshold.

The gas involved in any episodic release must first have been generated and stored for a time. We express the law of conservation of mass as

$$
\sum V_{R}=\bar{R}_{R} T-\Delta V_{\text {ret }}
$$

The terms in this equation are as follows:

$\bar{R}_{R} \quad$ The average retention rate - the gas retention rate is bounded by the gas generation rate, but is reduced by some amount of continuous release. While the (time varying) retention rate may be of independent interest, the average retention rate is the quantity that appears in this formula.

$T$ The selected time interval $T$. In this section, $T$ is a mathematical quantity which, in the limit, gets quite large. In practice, we need to have observed the tank waste level long enough to get a good estimate of the average retention rate (however, $T$ is not the number of years we have observed the tank).

$\sum V_{R}$ Total gas volume (at STP) released as GREs in time interval $T$.

$\Delta V_{\text {ret }}$ Difference in retained volume (at STP) from start to end of time interval $T$. This term accounts for the net storage of gas in the tank waste. 
This equation holds exactly, regardless of the sizes, frequencies and mechanisms of gas release events (GREs). However, it does ignore the effect of some of the gas going into solution in the waste (we assume a negligible amount).

Suppose episodic release sizes are constant and denoted by $V_{R}$. Also suppose that $\Delta V_{\text {ret }} / V_{R}$ is small compared to the time span $T$; then we can neglect net storage, and the equation above becomes

$$
N V_{R}=\bar{R}_{R} T
$$

where $N$ is the number of releases that occur in the time interval $T$. Then the frequency of release, in the long-term, is

$$
f=\frac{N}{T}=\frac{\bar{R}_{R}}{V_{R}}
$$

Figure 16 is a graphical representation of the information in Equations (16) and (17), where the retention rate is constant.

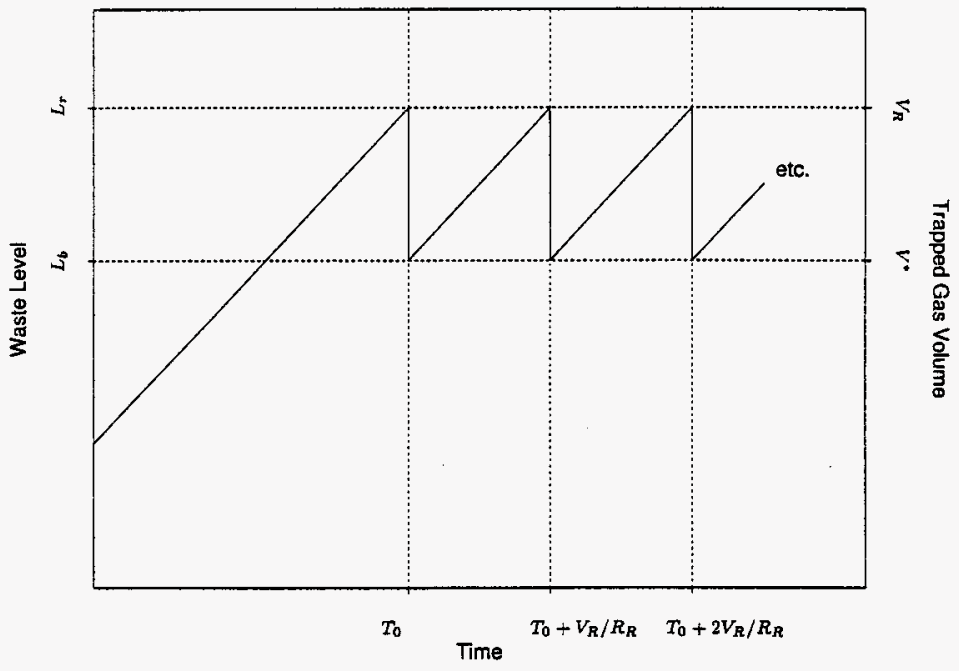

Figure 16: Amount of gas in tank waste as a function of time

Our model postulates that once the gas has been released from the waste into the tank headspace, it is mixed with the existing headspace gas and eventually, through passive or active ventilation, is removed from the headspace. The concentration of $H_{2}$ in a well-mixed headspace follows the standard exponential decay model:

$$
\left[H_{2}\right]=\frac{V_{R}}{V_{H S}} \exp \{-t / \tau\}
$$


where $V_{H S}$ is the volume of the tank headspace, $V_{R}$ is the volume of $H_{2}$ released into the headspace, and $\tau$ is the characteristic time of the ventilation rate of the tank headspace (the time it takes to clear out a volume equal to the tank headspace). Figure 17 shows how the decay of an initial concentration of hydrogen occurs under the model in Equation (18). Note that if a release $V_{R}$ occurs which is larger than a threshold volume $V^{*}$ which would make the headspace hazardous, then the time $T_{H}$ for which the amount of gas in the headspace is greater than $V^{*}$ is

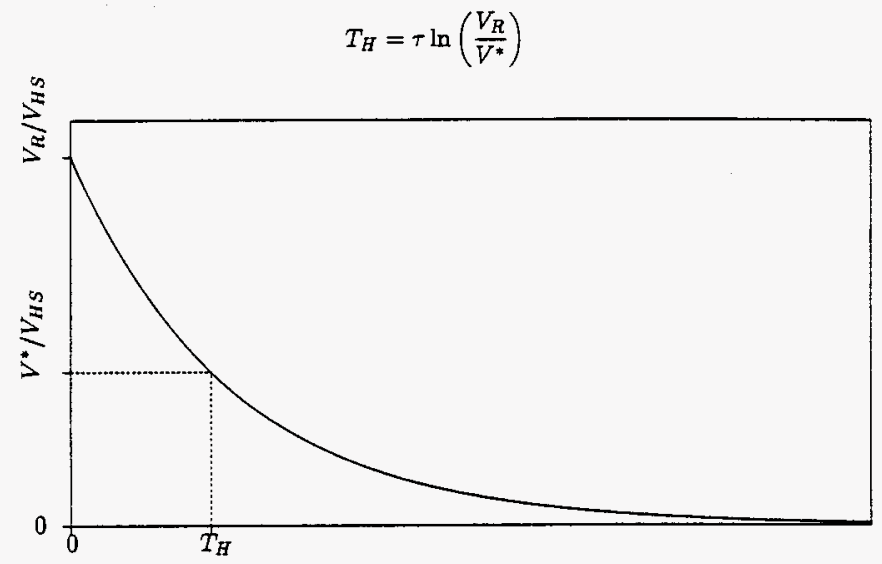

Figure 17: Theoretical decay curve for hydrogen concentration in tank headspace. $V_{R}$ is the hydrogen volume of the original release, $V_{H S}$ is the tank headspace volume, $V^{*}$ is the threshold amount of hydrogen (see text), and $T_{H}$ is the time interval during which the tank headspace concentration is above the threshold $V^{*} / V_{H S}$.

Equations (17) and (19) can be combined to estimate the proportion of time the tank headspace is in a hazardous condition, assuming releases of equal size as shown in Figure 16; the proportion is

$$
T_{H} f=\tau \frac{R_{R}}{V_{R}} \ln \left(\frac{V_{R}}{V^{*}}\right)
$$

The proportion of time calculated in the above equation varies as a function of $V_{R}$; and the largest proportion of time the tank headspace is in a hazardous condition occurs when the release size is

$$
V_{R}=\mathrm{eV}^{*}
$$

where $e \approx 2.71828 \ldots$. The corresponding proportion of time the tank headspace is in a hazardous condition is

$$
\lambda=\frac{\tau R_{R}}{\mathrm{eV}}
$$


Thus, to bound the proportion of time the tank headspace is in a hazardous condition, we need estimates of $\tau, R_{R}$ and $V^{*}$. Note that this calculation ignores the time required for the tank headspace to become well mixed. Computer simulation experiments have shown that the tank headspace for an unventilated tank becomes well mixed within 10 minutes $^{12}$; this factor is ignored in these calculations.

Figure 18 illustrates the process used to obtain the bound on the proportion of time the tank headspace is hazardous. Figure 18(a) shows how the frequency of release varies with the release size: the larger the release, the less often it occurs. Figure 18(b) shows how the duration of a hazardous headspace condition subsequent to a single release varies with the size of the release; the larger the release, the longer it takes for ventilation to clear out the headspace. Finally, Figure 18(c) shows the product of the quantities in the previous two subfigures, which is the proportion of time during which the tank headspace is hazardous. This product is seen to have a global maximum. The value $V_{R}$ at which this maximum is obtained is as in Equation (21), and the resulting bound on the proportion of time is given in Equation (22)

\section{B.2 Estimating the Frequency of Hazardous Gas Releases}

The maximum frequency of hazardous gas release events is obtained by letting $V_{R}=V^{*}$. The time until the next hazardous release is then determined by the retention rate. Thus, the maximum frequency, $f_{\max }$, is

$$
f_{\max }=\frac{R_{R}}{V^{*}}
$$

\footnotetext{
${ }^{12}$ Antoniak, Z. and Recknagle, K. 1996. Letter report Modeling of Hydrogen Plume Concentrations in a Single-Shell Tank Dome.
} 


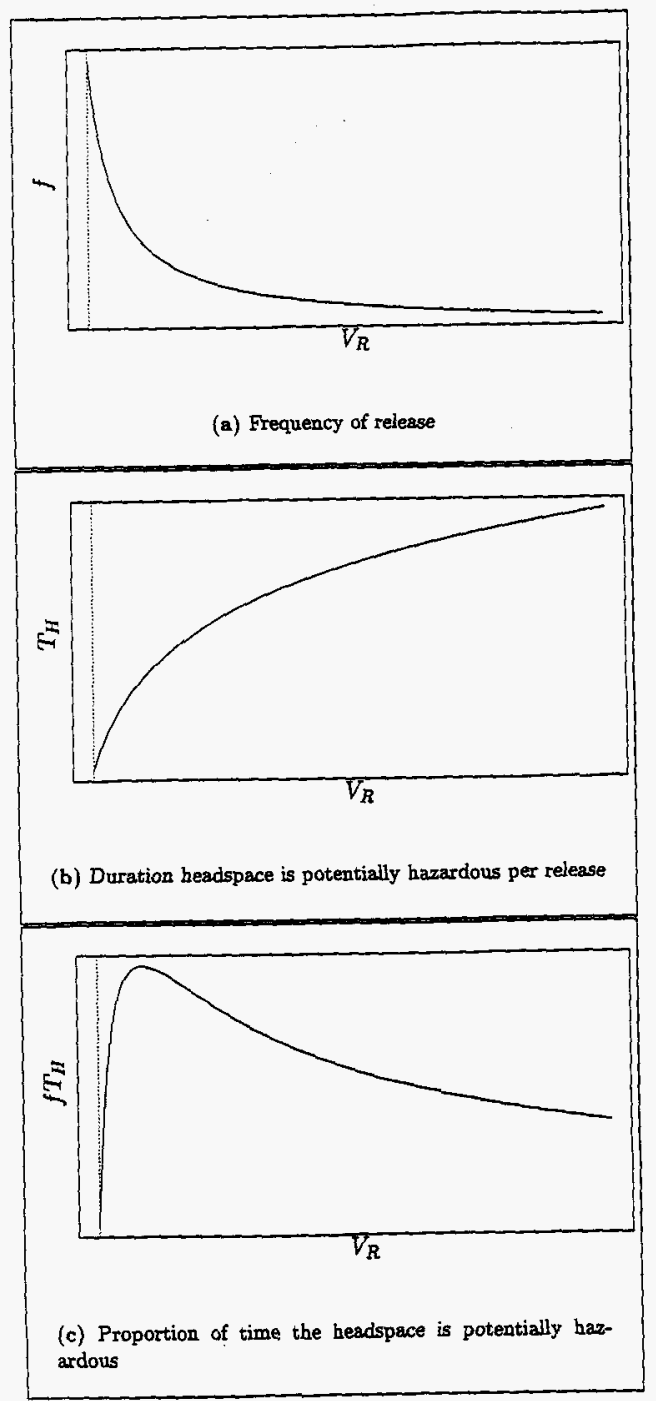

Figure 18: Frequency of release, duration of hazard and proportion of time in hazardous state, as functions of $V_{R}$. 